University of Louisville

ThinkIR: The University of Louisville's Institutional Repository

Electronic Theses and Dissertations

6-1992

\title{
Social warrants and classroom practices.
}

Carol Mattingly 1945-

University of Louisville

Follow this and additional works at: https://ir.library.louisville.edu/etd

\section{Recommended Citation}

Mattingly, Carol 1945-, "Social warrants and classroom practices." (1992). Electronic Theses and Dissertations. Paper 926.

https://doi.org/10.18297/etd/926

This Doctoral Dissertation is brought to you for free and open access by ThinkIR: The University of Louisville's Institutional Repository. It has been accepted for inclusion in Electronic Theses and Dissertations by an authorized administrator of ThinkIR: The University of Louisville's Institutional Repository. This title appears here courtesy of the author, who has retained all other copyrights. For more information, please contact thinkir@louisville.edu. 
Social Warrants and Classroom Practices

\author{
By \\ Carol Mattingly \\ B.A., Brescia College, 1967 \\ M.A., University of Louisville, 1977
}
A Dissertation
Submitted to the Faculty of the
Graduate School of the University of Louisville
in Partial Fulfillment of the Requirements
for the Degree of

Doctor of Philosopiny

Department of English

University of Louisville

Louisville, Kentucky

June 1992 
Social Warrants and Classroom Practices

Bंy

$$
\text { Carol Mattingly }
$$

B.A., Brescia College, 1967

M.A., University of Louisville, 1977

A Dissertation Approved on

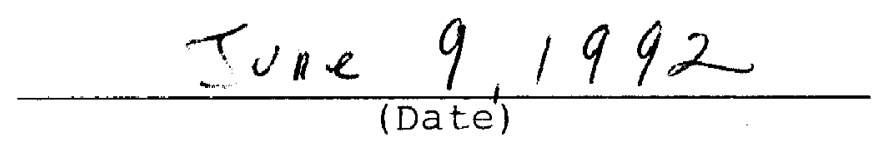

by the Following Reading Committee:

Dissertation Director 
Abstract

Scholars in rhetoric and composition have heralded a new way of thinking about writing, referring to the change as a paradigm shift (Hairston, Young) or naming the new direction a "social turn" in rhetoric and composition (Bizzell, Bruffee). Within the writing classroom, this emphasis on the social has encouraged pervasive use of three practices: use of personal experience in writing; contextualization of student writing; and collaborative learning. Although all three practices fall under the larger "social" rubric, practitioners draw warrants from numerous theoretical constructs which often represent very different or even opposing philosopnies. This study attempts to gain greater understanding of the social movement in rhetoric and composition by examining the most influential groups within the movement--those who draw warrants from feminism, Marxism, and social constructionism. The study points to inconsistencies and overlap among theoretical groups and highlights the intricate nature of practices that are often referred to and used in manners that belie their complexity. In using the term "personal experience writing," scholars have conflated the autobiographical and intimate with personal experience that 
represents a broader, more general daily experience, creating unexpected problems in the composition classroom. Teaching writing in context is defined differently by different theoretical groups; at the same time, early expectations for such "teaching in context" movements as writing across the curriculum are largely ignored today. And claims for collaborative learning often do not play out as expected, partly because efforts to relinquish authority to students and to "force" students to cooperate create other problems.

There are consistencies across theoretical groups, but different ideas about how best to serve students places a very different emphasis on most social practices. This examination points to the complicated relationship between theory and practice and to the need for classroom teachers to understand the theoretical underpinnings of their methodology. 
Acknowledgments

I wish to extend my deep appreciation to all who have been mainstays of support and information for me in the completion of this dissertation. I am grateful to many friends and colleagues who, while too numerous to mention, have contributed to my work in many ways.

I wish to acknowledge especially my dissertation director, Dr. Debra Journet. Because of her guidance, encouragement, and focused perspective, this difficult process was made easier. She advised me during uncertain periods, commiserated with me in hard times, and rejoiced with me when I experienced success.

To the remainder of my committee, I also wish to express my heartfelt appreciation. Dr. Dennis Hall has served as friend, mentor, and discerning reader, contributing much needed and appreciated humor along the way. Dr. Julia Dietrich has been a constant, considerate, and supportive reader. I am grateful for her patience and help during my early struggle to formulate ideas into a workable project. Dr. Robert Miller, as department chair, has been a worthy guide and support during my graduate years. And my deep appreciation goes to Dr. Mary Hawkesworth, who, unknowingly, was an inspiration to me long before I began writing this dissertation.

In addition, I wish to thank Dr. Lucy Freibert for her 
enthusiastic support. She is, by her dedication and integrity, a great inspiration to me. Her faith in me helped to make me a believer.

of course, my love and appreciation also extends to my family. My daughters, Amy and Maggie, have been a constant source of joy and support. Helping me to keep my feet on the ground and my head out of the clouds, they have been the best friends a mother could have. In addition, my seven sisters have provided a lifetime of humor, warmth, love, and support. My family has thus made the lonely process of writing a dissertation much less lonely and eminently more jovial.

Finally, thanks to Linda Rogers, Virginia Watkins, and Heide Weidner for providing a sounding board for my ideas and frustrations, for commiserating, for helping to edit, and for being good friends during a long, difficult process. 
ABSTRACT

Page

ACKNOWLEDGMENTS

INTRODUCTION: THE SOCIAL CONNECTION $\quad . \quad \cdot \quad \cdot \quad \cdot \quad \cdot \quad 1$

CHAPTER I: PERSONAL EXPERIENCE : A CLOSER LOOK • - 16

The Feminist Experience . . . . . . . . . 18

The Importance of the Personal . . . . . . 20

Journals and Expressivist Writing . . . . . 25

Problems with Expressivist Writing . . . . 27

Taking the Personal Seriously . . . . . . . 31

Aaditional Values... . . . . . . . . 35

Mew Directions . . . . . . . . . . . 36

Further Concerns and Implications . . . . . 40

Marxist Personal Involvement. . . . . . . . . 47

The Personal Connection with Mass Culture. . 49

Emphasis on Restructuring Society . . . . . 53

Diverse Views on the personal Within Social

Constructionism . . . . . . . . . . . . . . 54

Using the Personal for Relevance . . . . . 56

Empnasis on "Success" • . . . . . . . . . . 59

Positive Indications for Pedagogy . . . . . . 60

CHAPTER II: WORKING WITHIN THE CONTEXT OF SOCIAL

AWARENESS • • • • . • • • • • • • • • 66

Contextual Awareness for Critical Consciousness - 67

Context's Twofold Importance . . . . . . . 68

Perspective Through Separation . . . . . . 72

Prioritizing Situational Context . . . . . 73

Concern About Reproductive Schooling . . . 78

Cross-Disciplinary Writing . . . . . . . . 83

Critical consciousness and contradictory

Languages . . . . . . . . . . 85 
Social Constructionists: Emphasis on Discourse Analysis . . . . . . . . . . . . . . . . 86 Writing in the Disciplines . . . . . . . . 92 Keeping Faith with Academic Discourse. . . 97

Positioning women in context . . . . . . . . 98 Assuming a Place from Which to speak . . . 100

Joining Forces to Come to a Common Position . . 108

CHAPTER III: DEFINING COLLABORATIVE LEARNING . • . 110

Social Constructionists . . . . . . . . . 112

Problematic Terminology . . . . . . . . 117

The Question of Authority . . . . . . . . 124

The Making of Knowledge . . . . . . . . 126

Playing it out in the Classroom . . . . . . 129

Defining the Problematic . . . . . . . . 134

Feminist Cooperation . . . . . . . . . . 135

Defining the Collaborative . . . . . . . 138

Pedagogical Implications . . . . . . . . 139

The Authority Double Bind... . . . . . . 142

Toward a More Comfortable Fit....... . 145

Marxist Solidarity . . . . . . . . . . . 146

Pedagogical Support for the collective . . 148

The Difficult Collective Task. . . . . . . 151

Collaborative Problems Across Groups . . . . . 152

CHAPTER V: UNDERSTANDING THE COMPLEXITY OF SOCIAL

PRACTICES . • . . . . . . . . . 157

BIBLIOGRAPHY • . • . . . . . . . . . . . 166

$\operatorname{VITA}$ • • • . . . . . . . . . . . . . . . 183 


\section{INTRODUCTION}

\section{THE SOCIAL CONNECTION}

Most scholars in rhetoric and composition acknowledge great changes within the discipline over the past thirty years. One measure of change has been the progressive movement toward a more social emphasis, a movement that evolved from a growing distrust and discontent with the presentation of writing as a solitary act, with stress on the impersonal text, and with the notion that objective, context-free positions are possible.

The increased focus on the social within rhetoric and composition was strongly influenced by happenings outside the field. In the 1960s, numerous groups demanded recognition of the social nature of language and became highly visible within academe: the social constructionist movement, following the publication of Thomas Kuhn's The Structure of Scientific Revolutions, accompanied by a new wave of feminism, and a strengthening new left. These groups gained momentum, placing an increasing focus on the dramatic effect social structures have on learning. These three groups promoted a new consciousness avout how knowledge is constructed, valjdating what minority voices had suggested for some time. They have had significant impact on the 
"social turn" in rhetoric and compositjon, and members who draw warrants from the three groups have become perhaps the most influential in the discipline. Because members who draw warrants from these social groups have become so influential in determining the direction of rhetoric and composition, it is worthwhile to exanine the theories and classroom practices they suggest more closely, both because these leaders are signaling the direction for future theoretical underpinnings and for methodology and because much of the terminology by which we come to understand our discipline is being transformed.

For example, scholars in rhetoric and composition often refer to theoretical terms and classroom practices, such as collaboration and use of personal experience, as though the terms and practices have universal definitions--as though they mean the same thing always and to everyone. In addition, many long used practices have been newly defined under the growing social emphasis, with more far ranging claims made for their value. What we had once called "group work" and used merely to make learning more meaningful to students, has become "collaborative learning." Collaborative learning is usually defined differently from group work because it requires cooperation or consensus. Some proponents claim that collaborative learning is more valuable than group work because it imitates or allows for the construction of knowledge. Likewise, such terms as personal experience, context, interdisciplinarity, and 
collective, while commonly used within rhetoric and composition as though they are standard terms on which we all agree, in fact, often express very different intentions and expectations. While the use of "social" terms and practices has become widespread, the relationship between the pedagogies and the theoretical warrants used to validate them has gone relatively unexamined, concealing the complexity of many of these theoretical assumptions and classroom practices.

Acknowledging problems accompanying the social emphasis, James Reither and Douglas Vipond have noted that "theorists have advanced so many competing notions of the social in writing and knowing that the term's ambiguity is perhaps unresolvable" because "the term social implicates too little by way of concrete activity" to be useful in classroom practice (856). Other scholars have suggested problems as well. Marilyn cooper has pointed out that "intuitively developed methods" being incorporated into the composition classroom call for an examination and description of the assumptions on which they are based ("Ecology" 367). And, Nancy Sommers insists that "what seems to be missing [for a consistent, well-defined pedagogy] is a serious questioning of the underlying assumptions" (46). Sommers notes the fleeting nature of many of our classroom practices, an incorporation of "whatever is culturally or intellectually in vogue--journal writing, role-playing, bio-feedback," because of our failure to examine closely and make choices based upon the 
theoretical underpinnings of the methods in fashion. The ephemeral nature by which we apply techniques within the composition classroom does not allow us to discard the ineffective while building on our strengths.

This study represents an attempt to look closely at "socially" justified classroom practices to discern precisely from where supporters draw their specific theoretical warrants and to question how the intentions behind those warrants play out in the classroom. The study examines three pedagogical practices popular with what has been called the "social turn" in rhetoric and composition-specifically the use of personal experience writing, collaborative learning, and contextualization--by examining groups who draw warrants from the three most influential social theories--social constructionism, feminism, and Marxism. Each chapter begins with and emphasizes the theoretical group that places greatest importance on the practice examined in that chapter--feminists in the chapter on personal experience, Marxists in the examination of contextualization, and social constructionists in the efforts to define collaborative learning. I have first presented theoretical support for a particular practice and then examined how individuals suggest implementing that practice in the classroom. Because some scholars emphasize either theory or pedagogy to the near exclusion of the other, there is not a consistent chapter balance between theoretical support and pedagogical application. 
The terms and labels used here apply to the adaptation of those theories within rhetoric and composition. The terms feminism, Marxism, and social constructionism are admittedly general, and their ideological application within the composition classroom necessarily diluted. They are used here in acknowledgement of general theoretical constructs from which many rhetorical theorists draw warrants. These groups are certainly not monolithic, even within a discipline like rhetoric and composition. For example, within feminism, there are still those who call for what many believe to be an essentialist feminist position based on the notion of a nurturing mother, although, as in academe outside rhetoric and composition, most of the leading feminists are questioning and moving beyond such a position. Nor are the scholars within rhetoric and composition necessarily representative of the broader theoretical camps from whom they draw warrants. For example, when Richard Rorty was interviewed for Journal of Advanced Composition, he was obviously dismayed at and disagreed with the way composition scholars have interpreted social construction theories. Still, there are beliefs and practices that unite scholars who draw theoretical warrants from members of specific groups outside rhetoric and composition, and because these scholars have become so influential within the discipline, we might. benefit from an examination of how their ideas differ and where they overlap.

While taxonomies are almost always a problem, they do 
provide one means for examining the connections between theory and pedagogy. Although members often fit uncomfortably within the aligned categories because of the great diversity within and overlap among groups, I have generally positioned scholars according to the manner in which they most often present themselves, accepting their definitions, but also examining sources from which they draw warrants and taking into consideration the type of emphasis they place on composition instruction. The final placement into theoretical groups is mine and does not necessarily reflect the way these scholars view their personal allegiances. I recognize that as these theories are adapted to composition studies and play out pedagogically in the classroom, they are often modified from the broader political and interdisciplinary definitions they represent. While I have most often used members of each group who have a high profile in rhetoric and composition, and therefore probably a great deal of influence, in order to provide a broader theoretical basis, I have often included theoreticians from whom rhetoric and composition scholars commonly draw or have chosen scholars because of specific, influential studies in one of the areas.

For my purposes, feminists within rhetoric and composition define themselves and are located according to specific theoretical and pedagogical positions whose purposes are to improve the condition, most specifically of women, but also of other disenfranchised groups. The most 
prominent goals of feminists include a raised consciousness among students, a change in the structure and tone of the classroom in order to make learning more hospitable for all students, and a concerted effort to include information about and ideas and values of traditionally marginalized people. Feminists in rhetoric and composition draw warrants primarily from women who have been active in the women's movement in other academic disciplines. Their work is directed toward creating awareness of an unequal and marginalizing patriarchal system in order to effect change. Feminists are skeptical about university structure and pedagogical practices because they have been designed for and handed down by white men. They seek alternative or complementary methods that are conducive to the learning style of women and other marginalized groups. Because information about women has been treated as insignificant, feminists wish to adjust curriculum to include contributions by and information about women, eventually modifying the overall curriculum from one that reinforces the dominant patriarchal culture to a more egalitarian, comfortable one for all students.

The number of feminists within the discipline is increasing, as is suggested by growing numbers of feminist sessions at conferences and by conferences specifically designated as feminist. CCCC has sponsored an all day feminist workshop before its general sessions for the past two years. Still, the visibility of feminist theory and practice in the major composition journals was limited 
before the very late eighties, forcing feminists to draw from less discipline specific volumes, such as Gendered Subjects, or from journals in other disciplines, such as special feminist editions of Journal of Thought or from journals that are specifically feminist, such as Signs: Journal of Women in Culture and Society or Women's Studies Quarterly.

Marxists in rhetoric and composition emphasize the need for social restructuring chiefly in relation to existing material conditions. They draw primarily from a Marxistsocialist tradition, sometimes citing Marx, but more often drawing from such educational theorists as Basil Bernstein and Paulo Freire, or from such literary theorists as Fredric Janeson, Terry Eagleton, and Frank Lentricchia. I have included people in this category who might not call themselves Marxists, such as Henry Giroux, who does not define himself specifically as a Marxist, but whose critical pedagogy is firmly encamped within the Marxist/leftist tradition.

Scholars in the Marxist tradition are primarily concerned with creating social change that will lead to greater political and material equality. All emphasize the need for students to become critically aware of social and historical circumstances as a way of gaining awareness of self within mass society. While members of this group promote curricula that encourage a more critical consciousness on the part of students, some also emphasize the need for students to become proficient in socially 
mandated literacy skills as a means for establishing power for self and for gaining the ability to make changes in the system. Others, perhaps fearing a system whose structure and content might acculturate students into an established, hegemonic mode of thinking, highlight the ability of students to think critically. These Marxists encourage students to step outside their usual hectic pace in order to gain a distanced perspective and to question the mass culture that pervades their everyday lives.

Marxists wish to undermine the reproductive hegemony of mass culture by helping students to understand and resist it. They hope that helping students to become empowered, either by improved literacy or through focused critical awareness, might lead to social change. They promote solidarity in hopes that students might resist the competitive selfishness encouraged by the mass society. Feminists and Marxists have in many ways become closer theoretically. Marxists now usually argue specifically for the inclusion of women in their demands for the redistribution of economic and social power; feminists call, not only for improvements for women, but for other minorities and for the economically deprived. Still, each group's emphasis differs, and the causes they choose to address continue to reflect the past from which they draw. Much of the strength of feminists in recent years lies in their positive arguments for the inclusion of women and the value of the feminine. This approach has served them well. Marxists meet with greater obstacles when arguing for the 
positive value of a less well-defined, economically disenfranchised population within a society that places its highest values on economic and material power. Feminists and Marxists, long adherents of the importance of the social, accept the social nature of language and knowledge but do not place the same emphasis on the social construction of all knowledge as do social constructionists. Social constructionists draw warrants from theorists like Thomas Kuhn and Richard Rorty and generally agree that knowledge is what a community agrees it will be. Members of the other groups rarely make these same claims about knowledge. For feminists and Marxists, knowledge may be what a community agrees to, but they would also find this statement inadequate and simplistic because they believe that many groups and individuals, acculturated into mass society and a patriarchal hierarchical system, have been "given" as knowledge information that is agreed to by others. The tenuous relationship between the marginalized and the keepers of knowledge, as well as the varying degrees to which the marginalized accept the truths, or knowledge, of those in power, complicates the perception feminists and Marxists have of the social nature of language and knowledge.

Social constructionists accent the social nature of language and tend to be more committed to teaching academic discourse than feminists and Marxists, who believe academic discourse to be a creation of socially privileged groups. 
Feminists and Marxists do not really see academic discourse as their language and concentrate instead on helping students to think critically and to gain critical consciousness and increased social awareness.

Social constructionists call academic discourse our language and usually value it highly. Their primary emphasis is generally upon helping students to enter the academic discourse community. "The student has to appropriate (or be appropriated by) a specialized discourse. He must learn to use our language (Bartholomae, "Inventing the University" 135). "To discover or to learn, the student must, by writing, become like us--English teachers, adults, intellectuals, academics. . . He must know what we know, talk like we talk." (Bartholomae, "Writing Assignments" 300). By comparing results of groups of students with those "of the larger community of knowledgeable peers--the teacher's own community--the teacher helps complete the [students'] movement into this larger community" (Wiener 59).

For Kenneth Bruffee, collaborative learning's value is that "students can experience and practice the kinds of conversation valued by college teachers" ("Collaborative Learning" 642). Similarly, the worth that Patricia Bizzell places on academic discourse is evident in her declaration that, "I believe that the abstracting, formalizing power of academic work enables us to understand our experience in ways not made available by conmon sense or folk wisdom" ("College Composition" 206). 
In contrast, Marxists see academic discourse as the language of the oppressors. Teaching language conventions of the upper- and middle-classes "functions as an almost pure ritual of control and domination, [and] serves as an effective sorting mechanism for race and class discrimination, with poorer students always already speaking and writing incorrectly" (Clifford, "Subject" 46). In teaching specific form and conventions "[w]e are teaching a way of experiencing the world, a way of ordering and making sense of it" (Berlin, "Contemporary" 58). Academic discourse is the language of the privileged, and Marxists fear that in emphasizing its structure and conventions we are teaching acceptance of and conformity to the dominant ideology.

Likewise, feminists wish to resist a view of writing that reinforces militaristic and aggressive attitudes. They wish to teach writing "not as a game of war or act of rape, but as a collaborative effort between reader and writer" (Meisenhelder 192). Feminists wish to circumvent the patriarchy's ability to present its features as normal and natural. They are unlikely to privilege academic discourse; their efforts lie primarily with creating an overall "theory of feminist pedagogy consistent with our needs as women operating on the fringes of patriarchal space" (Friedman 207). They question, not only the rigid forms and conventions of male language, but all "expert" information handed down to passive students from a tradition that has excluded and demeaned women (Maher, "Classroom Pedagogy" 30) 
as well as the hostile, male-created instutional structure that is not conducive to women's positive performance (Friedan xxiv-xxv) .

For social constructionists, helping students to gain a measure of control and advancement within the system is most productive. Social constructionists see membership in the academic community as a necessary step that many believe will lead eventually to more effective effort toward social change. For Marxists and feminists, the need to separate in some way from the hegemonic system is essential; these groups find the existing system oppressive and emphasize teaching toward a critical consciousness from the beginning because they believe it is more difficult to achieve critical consciousness after acculturation, from a perspective within the dominant system. They therefore usually accept academic discourse as a necessary supplement to, rather than as a means for achieving, critical awareness. Feminists, especially, seek new ways of structuring the institution and classroom as well as new pedagogical methods that are less hierarchical and less competitive.

I wish to recognize the problems associated with creating a taxonomy such as this and to acknowledge that there may be reasons for placing scholars differently. Ultimately, I have categorized members by examining the individuals and groups from whom they draw warrants, but also by taking into account their views on how best to provide for students. Members, however, often do not fit 
neatly into categories; there is a great deal of overlap. Possibly because the scholars referenced here are some of the most knowledgeable and dedicated people in the profession, they are familiar with the wide variety of theoretical stances within the discipline, and they often draw from more than one tradition in an attempt to provide the best possible combinations of theory and pedagogy. Further, categorizing is, of course, always a problem because writers' ideas evolve and change. Indeed, a great many of the most visible scholars in the field seem to be making a move toward the left. In the recently published Contending with Words by Patricia Harkin and John Schilb, which includes writers prominent within the discipline, four of the twelve articles examine a Marxist approach to rhetoric and composition. In addition, many theorists are beginning to express interest in reflective pedagogy, also a leftist approach to education. On the other hand, other prominent scholars are beginning to react to such a leftist emphasis in an effort to curtail such a move, as exemplified in Maxine Hairston's recent article, "Diversity, Ideology, and Teaching Writing."

Admittedly, significant problems arise in attempting a taxonomy of such a large group of intellectually lively scholars. However, I do believe we have something to gain by attempting a systematic examination of the work of those scholars in our discipline who draw warrants from these larger social groups in support of their work in rhetoric 
and composition. Such knowledge is vital to those teaching composition, especially to those with limited knowledge of the theory supporting popular practices. A broader knowledge of the implications behind practices helps to make for more effective and consistent pedagogy. Composition teachers need to know that oftentimes pedagogies described with terminology that is defined monolithically or used very broadly, may be variously implemented and accomplish varying purposes within the classroom.

If I am correct in believing that many scholars in rhetoric and composition are moving further to the left theoretically and that others signal a move to the right, such moves typify the rapidly changing interests within the field. We seem to become greatly interested in adopting an approach--cognitive models, social constructionist theories-and after only a few years move on to new interests. I hope that more consistent examinations of where such popular theories and subsequent practices differ and agree might help us to better understand the discipline of rhetoric and composition and to preserve and eliminate based on more solid information. 
CHAPTER I

PERSONAL EXPERIENCE: A CLOSER LOOK

Writing that incorporates retelling of and reflection about events or experiences of personal significance has most commonly been called personal experience writing, or simply personal writing. More recently, Linda H. Peterson and others have referred to this writing from students' personal experience as autobiographical writing. In reference to coles and Vopat's what Makes Writing Good, a collection of "good" writing selected by leading figures in the field of rhetoric and composition, Peterson, Leslie Faigley and Patricia Bizzell have emphasized the prevalence of personal or autobiographical writing within composition classrooms.

Although composition scholars use the terms personal and personal experience widely, they have ràrely defined the exact nature of writing assignments using the personal or discussed criteria with which the writing should be evaluated. When teachers speak of personal experience in writing, they may mean anything from expressive accounts of intimate personal happenings to more general narrative or description, a retelling of something observed. Qualities teachers appreciate or look for in personal 
writing also differ. For example, Peterson, in establishing criteria for evaluating quality in autobiographical writing, cites three standards for measurement:

1. Significance: Does the writer understand the significance of the event and communicate it effectively to the reader?

2. Clarity: Does the writer render the episode and its context in a clear, coherent way?

3. Richness of detail: Does the writer use examples and details to depict the episode and make it interesting to the reader? (172)

Faigley, however, pointing to rationales given by teachers in what Makes Writing Good, notes that qualities most often praised in personal writing were honesty, authentic voice, and integrity ("Judging" 404). Bizzell believes that emotional intensity, effectiveness in moving the reader's emotions, is the principal criterion used for evaluating personal experience writing (Review 245).

Motives for assigning personal experience writing differ as well. Peterson cites such purposes as a wish to change attitudes towards writing, an effort to improve skills, and an intent to promote awareness of genre. Faigley, on the other hand, points cut that those who encourage personal writing, especially those seeking an authentic vojce, hope to empower students. Faigley questions the ability of teachers to empower anyone and finds this intent problematic since "these same students 
will be judged by the teachers' unstated cultural definitions of the self" ("Judging" 410). Still, the notion of empowerment is strong within such groups as feminists and Marxists because close examination of the personal is closely related to developing critical consciousness, a political commitment that readily applies to concerns associated with the teaching of writing.

Both the theory supporting use of personal experience and pedagogical methoa are undergoing careful scrutiny as never before. A close examination of such a broadly used practice may help us to understand and more effectively make choices about the use of personal experience and its manner of incorporation in writing courses. The following chapter is an effort to gain greater understanding of the role of writing in the classroom by examining theoretical underpinnings and pedagogical approaches of those who draw warrants from the three major social groups for their use of personal experience writing in the first-year classroom.

\section{The Feminist Experience}

Ironically, perhaps inevitably, inclusion of personal experience has been most problematic for feminists. Feminists feel the greatest need to validate personal discourse because of women's long association with the personal and private. The volatile issues arising from the struggle to validate personal discourse reflect that importance, but also threaten to disrupt the delicate balance of other concerns significant for women. Feminists 
have long been committed to the personal, but recent examination of past feminist practices in promoting personal experience writing in the classroom has rajsed concerns that some of these practices might actually create situations incompatible with original intentions. A number of feminists are beginning to fear that some practices actually romanticize problematic differences or support hegemonic notions. Others worry that the protective practices surrounding much personal writing diminish its validity. Perhaps the most troublesome concern is the possible emotional and psychological danger for students inherent in some practices that promote the "emotionally intense" writing that Patricia Bizzell has noted.

For feminists in the composition classroom, some problems have evolved because teachers have often transposed practices that had proven successful in earlier, more homogeneous settings onto the more diverse writing classroom. Feminist theory's interest in personal experience evolved from the late 1960 s and early 1970 s women's consciousnessraising groups. Feminists continued to emphasize the personal in women's studies programs, in literary theory classes, and within feminist journals. Students in women's studies classes and subscribers to feminist journals were primarily women, very often mature and academically sophisticated. Students in literary theory classes were generally upper division English majors or graduate students who were sympathetic supporters of the feminist cause. These users and shapers of early feminist theory and 
pedagogy represented a uniquely coherent group.

Elizabeth Flynn has described composition studies as a "feminization of our previous conceptions of how writers write and how writing should be taught" ("Composing" 423), but she bases this assertion on the fact that composition stuaies "has been shaped by women" (424), not necessarily by feminists. She acknowledges that "the fields of feminist studies and composition studies have not engaged each other in a serious or systematic way" (425). Indeed, no conscious, systematic adjustment of the theories and applications previously implemented for and by rather elite, homogeneous groups accompanied their acceptance in composition classes although the make-up of these classes is commonly younger, more diverse, and often unsympathetic or even hostile to feminist ideals. The subsequent use of practices previously geared to more homogeneous groups has raised issues for feminists in composition. These feminists are now beginning to question and alter some feminist theory and practice in an effort to achieve a more appropriate fit with the diverse composition classroom. The issues are complex because of the acknowledged importance of personal discourse for women and because of the increasing awareness of problems inherent in some practices connected with the personal.

The Importance of the Personal

Few feminists deny the overpowering importance of personal experience for women. "The beginnings of 
contemporary feminism are rooted in a recognition of the connections between expression and epistemology, naming and knowing, seeing and saying, forms of consciousness and the content of women's experience" (Annas, "Silences" 3-4). Because women have been "other," their selfhood named by and in relation to others, identity recovery, a reformulating of what it means to be woman retrieved from women's lived experience, is crucial. "Personal" experience must be valued because "women's distinctive experience as women occurs within that sphere that has been socially lived as the personal--private, emotional, interiorized, particular, individuated, intimate" (Mackinnon 535). Women "speak out of a tradition of silence, a tradition of the closely guarded, personal, revelatory language of diaries and journals" (Penelope and wolfe 125).

The emphasis on the personal and its connection with the political, the idea that "the personal is political," comes directly out of women's consciousness-raising groups in the $1960 \mathrm{~s}$.

To say that the personal is political means that gender as a division of power is discoverable and verifiable through women's intimate experience of sexual objectification, which is definitive of and synonymous with women's lives as gender female. Thus, to feminism, the personal is epistemologically the political, and its epistemology is its politics. (Mackinnon 535)

Early feminist theorists emphasized patriarchy's ability to present its features as normal, or natural, and hence the importance of "raising consciousness," or becoming aware of reliable information with regards to the reality of 
women's experiences. Women encouraged one another to meet in order to share narratives and feelings for the purpose of validating their experiences--experiences denied or devalued by the patriarchy--and to examine those experiences within the larger framework that distorted their meaning. Women stressed the importance of validating their own experiences because, as Liz Stanley and sue wise argue, "all existing systems of thought, without any exception, have treated women's everyday experiences and understandings of social reality as peripheral or unimportant: they've generally failed to notice that such a thing as 'women's experience' exists" (134-5).

Consciousness-raising groups, where women could share experiences and see that others had experienced the same reality, validated women's felt experiences. Participants rebelled against

\footnotetext{
- . other people, 'experts', telling us how it is and how we should be experiencing it, if only we weren't failures, neurotics, stupid, women. . . [T] he essence of feminism . . is its ideas about the personal, its insistence on the validity of women's experiences, and its argument that an understanding of women's oppression can be gained only through understanding and analyzing everyday life, where oppression as well as everything else is grounded. (Stanley and Wise 135)
}

Feminists have been specifically concerned that women's perspectives be included and discussed because

- . women's roles have been demeaned, ignored, privatized, and/or made the exception. Men have been the subjects of the actions, women the objects. If women's experiences are to be equally represented, then, we must locate and describe these experiences, 
analyze them, and give them theoretical and conceptual frameworks" (Maher 33).

Focus on personal experience, then, has been a primary concern for women. However, validating personal experience within the original feminist context, among women, was far less problematic than confirming the worth of individual experience among diverse groups of students, both male and female. The 1980 s and 1990 s social and political climate also reflects less concern for egalitarian democracy than the earlier period of feminist reform.

Theoretically, feminists have been of one voice in support of the importance of personal experience. Only in recent years have objections from those feminists who felt marginalized by the mainstream feminist movement (Davis, Frye, hooks, sciachitanol, accompanied by increasingly sophisticated examination of diverse classroom use, (Bauer, Bizzell, Brodkey, Jarratt, Maher, Schiachitanol exposed problems, forcing acknowledgment that satisfactory implementation is more difficult than originally believed.

In the beginning of the "second wave" of feminism, that period beginning in the late 1960 s that resurrected and complemented the fervor of the earlier drive for suffrage and social reforms, academic feminists made inclusion of the personal a primary cause. Proponents saw exclusion of the personal and the concomitant emphasis on the objective and abstract as a patriarchal exclusion of those things most. closely associated with women. They argued for incorporation of the personal as a means of making education 
more relevant to women.

While relevance has long been a significant goal in teaching, for women the issue is vital. Institutional structure and curricular content, evolving out of a strictly male educational system, has, feminists believe, unquestionably been more relevant to males than to females. Betty Friedan has noted the alienating structure at Harvard that, even though the institution began admitting women, was so hostile to women's needs that they were unable to perform as expected (xxiv-xxv). Similarly, Adrienne Rich has argued that coeducational does not mean equal. Traditional classroom content validates men and invalidates women. outside the classroom the high incidence of rape and verbal abuse on and off college campuses undermines a woman's sense of self by undermining her right to occupy space and walk freely; and sexual overtures from male professors are acts of domination ("Taking" 239-40). Because course content, methodology, and the hierarchical structure have undermined women's "equal" self, inclusion of all students' personal experience is one attempt to promote relative meaning for every student while giving value to the experiences of all students. Feminists agree overwhelmingly that the personal should be included in order to balance the objective, abstract nature of academic content and structure, but they have often referred to the personal as though the term itself can be objective and its manner of inclusion universally understood.

Although references to personal experience often imply 
a universal connotation, in pedagogical practice personal experience writing reflects a variety of meanings. Personal experience may mean journal writing to express individual feelings or responses to readings or to a variety of situations. It may mean narrating a happening one has viewed in some way or in which one has been involved, or may suggest other more formal writing assignments in which a personal experience of some kind is used as an example for making a point; or inclusion of personal experience may refer to class or small group discussions in which readings or other class materials or topics are examined in a way that permits students to express personal opinions. Past generalizations are breaking down as particular uses of the personal are being more closely examined. While theoretical references to personal experience writing have been general in nature, the most prolific pedagogical practice using personal writing in feminist classrooms has been journal writing.

\section{Journals and Expressivist Writing}

Feminists often use journals as a means of allowing students to express themselves in order to validate personal experience. "From journal writing, students learn that language doesn't have to be distanced, logical, objective, and abstract in the traditional model of rational thought. for it to convey meaning" (Meisenhelder 184). Journals are sometimes seen as valuable because they provide a "safe place" for students to "critically examine their worlds" 
(Perry 152). Teachers seeking to use journals in this manner often promise confidentiality, and may even use a system, such as identification by social security number, to insure a student's comfort with that confidentiality (Reimer 159), or suggest that students staple or clip pages so personal that the teacher should not read them (Perry 152). In these cases journals are used to encourage personal introspection and to give students an opportunity to share those private thoughts they feel uneasy about sharing in class. To assure students' comfort with personal experience writing, teachers may make the journal count for only a small portion of the semester grade and often guarantee an $A$ to each student who turns in the total number of required journal pages (153).

Feminists often wish to encourage and validate personal discourse and therefore may refer to journals as a place where students can express themselves without fear of criticism or ridicule, but they rarely define this manner of journal writing explicitly. Journals may be used for numerous purposes: for expressivist narratives recounting personal experience; for personal responses to readings or classroom discussions; for critical evaluation; for continuing dialogue with the teacher, etc. By implication, feminists most often have used journals as safe havens for personal, sometimes intimate, recounting of experience.

This very personal journal writing, or expressivist recounting of experience, has been valued by feminists because 
of women's silencing. Women needed to give voice to their experience in order to reclaim it, to validate it, and so as to construct their own reality and identity apart from that categorized for them by men. More recently, to support validating of the personal, feminists have drawn upon work by Field Belenky, Blythe McVicker Clinchy, Nancy Rule Goldberger, and Jill Mattuck Tarule which defines the cognitive development of women in a number of different learning situations. Belenky et al. have defined five perspectives from which women perceive knowledge. Because the first of these perspectives is silence, some feminists continue to promote the value of expressivist writing, although Kathleen Dunn and. Frances Maher's studies seem to show that few, if any, women in college remain in this first stage.

Problems with Expressivist writing

Although feminists often claim that women in college classrooms are silenced, the term is used in a different sense than that established by Belenky et al. References to women's silencing in classrooms generally refer to privileging of responses by male students, the preferential attention and unequal amount of discussion time extended to men. Belenky et al.'s silence refers to a deeper, psychological silencing. Few composition teachers confront truly "silenced" women in composition classrooms, and there has been greater emphasis in recent years in going beyond the merely expressivist inclusion of personal experience. 
Even though feminists who use primarily expressivist writing in the classroom often cite Women's Ways of Knowing as justification, Belenky has noted the "danger in a narrow focus on private journal writing and private freewriting that doesn't broaden into a more extended and hard-nosed kind of dialogue and thus keeps a person lodged in the subjectivist mode" (Ashton-Jones and Thomas 289). A variety of measures may prove of benefit to silenced students, but any attempt to remedy such problems must address the specific nature of the silencing.

While silence has traditionally been seen in a negative light, Deirare Mahoney has recently called for a revision of past theories of silence in favor of one that reconsiders its importance as potentially empowering. Mahoney suggests that "silence plays a crucial role in helping women hear their most distinctively feminine voices" and warns against a continued reinforcement of women's oppression related to silence.

Like personal experience, the term silence has often been used as though it has a singular definition which is universally understood. That we may misread women's silence as Mahoney suggests is a likely possibility. For example, Ann Lavine has expressed concerns with regards to differing male and female responses toward a personal writing assignment. The assignment asked for a narrative highlighting a distinctly male or female experience. Lavine found that while men were "embarrassingly confessional," an excellent woman writer hid "behind platitudes without delving into any 
kind of meaningful specifics" (136). For Lavine, an obvious explanation for the difference in resulting narratives might be that women and men have become attuned to the different receptions accorded to writing about male (accepted) and female (unacceptable) experiences. While women may have learned that "to be well received, women must avoid writing about topics whicn point out the femaleness of the author" (140), it seems possible also that a woman may choose not to reveal very personal experiences. Many women may have learned both the power and the protection implicit in silence. More complete studies of silence may provide a greater understanding of the nature of silence with regards to women's writing.

The potentially marginalizing effect of validating simple accounts of personal experience is even more problematic. Moving beyond the expressivist is vitally important to women of color. They fear the simplistic celebration of personal narrative over "the complexity and contradictoriness of our subjectivities, voices, and personal histories" (Sciachitano, Penn). These feminists believe that personal narratives are much too complex for simple readings and celebrations. As Marian Schiachitano points out, "voices, histories and stories need to be legitimated, valued, and celebrated--but unless they are linked to a socio-historical context, we run the continual risk of ignoring the very real lived pain and damage these narratives cone out of" (Letter). 
bell hooks has also noted the need to move the emphasis in "the personal is political" away from "personal." Because cultures of domination are necessarily narcissistic, she claims, taking women in white-supremist, capitalist patriarchy as the starting point is risky (105). "The idea of finding a voice risks being trivialized or romanticized in the rhetoric of those who advocate a shallow feminist politic which privileges acts of speaking over the content of speech" (14).

Women's confessions and narrative tales of victimization have a long history among African-American women. Michele Russell has noted the historic importance of "testifying," but she too insists that women must move beyond the commiseration, must generalize from the specifics $(155-56)$. The fear here is again that of oversimplification, concern that many women see narrating personal experience as synonymous with politicizing, but hooks warns, "politicization necessarily combines this process (the naming of one's experience) with critical understanding of the concrete material reality that lays the groundwork for the personal experience" (hooks 108). While acknowledging the value of confession and memory as "a way to narrate tales of victimization," hooks warns that feminists must "be careful not to promote the construction of narratives of female experience that become so normative that all experience that does not fit the model is deemed illegitimate or unworthy of investigation" (110). other feminists are also becoming increasingly concerned 
with respect to difference. In her "interactive" pedagogy, Frances Maher's primary purpose is to allow for differences in perspectives, "to use concrete experiences to identify the sources of our djfferent viewpoints, see each one as partial, and use them to create a more complex and composite picture of reality" ("Pedagogies" 52). While Maher also wants to allow all students to relate to course material by integrating their own personal experiences, at the heart of the pedagogy is an insistence on an inductive method that builds from students' personal experiences--shared, compared, and examined in light of course materials--toward generalizations, rather than moving from generalizations to specific examples. Maher discounts deductive methods because there is no room "for individual variations to be compared and built upon" because when a universal has already been named, some students will feel included while others feel excluded (62).

Taking the Personal Seriously

In addition to issues involving simplistic, expressivist writing of personal experience, feminists are addressing the concern that, although personal experience has increasingly been included in writing pedagogy, it is often taken less seriously than traditional, "objective" writing. Some feminists are seeking a restructuring of methodology using personal experience in an effort to validate its importance and to emphasize the need to change the model of what powerful language is. The most prominent suggestions 
for accomplishing this goal demand more rigorous use and consideration of personal experience.

Rarely, during their early use, were journals graded, and feminists seldom questioned the curricula that moved from narrative during the early part of the semester, to argument, as students became more experienced, more proficient at academic writing. Virtually every syllabus for first year writing classes reflected this implicit acceptance of narrative simplicity and argumentative complexity. In questioning the values and messages given students when grades are derived from more "formal," "objective," and expository writing, Jerilyn Fisher insists that to "truly and consistently support a feminist pedagogy - . in which connected learning from experience is at least as prominent as separate theory-centered learning," students' journals must be graded (92). Feminists still support writings "that begin with the assumptions that what women have to say is valid, important, and absolutely necessary for our lives" (Gambill 201) and reflect the concern about "how necessary it is for [students] to discover their voices in an expression, assertion, and grounding of their own identity in their own experience" (Annas, "Style" 360). But at the same time, they wish to overcome the negative messages about the personal. Pamela Annas, for example, avoids the implicit negative messages composition teachers promote by their "attempts gradually to 'wean' students from subjectivity into objectivity." Annas 
believes traditional treatment questions the real value of the personal, and she warns against examining journals, sketches, and response papers "with our usual critical faculties suspended" (360). In other efforts at confirming the value of the personal, Annas makes the last assignment of the semester a position paper based on a topic chosen by the students and of "intense interest" to them. They "base their arguments at least as much on lived personal experience as on more conventional sources of information." Her attempt is not to focus entirely on the personal--she believes women writing the political is especially important since they "have been channeled toward private forms and denied access to more public forms" (369)--but to guide her students toward an ability to bring the two together, giving equal significance to the personal.

While many feminists are trying to ensure equal status to personal writing by submitting it to the same rigorous standards as other types of writing, others suggest additional values for personal writing and find alternative ways of valiảating it. Feminists, for example, have in theory valued the connection with the larger world that goes one step beyond the purely expressivist. Feminist. classroom methodology increasingly acknowledges this importance of relating the individually personal to broader societal and global issues.

In such an effort at incorporating the personal within contexts of broader issues, Ellen Berry and Elizabeth Black contend that, since personal expression is important and 
instructors may not wish to "risk stifling the student's self expression," such use is primarily therapeutic, and the "classroom is not a therapy group" (60-61). Berry and Black suggest using integrative learning journals as a way to circumvent the "true confessions" approach without resorting to impersonal, "cold knowledge." The intent is to force students "to engage with class material on a regular basis and help them to clarify difficult concepts" (61).

Berry and Black also worry that, in attempting to validate the personal, teachers may in tact devalue it. The practical reality is that if "in the academic marketplace students measure the seriousness of an assignment in terms of how much it 'counts,' they may regard the unevaluated diary journal as less important than the critical papers and exams, which 'really' test their writing/thinking/ability" (61).

Berry and Black, like Annas and Fischer, do assign letter grades. Additionally, although their primary intent is to help students make connections beyond the personal, "to discover their own points of intersection," their integrative journals, like Annas's assignments, avoid the structuring that begins with the expressive and moves toward the objective or argumentative, attempting instead to incorporate and integrate the various types of writing. In order to stress the importance of this integration, they make time for journal writing during class time and use journal writing as the basis for much of class discussion. 


\section{Additional Values}

Other feminists see personal writing primarily as a diagnostic tool, as a channel of information that allows teachers more clearly to assess the needs of students. Kathleen Dunn suggests using journal writing as a way to bring students along the continuum of cognitive development that allows them to own knowledge, "rather than simply parroting it on an exam" (45). For Dunn, the writing in journals is useful primarily because it provides knowledge that permits the instructor to help students "lower their barriers to learning, rework new ideas, and consciously integrate them into their developing ethical and cognitive systems" (45). This detailed personal writing, however, like early acceptance of all expressivist writing as constructive, may work against more important concerns for feminists. There is unspoken danger in too intimate exposure in classrooms where the make-up is heterogeneous and the structure is implicitly authoritarian despite attempts to undermine classroom hierarchical structure.

In line with increased emphasis on contextualizing the use of personal experience, greater emphasis on theory building seeks to construct links between the community, the academy, and the larger world. Terry L. Haywoode and Laura Polla Scanlon encourage students to go beyond the practice of giving expression to experience, to seek reasons behind behavior and suppositions, and to formulate generalizations about similar practices in the larger society. Haywoode and 
Scanlon see this theory building as a means of breaking down hierarchical relationships because each student participates in theory formulation by contributing knowledge gleaned from her own experience. They believe the classroom becomes "a place for theory building as a collective activity rather than one where knowledge is transmitted from those who know to those who do not" (106). According to Martha E. Thompson, potential theorists need a supportive environment but must also learn to analyze information by developing essential skills such as systematically gathering information and discerning patterns from the assembled data. For Thompson, theory building means looking at and discussing paradigms and knowledge, examining existing theories, and constructing a new theory in which students' own experiences and knowledge can have meaning.

\section{New Directions}

The recent concerns that feminist positions on experience, especially those emphasizing a broad subjectivity based on gender posit a "universal" experience, has led to further re-examination of women's epistemological position and its significance for feminist theory. Feminists are concerned that such a position belies the varying conditions of women based on race, class, age, sexual preference, and geographic location. The place of personal experience in feminist theory is again, then, a major focus of concern and poses problems especially with regards to its significance for epistemological purposes. 
Many feminists are attempting to assimilate a theory that avoids the essentializing cultural feminist claim to a uniquely feminine and superior position from which women experience life, but which also deals constructively with issues of social determinism in an attempt to define a theory more palatable to feminists as a whole.

With expanding interest in all aspects of feminist theory, early feminist emphasis on retrieving and validating personal experience has come to seem inadequate. Feminist theory increasingly has recognized the complexity of women's subjectivity and the problematic nature of dealing with women's experience in a manner that denies determinism and allows for agency. The focus cultural feminists have placed on the feminine in order to emphasize positive feminine qualities, while beneficial in some ways, is problematic because of its continuation of a dichotomy that, while glorifying the nurturing, intuitive nature of women, "conform[s] to all of the stereotypes of them invented under patriarchy. - . [T]he categories themselves are inathentic relics of patriarchal social relations" (Grant 103). Other feminists, while fearing the essentialism of cultural feminist theory as well as the post-structuralist tendency toward nominalism, seek to avoid these problems by proposing a new concept of subjectivity and experience, one that requires a continuous engagement of the self or subject in social reality. Linda Alcoff, drawing especially on the work of Theresa De Lauretis and Denise Riley, suggests that we "waylay the tendency to produce general, universal, or 
essential accounts by making all our conclusions contingent and revisable" (431), recognizing "one's identity as always a construction yet also a necessary point of departure" (432). This "positionality," a modification of earlier standpoint theories, permits women to mediate between the practical reality of their situated position at present and the constantly changing social reality--allows them, for example, to demand that women here and now need child care without invoking the essentializing "rhetoric of idealized motherhood" (427). For Alcoff, two points are important to positionality: first, that the concept of woman be a fluid, constantly changing, relational term; and second, that women's position can be one of active agency, "a place where meaning is constructed, rather than simply the place where a meaning can be discovered" (434).

In a similar attempt to allow for a distinctive feminist perspective that permits difference, Susan Jarratt and Nedra Reynolds borrow from Alcoff and others closely associated with positionality in order to make connections with rhetorical ethos. Jarratt and Reynolds place emphasis on a "spatial politics [that] avoids the naive privileging of 'individual' experience," one that, like rhetoric, depends on distance for perspective. Jarratt and Reynolds draw an analogy with rhetorical ethos, which permits a dual positioning, that of the person, which remains constant, and that of the speaker, which may change according to the situation under which she speaks. This position, they 
believe, acknowledges the complex nature of ethos, and of the subject, and marks "the position of the self, to the admittedly limited extent that it can be articulated by the author, making no claim that that speaking self is completely known or stable."

Thus far, few composition specialists have applied these new theories to composition pedagogy. In their short conclusion, Jarratt and Reynolds suggest using a concept of ethos to help students position themselves socially and politically, to discover differences "between themselves and within their multiple 'selves'" while they build on points of "commonality with audiences." Jarratt and Reynolds seek to encourage students to speak from the position of their experience while at the same time examining that position with relation to the differing experiences of others.

Jarratt develops these ideas for the writing classroom in "Feminism and Composition: The case for Conflict." Here she challenges the use of expressivist relating of personal experience, and more specifically Peter Elbow's unquestioning acceptance of voiced experience in groups that are essentially value-free (110). Jarratt opposes this simplistic validation because many class members may be violated by others' writing about personal experience. Jarratt points to examples she has collected: narratives about sexual conquests from heterosexual male students; a white male student's fictional account of violence committed against a female teacher; blatant sexism in the work of 
white male students that is overlooked because of honest voice. She believes there is a problem inherent in expressive pedagogy, and she uses striking examples from Elbow's writing that overtly position women in degrading and exploited positions.

Jarratt also questions, as do many recent feminist writers (see also Bauer, Bizzell, Grant, Hoagland, and Spelman) the nurturing, maternal model closely associated with the open acceptance the expressivists recommend. The efforts at displacing the teacher's authority, Jarratt. notes, must be supplemented with a greater understanding of the multiple forms of power at work in the classroom so as to prevent the continued marginalizing of women and minorities. Because conflict will arise, Jarratt believes we must have "more than the ideal of the harmonious, nurturing composition class in our repertory of teaching practices in order to deal with them". (113). She finally calls for a "productive conflict in feminist composition pedagogy" that acknowledges difference and challenges domination $(124-31)$.

\section{Further Concerns and Implications}

Relatively little work has been done with regard to feminism's use of personal experience in the writing classroom. The new Bedford Bibliography lists only seven entries under "Gender and Writing," several of those only tangentially related to writing and most unrelated to the use of personal experience. However, disagreement about. 
how personal experience can most effectively be used increasingly presents a problem for feminists because they are committed to the need for giving value to the personal, but they also wish to create critical consciousness and allow for difference.

Do they, then, like bell hooks, insist that students share experiences with one another so as to validate those experiences? Do they encourage "students to work at coming to voice in an atmosphere where they may be afraid or see themselves at risk... [thus] enabl[ing] all students, not just an assertive few, to feel empowered in a rigorous, critical discussion" (53), or do they provide opportunities for students to express feelings and thoughts without fear of exposure, permitting them to opt out of class discussion and providing safe places in the manner of Donna Perry? If feminists insist that students go beyond the expressivist, what are the specific connections they wish to encourage students to make? More importantly, whether they wish to provide a "safe place" for students or to push them toward participation, doesn't the success depend largely upon the ethos of the teacher, an element few feminists mention in connection with today's writing classroom except with regards to the maternal, nurturing model, one that is increasingly acknowledged as problematic? And finally, even if the teacher's ethos encourages trust on the part of students, isn't there danger in students' revelations of very intimate personal experiences? 
In further questioning of classroom use of the personal, Linda Brodkey has pointed out how the "unacknowledged tension over the control of subject positions contributes to rather than alleviates" the antagonisms inherent in the hierarchical structure of a male constructed system ("On the Subjects" 133). Brodkey's study of the use of the personal both supports and moves beyond Robert Connors's notion that the "curious discomfort in English teachers' attitudes toward students writing from personal experience. . [led to] a subordination of personality to information for practical purposes" (178).

For Brodkey, narrative is a potential means of resistance (132), but the problem goes beyond the usual discounting of the "merely" personal. In order to permit the empowerment of students through the personal, teachers must "learn how to 'read' the various relationships between writer, reader, and reality that language and discourse supposedly produce" (125). Brodkey believes this reading requires confronting the hierarchical structure of educational discourse that places authority in the teacher. She believes we must re-examine not only overt methods, such as setting topics, determining direction of discussion, and allocating turns, but also covert practices that place teachers in subject positions and students in object positions. Regardless of the admirable intentions behind "the literacy letters," in which interested teachers shared narratives with students, the hegemonic nature of the teachers' control in deciding what constituted acceptable 
subjects for narrative determined the direction and intensity of the discourse and confirmed teachers as subjects, students as objects. Even more problematic, the directions thus taken also implicitly validated white middle class experience while invalidating that of members of lower socio-economic backgrounds.

The very personal recounting of experience meant to give voice to silenced women in the late sixties and early seventies consciousness-raising groups may be inappropriate for writing classrooms. As noted earlier, few students who reach college classrooms are still at a stage of silence. But, perhaps more to the point, writing teachers are not trained psychotherapists. Encouraging students to bare their most private feelings, as in the manner of, say, Anne, the first year college student in Thomas Newkirk's "Anatomy of a Breakthrough," may entail risks composition teachers are unprepared to cope with properly.

In addition, there is a hint of voyeurism in encouraging students to write about personal matters beyond those appropriate for the very limited relationship between a college professor and first year student, within a classroom situation, three hours per week for one semester. When feminists search for a "safe place" for students to write, strive to empower students by an acceptance of the worth of students' experience, and make efforts to relate to and value student writing through expressive writing, the personality of the teacher, the ethos, if you will, must be 
a defining ingredient. Journals can never be a safe place for students, regardless of clips and staples and promises of confidentiality, unless there is implicit trust and acceptance.

The notion of acceptance and validation comes into question even though teachers may consciously wish to empower students by validating their experience. Patrocinio Schweickart has noted that we are "subtly undermining . . [the] sense of self-worth" of minority students while we "imbue [mainstream students] with the confidence that the experiences, concerns, and perspectives of people like them constitute what is valued by the culture," making them unconcerned for the voices of others (25). As Linda Brodkey has suggested, unless teachers explicitly resist and consciously confront the nature of the hegemonic discourse hidden within the hierarchical structure of society and the institution, the results are bound to be marginally effective at best and may even serve to work against espoused intentions.

Use of personal experience in the writing classroom has become problematic for otner reasons. How can feminists validate the personal while allowing for difference--of acknowledged importance to most feminists--or assure students' rights to privacy? Dale Bauer has pointed to students' insistence on separating the personal and the public, the belief in classroom neutrality (385-86). Bauer speaks against the expressivist model because it reinforces the dominant patriarchal culture (390) and 
insists that we must not return to the politics of the personal (387). But, for many composition teachers, there has been no escape from the personal, and Bauer would agree that a public-private split is no solution. For Bauer, the answer is to foreground issues of dominance, and she initiates this primarily by her choice of material selected for use in her classes.

While writing teachers draw from a broad variety of theorists in their use of personal experience, they sometimes fail to acknowledge differences specific to writing classrooms. bell hooks, for example, who insists that all students share and participate in her classes, teaches classes in which students choose to enroll. First-year writing courses are almost always mandatory.

We must take into account other differences as well. Many practices have evolved from women's studies classes, which are uniquely homogeneous. There are a number of dangers involved in transposing the same pedagogy onto the composition classroom. Basil Bernstein, for example, has noted the significant amount of control implicit in situations with weak framing. That is, when pedagogy becomes less explicit, more open, and appears freer, as in "nurturing" classrooms where validation of the personal is important, ofter very specific expectations exist, though they may be hidden. Many students become attuned to expectations, however implicit, and strive to produce whatever will gain the teacher's acceptance. If honest, 
emotional, revealing writing is the weakly framed expectation, students may try to provide more and more intimate details, information that may be inappropriate for the composition classroom, unnecessary for teaching writing, and dangerous for students. Aside from the fact that too much encouragement to expose the personal might create situations teachers are not properly prepared for, this seemingly free, accepting atmosphere, as Bernstein points out, actually makes maximum surveillance possible. The vulnerability of students and the possibility for control becomes much greater than in the more apparently controlling classroom that registers overt strong framing.

What appears to be a nurturing, open environment, may provide dangers students are less equipped to handle. Where the pedagogy is visible, the hierarchy is explicit, and any infringement on boundaries is obvious. Weak framing, such as that used in more open classrooms, according to Bernstein, "encourages more of the child to be made public and so more of the child is available for direct and indirect surveillance and control" (vol. 3, 235). Certainly, encouraging writing about personal, often intimate experiences, exposes and endangers in ways traditional objective writing does not. First-year students are not always sophisticated about the appropriateness of revealing personal details. Too intimate revelations about personal experience in class discussion, and intimate exposure in writing to college professors make already vulnerable students even more open to possible exploitation. 
Feminists must decide how intimate personal experience in writing may become and still be appropriate for the writing classroom without violating students' rights to privacy, and they must define personal experience more explicitly. Although feminists have always valued the personal, the very intimate sharing of private experience that empowered women in homogeneous consciousness-raising groups may make young students unsuspectingly vulnerable in the diverse writing classroom, and may devalue or oversimplify the experiences of marginalized people.

On the other hand, composition scholars are finally undertaking a serious, systematic examination of pedagogical practices. In a profession that has, as stephen North notes, devalued practitioners, and therefore implicitly pedagogy as well, this diligent look at a common classroom practice is inspiring.

\section{Marxist Personal Involvement}

While feminists may commonly espouse the belief that the personal is political, Marxist interest in the personal has been far more explicitly political, especially with regards to the composition classroom. In an effort to undermine the reproductive nature of education--that is, its instrumental use by the dominant culture to reproduce the values and social practices of that culture--Marxists recognize the need to rescue the individual from hegemonic inclusion in this reproduction.

Whereas feminists within rhetoric and composition place 
great value on the personal for the purpose of gaining and validating identity, Marxists are more inclined to see use of the personal as a step toward group formation for the greater political power of oppressed groups. For example, Henry Giroux stresses that the curriculum "must be deeply personal, but only in the sense that it recognizes individual uniqueness and needs as part of a specific social reality" (Teachers as Intellectuals 19). Giroux's position on personal experience is similar to that of feminists of color because Giroux emphasizes that students' "histories, experiences, and stories" must be examined for "contradictions as well as for their possibilities" lest they be idealized and romanticized without an understanding of their complex histories ("Border Pedagogy" 176).

Giroux differs from others drawing from Marxist influences in that his concern for difference is as great as that of feminists. While most Marxists now acknowledge women and other marginalized groups when referring to oppressed people, Giroux outlines this concern in very specific language, although he does not offer practical models. He calls for a "critical pedagogy" that "rejects a discourse of value neutrality" ("Liberal Arts" 127) and incorporates ethics as a "continued engagement" in which the "social practices of everyday life are interrogated in relation to the principles of individual autonomy and democratic public life" (128). Like Jarratt, Bauer, and feminists of color, Giroux is trying to fina an acceptable 
balance between affirming and critiquing personal lived experience.

The discomfort here arises from concern that a too eager acceptance of the personal might exclude a critical examination, allowing for a broad, neutral acceptance typical of many expressivists. Instead, the personal is valued as a way to "appropriate and renew [students] as part of the reconstruction of a public philosophy that legitimates a politics and pedagogy of difference" ("Liberal Arts" 127)

Like Linda Brodkey, Giroux warns that schools "are removed from the tensions and antagonisms that characterize the wider society" (Teahers as Intellectuals 100). He fears that "what is legitimated as privileged experience often represents the endorsement of a particular way . . . [so that] the experience of the student as other in (sic) cast within a discourse that often labels that experience as deviant, underprivileged, or uncultured" (Teachers as Intellectuals 931 .

\section{The Personal Connection with Mass Culture}

Though use of personal experience is seen as only one step toward political change, it is nevertheless important for Marxists because, as for feminists, it is implemental in raising consciousness. Consciousness raising is essential for Marxists, a "key task of the liberatory class" (Shor, Critical Teaching 68), but differs subtlely from feminist use of consciousness raising in emphasis. Though both 
groups stress empowerment, feminists place more emphasis on the individual, validating, shaping, and assuring a strong personal (individual) identity, creating change for the person, whereas Marxists insist on empowerment as a first step toward re-perception of mass culture. Thus, Marxists more commonly embed personal experience in an examination of the ordinary daily life within mass society. This incorporation of personal experience creates fewer problems because it is usually less intimate.

For example, Richard Ohmann suggests using such themes as work, wealth and poverty, conceptions of college and education (Politics 256), and Ira shor chooses to use personal experience in relation to such routine, daily specifics as fast food, work, housing, transportation, and education. Shor's purpose is to encourage students to problematize areas of daily experience that they take for granted, to inspire them to abstract and examine important themes from their own experience in order to examine that experience critically, apart from the anesthetizing rush of their hectic schedules.

For Shor, the use of students' own personal knowledge and experience also subverts authority. When students use their own words and thoughts, pedagogy "encourages withering away of the teacher" (Freire 106), demystifies the authority of printed material, and allows the text to be "absorbed into the field of their language rather than . . being ruled by it" (117).

Shor offers specific sequenced exercises to move 
students quickly beyond the subjective personal toward a critical examination of the larger environment and a look at possible alternatives by "writing their own realities." His suggested problem solving method includes three steps: life description, which decelerates the rate of life to allow for close observation, always of something taken from the everyday life of students; diagnosis, which investigates the object or theme already observed and described for its problematic nature; and reconstruction, or a more humane restructuring of the object or therne (Critical 156-61). Shor offers numerous models for what he calls "reconstructed learning," guiding students from personal knowledge and experience to a broager examination of the immediate social setting and toward a larger global representation and extension through time and space (Critical 162-74).

Shor, of course, has been greatly influenced by paulo Freire who concentrates heavily on the personal experiences and familiar situations of students. That context is important for Freire because of the "culture of silence" that surrounds oppressed peoples. In addition to giving voice, the familiar empowers students, not only by validating their experience, but also by allowing them to teach themselves. Freire insists that critical education cannot be accomplished from the top down. A crucial factor in providing instruments for students' self-teaching is concentration on the familiar words and situations of their own experience. 
Freire's famed "generative" words and themes are chosen for their syllabic elements, but also for their link to the everyday experience of the groups of students participating. The words themselves are presented as part of a situation commonly experienced by students. Like the themes of ohmann and shor, they are not drawn from intimate personal experiences but from the social and cultural reality of students' lives (Education 49-53).

In a similar attempt to help students to objectify the reality of their lived experience, to help them gain an awareness of the "contingent nature of their social world," both the world of their roots and the world of their aspiration, Myron Tuman suggests such writing assignments as "How are you different from your parents?" Like Shor, Tuman uses these assignments in an effort to help students gain distance from the present as a means of gaining objectivity (A Preface 158).

Tuman is less concerned with preserving students' difference than are Giroux and most feminists. Tuman's position on difference is closer to that of British Marxist Maurice Levitas, who believes that the working class must necessarily transform itself in transforming society. Tuman also cites George Lukac's views that education's purpose is to promote an increased awareness of cultural diversity, but not its maintenance, "as if groups of people are to be preserved as endangered species" (157). Tuman leaves the choice of maintaining difference to the student, recognizing that those who do wish to preserve their cultural identity 
will have to "work harder, learn more, and confront more difficulties" (158).

\section{Emphasis on Restructuring Society}

Although Marxists always acknowledge that personal experience is worthwhile and essential to empowering stucents, its value is most apparent as a means for achieving a critical re-examination of the nature of mass culture in an effort to effect change. As Catherine Mackinnon tells us, Marxists are more likely to see powerlessness as "concrete and externally imposed," whereas feminists tend to view powerlessness as both internally and externally imposed (520). The differing concepts affect attitudes toward the personal. Focusing on personal experience is a means of validating and empowering individuals for both, but whereas feminists emphasize the retrieving and valiating of identity and experience as a means of empowering individual women, the major emphasis of Marxists is reserved for a critical evaluation and restructuring of society. Because Marxists believe that society denies opportunity and participation, Marxists choose themes that examine societal and cultural impact on the individual. These topics tend to be less problematic than the more personally intimate ones often chosen by feminists.

while, generally, the question of difference is less important for Marxists than for feminists, commitment to the oppressed and efforts to gain a more critical perspective on 
cultural ideology does give the notion of difference a place of concern. Tuman, for example, calls for "true sympathetic understanding," but implicit in this phrase is an evaluative suggestion not present in feminist recognition of difference. Because reversing economic and social injustice is central to the Marxist cause as the most likely means of improving conditions for oppressed individuals, and because difference in this society most often means economic and social deprivation, most Marxists simply do not place the same value on the individual or on preserving difference.

\section{Diverse Views on the Personal within Social Constructionism}

Social constructionists, because they place greater importance on academic discourse, find less value in the personal for college composition. If mastering academic discourse is the primary goal, and academic discourse values a distanced, abstract form of writing, personal experience necessarily is devalued and may even be seen as detrimental to less privileged students.

Patricia Bizzell, for example, notes that working class students may have an advantage over more privileged middleclass students when personal experience is a valued component of composition writing because "their life experience has been more varied than that of their sheltered classmates, and they are also more likely to be emotionally in touch with this experience" ("College Composition" 194). This short term advantage, however, can be detrimental in 
the long run. Bizzell found that students often complained later because other teachers did not value their writing as she had. She has come to believe that classes that value "authentic voice" may be detrimental to precisely those students who do well because they fail to learn what they really need to know--academic discourse--, and because it delays their inevitable confrontation with the realities of college writing (194).

Bizzell believes that politically oppressed students need to master academic discourse even more than others. They "need composition instruction that exposes and demystifies the institutional structure of knowledge, rather than that which covertly reintroduces discriminatory practices while cloaking the force of convention in concessions to the 'personal'" (196): Because she believes that the best way to help disadvantaged college students is to denystify academic writing, Bizzell claims that "engagement in college intellectual work should come first" (198), allowing students to attain a critical distance on experience.

While Bizzell attributes "profound influence" on her position to the work of Paulo Freire, quoting his insistence on the need for "critical distance on experience," she has in fact reversed the order Freire recommends. Freire situates methodology within the personal and concrete in order to move towara a more critical distance; Bizzell suggests that students "go native," that is, that they first 
be immersed in academic discourse.

An additional concern for $\mathrm{Bizzell}$ is the irrelevance of personal experience writing to good business and technical writing, and to academic writing. Bizzell points out that "[0]ne could argue. . that concentrating on the personal essay is pernicious because it does not prepare students to write in the variety of situations they will encounter elsewhere witnin and beyond school" dangerously leading them to believe that "the criteria they develop for personal essays will serve them elsewhere" (Review 246).

\section{Using the Personal for Relevance}

When social constructionists do value personal experience, it is most often in a pragmatic effort to make academic writing more meaningful to students. Writing is a "continuous process" of "using language to examine ranges of experience, personal and public" (Knoblauch and Brannon Rhetorical 105). The purpose should be to help the writer to "confront the world," and because the writing then "matters to the writer, he or she has a more sustaining motivation to develop competence than the austere insistence of a school demand for exercising" (105) . C. H. Knoblauch and Lil Brannon believe that people normally write out of a "need to explore and convey personally important meanings" (106). Traditional classroom assignments, lacking "a broader context of personal investment," leave students with no motivation for writing except to fulfill a school assigninent. Knoblauch and Brannon's model workshop examines 
personality and self-knowledge with the purpose of developing "expressive competence through sustained effort to investigate a genuine, provocative issue on which [students] have the authority to take personally meaningful positions and about which they have full responsibility for articulating conclusions" (115).

Knoblauch and Brannon are careful to differentiate between the personal narrative writing assignment and writing from personal experience. For them the former is formulaic, "following Rules of expressive writing" which every student knows how to plug into, but which has little or no meaning. The latter provides students with a chance to articulate their own responses to significant situations, requiring rigorous intellectual and inaginative effort that differs from the pretense and self-indulgence of Ruled personal narrative (110-111).

For Kenneth Bruffee, as well, the value of personal experience is primarily in making writing meaningful to students, but it also prepares them for more complex academic writing. Bruffee values personal writing because it can help to ease anxiety, allowing students to progress toward more serious and more complex writing. Bruffee begins his A Short Course in Writing with personal experience writing because "All inexperienced writers can write the kind of personal experience narratives that exercise 1 requires" (A Short XVi). Exercise 1 is a reniniscence, asking students to write a true story of something that has happened to them. Exercises 2 and 3 
also involve personal experience; exercise 2 asks the students to tell a family story, and exercise 3 calls for brainstorming, beginning by "recollecting what happened during the day or during the past week" (4). Bruffee gives few directions for accomplishing the early exercises--about half a page for the first two as opposed to up to nine pages for later exercises that generalize, defend and explain-attesting to Bruffee's acceptance of personal writing as something any writer can do and his commitment to helping students become competent in academic discourse. For Bruffee, as for many other social constructionists, writing about the personal "is a first and very important step in writing" (7), but still just a step toward the more significant mastering of academic discourse.

Shirley Brice Heath's recounting of teachers' efforts in the Carolina Piedmonts emphasizes the value she places on academic learning but gives value to the everyday lived experiences of students, as well. The teachers in this study hoped to improve students' ability at academic pursuits at the same time students examined and maintained relationships with values and lived experience of their daily community lives. Learning became a translating process, a "two-way manipulation of knowledge from community to school and from school to community" (Ways 321), a way of using the familiar to learn the unfamiliar. There is an implicit valuing of students' personal experiences, but tine explicit purpose is "to help students learn to see their 
daily actions in new terms, then transfer these ways of investigating and analyzing into content areas" (339). Heath's teachers use definitive exercises and experiments that draw specifically from the students' environment. students examine the methods and lore of planting or other local activities by interviewing experienced individuals in the community, by talking with merchants and other established members, and by observing more closely the everyday goings-on. The close examination of everyday life is similar to Shor's emphasis on the personal, yet the explicit purpose is not to re-examine culture but to make academics more meaningful and to establish a transfer of knowledge from the familiar to the unfamiliar.

\section{Emphasis on "Success"}

Social constructionist positions on the personal are more diverse than those of either feminists or Marxists. This is probably because this group is less focused ideologicaliy than either of the other two, because the category is newer and therefore less specifically delineated, and also, as Lester Faigley emphasizes, because of the diverse nature of disciplines from which it araws ("Competing" 534). While social constructionists agree on the social nature of language, they tend to focus more on consequences for academic discourse, less on more overt sociopolitical implications. Even when social constructionists share ideological concerns with the other groups, (e. g. Bizzell, Heath) their agendas differ. While 
all groups claim to promote critical thinking and empower students in an effort to improve writing skills, they differ on the best means of accomplishing these goals. Feminists and Marxists choose to move students in this direction by helping to develop a greater awareness of cultural and social implications for individuals and groups; social constructionists work toward their goal by preparing students to succeed monetarjly and socially (after all the purpose of most college students), even if hoping ultimately to make changes in that society. Most teachers in all three groups hope to do both; however, for social constructionists, emphasis is more firmly placed on the latter.

\section{Positive Indications for Pedagogy}

Personal experience is used broady in the writing classroom but is rarely carefully defined. When teachers refer to personal experience, the reference seems often akin to something warm and wholesome and abstractly acknowledged as good for students. In addition, composition scholars are just beginning to examine its value for the writing classroom systematically. Although personal experience is widely used, for example, very little research has focused on methodology or results.

In recent years, especially among feminists, use of personal experience is being more closely scrutinized. Like many practices that we tend to view as "new," use of the personal has a long history, but never before has it 
been systematically examined for possible exclusionary potential, inherent rewards or dangers for students, or implicit messages in its manner of usage. A continued examination that leads to a measured and clarified pedagogy can only strengthen composition studies.

In re-examining the use of the personal, scholars may wish to take another look at narrative and description as ways of including the personal, perhaps in a less intimate manner, closer to that suggested by Ira Shor and other Marxists. Narrative is a form of personal writing that has been undergoing re-examination. For instance, David Jolliffe has noted the increasing questioning of the continuum James Britton suggested with regards to the difficulty of writing. Jolliffe and others (see Jolliffe) question the continuum that always moves in complexity from expressive to transactional writing. In addition, Debra Journet's work with narrative has shown that narrative, rather than being a "simple" form of writing, may instead provide a powerful means of communicating and understanding that traditional academic or expository writing is unable to fulfil1. Journet's study shows the importance of narrative for two neurologists and their patients in attempting to create a more clearly defined reality. As we learn more about narrative, therefore, social constructionists, such as Kenneth Bruffee, may wish to reconsider the way they think of the personal.

Greg Sarris urges use of narrative for its value as a classroom tool to gain understanding of difference. Sarris 
uses storytelling as a means for encouraging critical discourse, and as a method for bridging the split that he, like Dale Bauer, has found between students' life experiences and classroom critical thought. Sarris finds storytelling effective in forcing culturally diverse students "to negotiate the discrepancies between home life and that which is found in the classroom" (173). By asking students to rewrite narratives, Sarris helps make them aware of how their assumptions are based upon their own cultural experiences.

Perhaps the greatest need is for a closer examination of implicit messages teachers impart in classroom teaching with reference to personal experience. If Linda Brodkey is correct in her assessment of the middle class discomfort with experiences that are not a part of the dominant culture, it is imperative that teachers examine their unconscious valorizing of the dominant culture's experience. When classroom discussion incorporates personal experiences, if the examples used are always ones that validate the dominant culture, some students are again marginalized even though use of the personal is intended to empower.

Although there has been no systematic study of the use of personal experience, there do seem to be patterns. Feminists have in the past often encouraged writing about private and sometimes intimate personal experiences, whereas Marxists are more likely to place less value on the individually personal and examine students' experiences as 
constructed by mass culture. When social constructionists use personal experience as part of writing activities, there is less consistency, probably because they are less likely to accent its value. For example, Bruffee's suggestion to "Write the true story of something that happened to you, which deeply moved you, upset you, frightened you, or made you angry" (A Short 3 ) suggests very personal expressivist. recounting while Heath's use of students' cultural environment is far less intimate, and other social constructionists avoid use of the personal altogether.

An examination of writing about personal experience attests to concern within all three groups for the best interests of students. However, the way that concern plays out is determined by how composition teachers view personal experience and their purpose as teachers. A major dividing point runs along lines of intent. Teachers generally wish the best for students, in most recent terms, want to "empower" students. But how teachers choose to empower students determines their pedagogical directions.

Teachers' beliefs and knowledge about the implications behind their use of personal experience within the writing classroom are important because the teacher determines the degree of intimacy by making assignments and in directing class discussion. The teacher sets the tone for dealing with attitudes toward difference, decides the direction of critiques, and by overall pedagogical methodology behind the personal, relates messages with regards to its value. Since the teacher so obviously determines how theory is translated 
into practice, composition scholars might want to focus attention on teachers, a neglected group in recent years. One problem is that compositionists have tended to conflate the personal with the autobiographical and with the intimate. Students may write about matters that are very personal without revealing intimate secrets. In reexamining the use of the personal, we may wish to take another look at narrative and description as ways to include the personal, perhaps in a less intimate manner, similar to that suggested by Ira shor. Students do find personal meaning in numerous features in their society, especially from within popular culture.

The myriad questioning about incorporation of personal experience in the writing classroom exemplifies a renewed vitality for improving pedagogical implications behind theoretical suggestions. Since the 1963 watershed that initiated a greater emphasis on research, and subsequently a declining interest in practice, there has been an imbalance between theory and pedagogy, especially in composition journals. Practitioners have generally gone outside the field of composition and rhetoric for methodology, as exemplified by widespread reference to Paulo Freire, and dependence upon the fields of educational psychology and women's studies. While keeping abreast of pertinent information in other, relevant fields is valuable, scholars within rhetoric and composition may be able to improve the effectiveness of classroom methodology by re-emphasizing the 
practical implications of theory. In valuing our own "personal" classroom experience, we might allow for a dialectic between theory and practice that permits practice to inform theory, displacing the overwhelming privileging of theory as the shaper of practice. 


\section{CHAPTER I I}

WORKING WITHIN THE CONTEXT OF SOCIAL AWARENESS

In 1979 when Elliot. G. Mishler published his influential article on context in Harvard Educational Review, he signaled a move away from the positivist methodology that had glorified and enshrined context-stripping as a way of assuring objectivity. Mishler called for a reconsideration of context as a resource that might allow for an improved and more complete understanding, focusing attention on a growing tendency to question a limited perspective that purported to present a universal truth. While scholars had expressed suspicions about the claimed neutrality and objectivity of various positions for some time, increasing interest in and awareness of contextual influences led to a stronger demand for examining social and historical determinants on what we call knowledge.

The "social turn" has influenced rhetoric and composition stuáies as well, encouraging scholars to look more closely at social influences that affect students' learning and writing. Marxists have a long history of questioning the context from which a dominant ideology reigns. A traditional mandate for Marxists has been to expose the injustice of a system that presents a single, 
oppressive view as superior and to insist upon examination of real social and economic conditions. By the 1960s, the renewed wave of feminism had gained strength and feminists were re-examining context because of the partial view women had been asked to accept. Feminists were no longer willing to acknowledge as universal a view that excluded them or made them insignificant. Others across disciplines, such as Thomas Kuhn, Richard Rorty, and Clifford Geertz, were calling into question the notion that there is a universal truth, arrived at objectively. Kuhn's implications that even scientific inquiry might not be objective triggered a new kina of awareness. The convergence of ideas from various sources demanding a re-assessment of past practices has begun to reshape the academy's focus and has helped to shape rhetoric and composition studies. Questions about previously accepted aprroaches to content and form and their subsequent impact on the ways in which students are encouraged to think are creating demands for a restructuring of classroom practice and the theory that supports that practice.

\section{Contextual Awareness for Critical Consciousness}

Marxists have long accepted the importance of context, insisting upon the necessity of taking into account social and historical conditions in interpreting economic forces at play within a culture. Marxists within rhetoric and composition may place emphasis on the contextual for either of two reasons. First, the educational system, structured 
as it has been by privileged members within a stratified social system, often continues to privilege more affluent members of society for whom the institutional system was originally designed by promoting those situations most readily attainable by society's elite. Educational processes that make symbolic learning more meaningful for lower-class students by stressing immediate context may improve their ability to achieve higher levels of literacy. At the same time, emphasizing the context of the historical situation encourages a form of awareness that more readily recognizes the reality of a socially stratified society and therefore may lead to greater critical awareness and social change. While Marxists accept the importance of both uses of context, most empnasize either immediate situational context in order to make learning more meaningful or historical and socioeconomic context in order to raise critical awareness about how those factors shape societal structures.

\section{Context's Twofold Importance}

Perhaps the most influential Marxist educator in recent years is Paulo Freire. In Freire's pedagogy, the student's concrete, day-to-day context is emphasized almost equally with a broader, social and historical context that allows for critical consciousness. Placing learning within the context of the student's everyday environment is at the heart of Freirean theory and pedagogy. Freire criticizes traditional curriculum because it is "disconnected from 
life, centered on words emptied of the reality they are meant to represent, lacking in concrete activity" (Education 37). For education to consider students in isolation from the world, and the world and its happenings apart from students is impossiole. A presentation that separates the two is indoctrination, not education. "Men are because they are in a situation. Reflection upon situationality is reflection about the very condition of existence" (Pedagogy $100)$

The importance of critical consciousness surfaces repeatedly in Freire's writing as well. For Freire, examination of social context is vital because "[i]ntegration with one's context. . . results from the capacity to adapt oneself to reality plus the critical capacity to make choices and transform that reality" (Education 4). Such an ability to integrate allows one to become subject. In contrast, the person who simply adapts is always object. Critical consciousness, according to Freire, is imperative for the move toward transforming a society that has denied participatory opportunities to a majority of its citizens. Such societies have kept members "'submerged' in a situation in which such critical awareness and response were practically impossible" (Pedagogy 11). Citizens need to "have a total vision of the context in order subsequently to separate and isolate its constituent elements and by means of this analysis to achieve a clearer perception of the whole that is to truly know reality" (95). 
The great danger in contemporary society, as Freire sees it, is that the oppressed have accepted the present societal structure as "fated and unalterable" (Pedagogy 72), reinforcing myths that posit the natural inferiority of the oppressed and superiority of the oppressors. "Many persons, bound to a mechanistic view of reality, do not perceive that the concrete situation of men conditions their consciousness of the world, and that in turn this consciousness conditions their attitudes and their ways of dealing with reality." The only hope for change is in education that creates a critical consciousness of concrete reality, one that "clarif[ies] to the oppressed the objective situation which binds them to the oppressors, visible or not" (176). A deeper awareness of situation allows men to understand tnat situation as a historical reality and therefore one that may be transformed.

Freire's emphasis on context is closely related to his opposition to banking education. According to Freire, banking education mythicizes reality by concealing some facts and thereby filling students with content that is totally disconnected from their existential reality. The fragmented picture neyates any critical understanding of reality and presents 1 imited situations as insurmountable barriers rather than fetters (89). On the other hand, problem-posing education takes man's historicity and existential reality, his concrete situation, as the starting point.

Freire's curriculum is totally submerged in the context 
of the lived reality of his students because the way students view the world reflects their own circumstances in that world (85). His curriculum is based on a series of pictured "situations" with which the students are intimately familiar. For example, the first situation is "Man in the World and with the World, Nature and culture" and pictures a man, woman, child, house, well, and work tools and encourages discussion about the relations among subjects. The second situation depicts a man and woman in conversation, she holding and pointing to print in a book. The second situation is intended to motivate students to analyze dialogue and interpersonal communications (Education 61-65). This process, which Freire calls codification, presents a portion of the lived reality of students to be analyzed in a situation apart from its living, allowing for a more objective analysis (Politics 52). Critical analysis is essential because the fragmented perception of students may then be replaced by a "vision of reality with a total vision" (52). By allowing for distance to look at previous perspectives, "the learners gradually, hesitatingly, and timorously place in doubt the opinion they held of reality and replace it with a more and more critical knowledge" (53). Only by gaining distance, and thereby greater objectivity, may the dominated recognize the dominators as their antithesis, cease to emulate and glorify the practices of the dominators, and work towara a new culture $(53-54)$. 
Freire insists that discussion should always be in the context of students' reality. Even in subject areas where rote memorization is often the norm, as in mathematics, he urges that presentation and discussion of material always be made relevant to something in human life in order to make learning more meaningful and to encourage students to think critically (124)

Perspective Through Separation

Greatly influenced by the work of Paulo Freire, Ira Shor insists on separation and critical re-entry in his emphasis on gaining critical consciousness. Shor suggests that students identify, abstract, and problemetize important aspects of their experience in order to detach from oblique daily reality and examine that reality more closely

(Critical 104). Shor believes critical education to be a long process of desocialization (82). Contextual and conceptual studies are counterparts to democratic dialogue necessary for expelling false consciousness and for bringing students to conscientization, Freire's term for learning to perceive contradictions in the social and economic structures, and for taking action against oppressive forces (107). Contextualization, because it is based within experiences and languages of students, validates students. Contextual skill development, for Shor, constitutes teaching cognitive skills, such as reading, writing, and comprehension, through a "problematic examination" drawn from the real context of the lives of students. Traditional 
texts, lectures, and curricula teach through abstract examples that "relate to no one's experience, or promote the experience of the elite" (104). Refusal to integrate concrete reality negates any critical encounter with reality for students and domesticates them to the teacher's expertise, again constituting the passive structure Freire has named the "banking system" of education (104-105).

The critical examination of familiar contexts accomplishes two purposes according to shor. First, students become active participants, not passive recipients of the teacher's expertise. Second, submitting objects or situations to rigorous scrutiny allows for separation and re-entry, and thus, a critical consciousness of the complex relationships behind simple contexts of everyday life. of greatest value here are the "restorative implications of analytic thought . - when context involves revealing the structure of social relations which have disempowered the students" (Critical 107). One example is shor's celebrated examination of the hamburger, a "fried piece of dead beef," with which he initiates class discussion. Such examinations have, in turn, led to the discussion of health foods and junk foods and, eventually, to the need for cooperatizing the school cafeteria (106). In our mass cultured society, students caught up in the hectic pace of daily life must, Shor believes, re-experience the ordinary.

\section{Prioritizing Situational Context}

Myron Tuman, like Shor, emphasizes the need to lead 
students away from the present as a means of gaining the objectivity that permits their "seeing the contingent nature of reality" (158). Tuman believes that "educators most need ways of confronting students both as readers and as writers with texts that will objectify for them the insignt into their historical condition, which otherwise exists for them as intuition, if it exists at all" (Preface 161). For Tuman, "the real issue is nurturing within students a critical, imaginative, creative attitude about their condition in the world" (Preface 161). Tuman, like both Shor and Freire, believes that reading and writing must be practical, must become meaningful to the students by creating direct connections between the theoretical experiences of the texts and "arousal and fulfillment" of their own goals (161).

While Tuman agrees with Freire and Shor that students must come to understand their own historical, contextual situation, he is more likely than shor to emphasize the need for students to attain fluency in symbolic manipulation. Tuman believes that teachers can most productively work to ensure "the freedom for their students that comes with the deepening symbolic powers associated with the mastery of literacy" (토 Preface 164). Both Tuman and Greg Myers are skeptical of the ability of teachers to reform society by drawing attention to inequalities in society. Myers notes that an institution "adapts ideology to changing economic and social conditions, and produces a new version of ideology for each generation" (156). Schools teach 
students to accept authority and competition, to work according to schedule, and to adhere to numerous assumptions that reproduce ideology. The system's ability to build a protective structure around its ideology is so great that often perceivea forms of social change simply mask a new version of the dominant ideology (156). Drawing on the work of Basil Bernstein, Tuman also expresses fears that educational reform, while appearing to make educational processes more egalitarian, in fact insidiously promotes the success of those socialized in a particular way at home, namely the affluent, over those from lower-class backgrounds. Tuman suggests that teachers, rather than attempt to reform and equalize the classroom, concentrate on helping students increase their ability to use the symbol system that leads to proficiency in the kinds of literacy society expects.

While many academicians in numerous disciplines have questioned Bernstein's assumptions, especially those with regards to "restricted" and "elaborated" codes, as Harold Rosen points out, their acceptance throughout the world of education is so great as to have made Bernstein's terminology a part of the vocabulary of classroom teachers. Within composition, and among Marxists, however, there is some djsagreement about their validity. Most notably, Richard Ohmann finds Bernstein's interpretation of data restricted and therefore overly pessimistic. Still, Tuman agrees with Bernstein that the ability within the schools to 
transform society is minimal. While Marxists sometimes call for an overt effort to use schools for societal change, Tuman warns that any educational political agenda may be worked at only indirectly. Educators, according to Tuman, can effect change outside the classroom by overt political action as citizens, not as teachers, but only indirectly inside the classroom by building the ability of students to use symbolic powers connected with literacy. Tuman insists that teachers should not confuse the educational and political processes because any changes they can make inside the classroom must focus on improving the literacy of students:

By placing this commitment to symbolic truth at the center of reading and writing instruction, the teacher works to guarantee the integrity of the political system outside the classroom; to replace the symbolic freedom of the classroom with a miniature version of the political system itself is to confuse the imperfect machinery of democracy with the true spirit that guarantees its survival. (Preface 164)

Both Tuman and Myers accept the validity of the efforts of Shor and ohmann to raise critical consciousness through closer contextual examination of societal situations; however, both would place priority on matters of literacy, and both see the primary purpose of Marxist education as improving the ability of students to participate in the abstract symbolic literacy that society demands. Their priority of symbolic literacy places Myers and Tuman closer in purpose to social constructionists, such as Bizzell, Bartholomae, and Rose, than to other Marxists.

As either symbolic literacy or critical consciousness 
is the goal for most Marxists, attention to context is essential because, as Richard Ohmann suggests, critical literacy is impossible to foster if we block out the social processes that surround the teaching of writing to students. Ohmann emphasizes historical context and the everyday environment of students. The method he suggests in politics of Letters is interviewing, a practice he derives from Shor. For Ohmann, this method problematizes "any naive standard of objectivity" and makes apparent that writing is social, not just a factoring of rules and conventions, calling into play "moral judgment and a kind of politics" (255). Ohmann's students interview one another and other students about such topics as work, wealth and power, and dress. The purpose is to create a context of ideology and social class because "much truth comes through in an interview like this one, to enlighten the interviewer and all who share her write-up" (264).

Shor suggests another method to help students reperceive the ordinary and to validate their own experience and language. He requires students to profile two generations of workers, approximately twenty-five years apart in age, for such information as life-style, job history, and attitudes. He hopes that interviewing people in real contexts, gleaning information drawn from their experiences, allows students to observe real changes, to interpret the cause of those changes, and thereby to expel false consciousness. 
Since Tuman believes that the only real influence teachers may or should have for remedying class oppression within the classroom is the better transmission of literacy enhancement for the lower classes, he prioritizes concrete context that promotes literacy. Ohmann, on the other hand, insists that making changes to the educational system is not fruitless and can indeed create change. While on the surface Tuman's attitude appears to be much more pessimistic and directly at odds with ohmann's position, in reality the two may not differ greatly. Since Tuman accepts the value of examining the social and historical context that places students within their current situation, Ohmann's use of just such a context to promote critical consciousness would be in keeping with Tuman's suggestions. However, Tuman's hope of instigating change for oppressed students by raising their consciousness about historical and economic situatedness achieves value only as an accompaniment to improved literacy skills. Ohmann's efforts address societal wrongs primarily by raising awareness, in his situation, among more socially privileged students. In a society where students, especially more privileged students, are often jaded and work at giving the teacher whatever they think is expected, it is difficult to assess how effective such methods might be in making social changes.

\section{Concerns About Reproductive Schooling}

Marxists are also concerned that the teaching of writing is an ideological act that serves the dominant 
culture's reproductive needs by molding students to fill positions that will continue to reproduce its ideals and needs (Clifford "Subject" 39). "Every pedagogy," James Berlin claims, "is imbricated in ideology" ("Rhetoric" 492), and in teaching writing, "we are not simply offering training in a useful technical skill that is meant as a simple complement to the more important studies of other areas. We are teaching a way of experiencing the world, a way of ordering and making sense of it" ("Contemporary" 58). Some Marxists see schools as "more powerful conveyors of ruling-class ideas" than traditional agents of state power, the police and courts of law, with writing a powerful purveyor of practical knowledge in which ideology is subtly embedded (Clifford "Subject" 41). Teaching writing becomes a problem for Marxists because, according to John Clifford, they must ad̃dress difficult and complicated issues:

[D] o we want to fulfill our contractual obligations to the university and the state by focusing primarily on rhetorical competence, syntactic clarity, and other communicative conventions highly valued in business, industry, and government; or do we dare to encourage oppositional thinkers, social activists, and resistant readers and writers? Are these goals incompatible? Must we choose, or could we or should we do a little of both? Can we be politically responsible in traditional institutions? ("Subject" 38)

The notions of grammar, form, and academic conventions are particularly problematic. Grammar has traditionally been taught

because it was good discipline. It was rigorous and arcane, and it privileged upperand midale-class language conventions against those of the working class and poor. . . 
Traditional grammar instruction functions as an almost pure ritual of control and domination, [and] serves as an effective sorting mechanism for race and class discrimination, with poorer students always already speaking and writing incorrectly" (clifford "subject" 47).

Clifford believes that form constitutes an attitude toward reality by conveying assumptions to students that knowledge can be demonstrated simply by, for example, stating a thesis and using three points to support it (43). In an effort to circumvent the reproductive nature of Conventional English, Marxist scholars empnasize the need to teach reading, writing, and comprehension skills within a real context drawn from the student's life (Shor Critical 104) and to place the notion of ideology at the center of classroom activities (Berlin "Rhetoric" 478). Teaching introductory techniques through "materials or activities which express a critical view of daily life" becomes imperative (Shor Critical 104). Teachers might actually serve students better by avoiding rigid rules, excess evaluation, and all the other standard measures that acculturate students into the conventions of academic writing. (cliffora "Subject" 46 ).

The question then is, what rules, if any, do teachers impart to their students? Most Marxists seem to accept the necessity for teaching some acaderlic conventions. Some, such as Ira Shor and Richard Ohmann, seem to imply that standard academic conventions and rules should be taught, but only as part of a context that locates students within their own historical situateaness. Ohmann's major 
criticisms of rhetoric texts over the years has been that "they abstract the student away from society and history," effectively creating an activity apart fron politics (English 147). Shor offers examples for properly incorporating grammar and form into classroom instruction. Students use a "dictation sequence" in which paired members dictate to one another while the other member records exactly what is said. The purpose is to validate the language of students and to make clear that society's written language is simply encoded speech (Critical 131). Shor also suggests voicing for teaching grammar. Students "use the natural grammar in their speaking voices" by reading aloud their written work. By listening carefully for any hesitation or stumble in their reading, students will, according to shor, recognize areas where their written work has not kept pace with their stronger speaking skills. Such an exercise allows students to draw from their own resources $(133)$.

For organization and development, shor uses a cataloguing technique, asking students to generate details and to incorporate the details into lists. Students must examine details carefully in order to structure them into categories, thus developing skills necessary for paragraph development and organization (136-37).

Other Marxists are less specific about ways to teach academic conventions without serving as the tool of the reproducing culture. Most emphasize the need to teach critical consciousness, and many are wary of acculturating 
students into the hegemonic rules and conventions of traditional academic language. But, at the same time, they must address the very real problem of what happens to students who do not master conventions of standard English. The problem is not new to rhetoricians and is especially complicated for Marxists because language and its forms and conventions have historically been used to contain the lower classes. For centuries reformers have led the fight either to formalize conventions in order that the lower classes might more readily access a language that affords special privileges or to change the conventions to more closely reflect the language of the majority. But Marxists rarely speak of changing the conventions or suggest how or to what they should be changed. The issue for contemporary Marxists is even more complex because the language of the masses has become saturated with the images and vocabulary of the hegemonic mass culture and, therefore, may not be superior to conventional academic discourse. Most Marxists in rhetoric and composition recognize the importance of literacy, certainly, and imply that teaching academic conventions is necessary. But although they are critical of conventional academic discourse as representing the elite ruling class, their suggestions for circumventing the hegemonic oppression of the conventions of that language are problematic. They most often suggest teaching within a context that foregrounds ideology or encourages students to be inventive, "to read and write and think in ways that both resist 
domination and exploitation and encourage self-consciousness about who they are and can be in a social world" (clifford "Subject" 51). Marxists almost always include an implicit recognition of the need for fluency in traditional academic discourse. Such an acceptance, of course, begs the question of the appropriateness of assisting in the indoctrination and acculturation of students into a discourse that is by nature hegemonic and oppressive and does not address the possibility of an alternative discourse. The implication is that by making students more aware of the hegemonic nature of language they may be able to resist it.

\section{Cross-Disciplinary Writing}

closely related to the worry with regards to indoctrinating students into a hegemonic discourse is a concern about writing across the curriculum programs. Ohmann, in English in America, has suggested that the teaching of writing responds to the needs of powerful groups--that the teaching of writing provides the kinds of intellectual training most wanted by corporations and government (172-73). At the time of the publication of English in America, such a suggestion seemed a somewhat shocking, or at least a surprising and accusatory, conjecture. Ohmann's 1976 charges that "English 101 has helped, willy nilly, to teach the rhetoric of the bureaucrats and technicians" (205) seem to have been appropriated by a movement whose very purpose oftentimes is to teach the rhetoric of just those bureaucrats and technicians Ohmann 
feared. In fact, major funding for early writing across the curriculum programs came from such corporate giants as the Ford Foundation, and such programs continue to solicit and receive support from governmental and corporate sponsors.

While the writing across the curriculum movement is often promoted because of its interdisciplinary qualities, those qualities are not necessarily defined similarly to those espoused by Marxists who use the same term. For example, Ira shor claims that the "interdisciplinary approach, in a liberatory framework, is the most potent means to free consciousness from the limits of the particular" (Critical 114-15). But Shor's promotion of cross-discipline approaches is an attempt to reduce fragmentation that has resulted from increased specialization. He wishes to expand consciousness by enveloping a greater cultural milieu, a "holistic awareness of the reproduction of social life" (115). Therefore, for Marxists, disciplinary "writing in context," which encourages students to learn the narrow conventions of a particular discipline, is actually "writing out of context" because it is specifically alienated from the broader sociopolitical context that Marxists believe is necessary for critical consciousness.

Don Bialostosky addresses this concern. Bialostosky believes that while writing can allow students to question the "authority and finality" of the language and conventions of a specific discipline (17), many disciplinary courses simply promote conformity to the conventions that are 
"mutely impose[d]" within those courses (16). Similarly, Clifford warns that:

Because we so thoroughly inhabit academic discourse, we often reify its arbitrary and contradictory conventions into inevitable organizational patterns that seem to have evolved through judicious, apolitical consensus. This tendency is especially true for students, many of whom lack both a historical perspective on rhetoric and a skeptical turn of mind, particularly when they are eager to become willing participants in the university's discursive mystifications . . as if the whole point of becoming a writer could be limited to the learning of certain skills and the acquisition of abstract rhetorical principles. (46)

\section{Critical Consciousness and Contradictory Languages}

Marxists rely very heavily on course material for implementing theories they believe to be essential for attaining critical consciousness. They choose topics that foreground issues of social injustice; they examine notions of inequality students are most likely to encounter on their own or in other classes. Marxists hope that a closer examination of personal, historical, and situational context will expose the false ideology of the dominant class and lead to social change.

The more complex issue regarding the complicated nature of language acculturation, of restricted or narrowly defined thought processes confined by a rigid form and established code, presents problems for Marxists. Most have not addressed the contradictory and problematic possibilities implicit in teaching for critical awareness within a formal system of language development designed by and for a 
hierarchical elite. Those who do address the problem seem reluctant to take on implications behind the overwhelmingly popular writing across the curriculum movement. Marxists have not provided a comfortable alternative for the problematic relationship between teachers and the demands of the languages of academia and the professions on the one hand, and of mass culture on the other.

\section{Social Constructionists: Emphasis on Discourse Analysis}

When social constructionists refer to context, it is most often with regard to discourse analysis. Context is important for social constructionists because "Concepts, ideas, theories, the world, reality, and facts are all generated by knowledge communities and used by them to maintain community coherence" (Bruffee "Social Construction" 77). The problem for students, as social constructionists see it, is that students are mystified by the nature and conventions of academic writing. If "knowledge and the authority of knowledge is community generated" (77), what students most need is the ability to demystify academic discourse, to become initiated into the academic discourse community so that they may "gain the critical distance on their experience provided by an elaborated code" (Bizzell, "Beyond" 197). Patricia Bizzell believes that "the abstracting and formalizing power of academic work enables us to understand our experience in ways not made available by common sense or folk wisdom" (206). If more affluent students come to school better prepared to deal with 
academic discourse, we can best help less affluent students by helping them to enter the academic discourse community, by helping them to learn "what counts as adequate evidence in various academic disciplines" (662). Similarly, David Bartholomae believes knowledge to be "situated in the discourse that constitutes 'knowledge' in a particular discourse community" ("Inventing" 145). He feels that writers must imagine themselves to be inside a community in order to write (143), that we must "conceive of a writer as at work within a text and simultaneously, then, within a society, a history, and a culture" (162).

Bizzell, especially, acknowledges concerns about foundationalism; however, she believes that we cannot set academic discourse aside, noting pressure from parents, students, and administrators. Bizzel acknowledges that students will most likely be assimilated into a community that will distance them from communities to which they have previously belonged, and she also questions the ability to erase foundationalism simply by analyzing the nature of discourse. Bizzell fears that those attempting to be antifoundational become foundational in their belief that close analysis can achieve objectivity. She calls for efforts toward political change in the academy--efforts to change, for example, the nature of government funding, high school recruitment patterns, academic support services. Still, she sees learning of academic discourse as necessary for marginalized students, insisting that students must be 
socialized into the community's ways before they are taught to analyze the social and historical nature of its discourse (53).

In suggesting that students must "go native" and that learning academic discourse must be initially privileged over analysis, Bizzell differs from Marxists with regards to the value of academic discourse. Marxists insist that students learn academic discourse and its conventions only while scrutinizing the socio-historical implications behind that discourse. Bizzell's priority is an attempt to demystify academic discourse. She acknowledges a "reinstated assumption that initiation into academic discourse is the college writing course's goal" ("College Composition" 197), not an acknowledgment many Marxists and feminists would accept. She hopes to address inequities within the social structure as well as in preparedness for the academy by treating standard English as a convention of certain discourse communities rather than as the correct form or as a universal language pattern. Bizzell believes that, through discourse analysis, by naming and critically examining the selective discourse of the academy, we can avoid the deracination and failure otherwise inflicted upon many students who come to the university ("Cognition" 237). In hoping to protect marginalized students by analyzing academic discourse, Bizzell may fall victim to her own warnings by promoting a close analysis of academic discourse in order to achieve greater objectivity.

In similar respects, Marilyn Cooper distinguishes her 
idea of contextualization from contextual models that simply presuppose a work within a context that is "unique, unconnected with other situations" ("Ecology" 367). Her ecological model, conversely, takes into account far more than the writer's immediate context. Cooper's ecological model resembles an expanded version of intertextuality that considers not only other writers and other texts, but extends to every social aspect. She suggests a web metaphor "in which everything that affects one strand of the web vibrates throughout the whole" (370). Cooper's model appears to be compatible with that of both Marxists and feminists although she does not provide specific pedagogical applications for the model. Cooper does not specifically examine the relative importance of academic discourse or address the means by which students should learn academic discourse.

In "Why Are We Talking About Discourse Communities?" Cooper does directly address concerns about socializing students into the academic discourse community. She resists notions that students must inevitably be acculturated into already established conventions and modes of thinking, suggesting instead that we ask what students might contribute and how we might change our institutions to more readily accommodate students (205). Instead of insisting that students come to "talk like we talk" (Bartholomae "Writing Assignments" 300) or "practice the kind of conversation valued by college teachers" (Bruffee 
"Collaborative Learning" 642), Cooper advocates

hermeneutics as opposed to epistemology because hermeneutics "insists that the reality of discourse need not be grounded in something outside it or prior to it, that it exists in the real world in actual social practices" (216). From this perspectice, "real world" involves far more than the world of the academy, business and the professions, and "power in discourse flows not from acquaintanceship with the common interests and conventions of communities but from an interplay of social systems and relationships" (216). Cooper suggests that the values of students might indeed change, though not necessarily in the way we as teachers expect. The goal for cooper is to enable participation by all students. She wants teachers to be aware of tacit exclusion of students who do not fit into previously established stanaards.

Many social constructionists have emphasized context with regards to the "real" world and suggest making the educational and writing situation more closely attuned to that of the academic or corporate world. For Bizzell and David Bartholomae, immersing the student within the writing context of the academic community places her more firmly in a situation that necessitates learning the conventions of the discourse community that will allow for more systematic and profitable advancement. In this suggestion, these social constructionists express concerns similar to Myron Tuman and Greg Myers, who suggest that any real change for students must come from empowering students to excel at 
symbolic manipulation, practices which will eventually permit a critical cognizance of the ideological nature of society or, at least, a greater ability to participate in the construction and manipulation of society. Tuman and Myers would, however, place greater emphasis on students' contextual awareness of historical and cultural realities. Bartholomae and Bizzell focus primarily upon immersion into academic discourse and the learning, by students, of the academic community's conventions and nuances. They believe that the nature of academic discourse allows for a more critical mode of thinking, and they implicitly expect students to be better able to effect change in themselves and society once they have gained control of the workings and expectations of that society.

Like Bartholomae and Bizzel, Mike Rose accepts the importance of placing priority on teaching students academic discourse because he believes that academic writing is not simply the language of the academy but "is also the kind of writing students would use to challenge the academy" ("Remedial" 114). Rose emphasizes the need for remedial writers to be prepared early on for their university lives. He also believes that learning academic discourse will help students to trink more critically (110). Rose acknowledges his purpose as helping students "to write a relatively correct university prose" (114), emphasizing the need to acquaint even basic writers with academic topics (113) and "stylistic/rhetorical variation within the university" (112). 
Most social constructionists never question the importance of teaching students academic writing conventions. Even those who have addressed this issue, such as Bizzell, seem to accept that the primary goal of the college writing course is to teach students academic discourse. Power for students, this group believes, is intrinsically related to their ability to learn and use the language and conventions of the academy.

Writing in the Disciplines

closely connected to social constructionists' interest in teaching academic discourse is the writing across the curriculum movement, a movement to incorporate writing into courses in all disciplines. Writing across the curriculum is beneficial to students because in order to "be able to make confident qualitative judgments about writing in a discipline, they need to know how that discipline creates and transmits knowledge" (Faigley and Hansen 148).

Social constructionists, like Marxists, speak of the need to avoid isolationism. However, whereas Marxists seek to avoid the teaching of writing isolated from social and historical contexts, social constructionists express concern about teaching of writing in courses separated from other parts of the academic community. As Elaine Maimon attests, "It never made sense for composition teachers to work in isolation from their colleagues in other disciplines and for students to write outside the context of the rest of their academic lives" (Writing 70) 
Social constructionists also promote writing within the disciplines because it promotes learning. They often cite Janet Emig's "Writing as a Mode of Learning" as support for this position, as well as Piaget's claims that the movement from concrete to formal operations fosters the ability to think in abstract terms. Still, even among social constructionists, worries arise that writing across the curriculum will become concerned simply with convention. C. H. Knoblauch and Lil Brannon, for example, after reviewing a number of writing across the curriculum programs, found them to be "little more than 'grammar across the curriculum'" where the main concern was still mastery of content and where writing was used to test learning rather than its being used to learn ("Writing" 465-66). Knoblauch and Brannon cite passages from textbooks written by such experts in the field as Elaine Maimon (Writing in the Arts and Sciences, written with Gerald Belcher, Fail w. Hearn, Barbara F. Nodine, and Finbarr W. O'Connor): "Their emphasis is finally on prose decorum, the belief that writing is 'a form of social benavior,' that students must 'learn to control the common conventional features of the written code: spelling, punctuation, conformity to standard English usage'" ("Writing" 468); and Ann Herrington, who argues that "while grammatical and structural excellence will not. improve writers' grades, lapses in these areas may nonetheless lower them. The message to colleagues in other disciplines seems to be that they can disregard formal achievement in favor of 'content,' but not failures of form, 
which after all must be located before they can serve as motives for lowering grades" (469).

Another influential leader, Mike Rose, suggested early in the movement that a "properly composed" Senate committee might recommend a schema for evaluation that would include:

1) Fundamental mechanical/grammatical requirements

2) Either operational definitions of traditional organization/development terms or the adaptation of categories like Lee Odell's (e.g. focus, contrast, classification)

3) A statement of stylistic pluralism with humanities, social sciences, and life science guidelines ("When Faculty Talk" 279)

Assessment of writing across the curriculum programs has been inadequate to determine how prophetic Rose's predictions proved to become, but his emphasis on mechanics and stylistics, without addressing the broader learning possibilities connected with writing, represents just those fears outlined by Knoblauch and Brannon.

While many proponents of writing across the curriculum insist on the value of writing in the disciplines for learning more critical thinking skills, and Patricia Bizzell claims that it is an attempt to be anti-foundationalist by exposing the social nature of discourse, many universities and numerous teachers in the discjplines see the writing across the curriculum movement as a means to more readily acculturate students into the discourse of specific 
disciplines. Their purpose is generally to better prepare students to write the type of discourse that is expected within the disciplines and professions, not to examine the contextual nature of academic discourse. Bizzell hopes that writing across the curriculum programs may help to demystify academic discourse for students by helping them to learn expectations members of a community share and by exposing the socially constructed nature of their language ("Cognition" 217-18). Although the movement may help to demystify language by making students more familiar with its forms and conventions, there remains little evidence that its purpose is to reveal the contextual nature of language as agreed upon convention.

Often proponents emphasize writing's effectiveness for learning conventions and discipline-specific material in order to persuade colleagues in other disciplines of its usefullness. In Until I See What I Say, Karen Burke LeFevre and Mary Jane Dickerson list seven reasons why learning to write effectively might be useful:

To write a cover letter for a resume, explaining to a prospective employer how our experience pertains to the available job;

To demonstrate to a professor that we understand the possible causes contributing to world War I;

To draft a memo to co-workers suggesting ways to go about solving a mutual problem;

To write a letter to convince the traffic commission that we need a red light at the intersection of Vine and school streets;

To keep a journal for our own pleasure, to let us find out and remember who we are, how we change; 
To choose to write our own words rather than

Hallmark's "very best" to the family of a

friend who has died;

To compose an article, a poem, a play. (4)

Such suggestions for writing highlight the social

constructionist emphasis on learning academic and business

conventions and minimize notions of writing to learn,

especially writing to critically understand the social

and political nature of language and conventions.

That instructors in disciplines outside rhetoric and composition see writing in the narrow sense of helping to more effectively teach conventions and content seems apparent. For example, Alfred Powell cites advantages for writing within chemistry as follows: students have "need to learn some things about the subject and its applications to the major, and to get into the habits of writing, reading, and thinking Organic Chemistry" (415). Similarly, teachers in a study that used journals for teaching mathematics felt students benefited most because the writing helped students to seal concepts and problems in their minds, concretized students' understanding of concepts and problem solving strategies, and allowed teachers to better evaluate learning (Selfe, Petersen, and Nahrgang 201). Most articles of support and example pose the benefits of writing across the curriculum as writing to learn, but the intended learning, both implicit and explicit, is almost always better learning about the content or conventions of a particular discipline, not a contextual examination of the relative nature of those 
conventions. (See, for example, Allen and Fauth 368, Steffens 226, Kent 270, Mett 293). In addition, most research on writing across the curriculum has been designed to examine the ability of writing exercises to more effectively encourage learning of content or conventions within the discipline (Marshall; Newell; Newell, Suzynski, and Wiengart; Tierney; and Weiss).

\section{Keeping Faith with Academic Discourse}

The great value that social constructionists place on academic discourse influences their attitudes with regards to the importance of context: References to context almost always reflect its importance to academic discourse. The overwhelming emphasis on writing for academia, business, and the professions, and concomitant support for writing across the curriculum define the nature of contextualization for this group. While social constructionists are obviously concerned with empowering students and with teaching students to think critically, they continue to return to academic discourse as the most effective means for achieving those goals.

Writing within the disciplines has become a natural interest for social constructionists because such programs further promote the learning of academic discourse. However, early hopes and expectations of such social constructionists as Bizzell and Knoblauch and Brannon that writing across the curriculum would promote critical thinking skills and an understanding of the social nature of 
discourse are rarely mentioned by members of this group. Writing to learn content and conventions appears to be becoming the accepted purpose of such programs.

\section{Positioning Women in Context}

Feminists espouse a need to emphasize context, both because course content has presented a partial view as universal, excluding women's history, experiences, and contributions, and because the institution's structure has emphasized the abstract and excluded the context essential for comfortable, effective learning for women. Feminists feel a need to reclaim women's past in order to establish a more historically accurate understanding of women's place. Denied a complete knowledge, women "live and have lived without context, vulnerable to the projections of male fantasy, male prescriptions for us, estranged from our own experience because our education has not reflected or echoed it" (kich "Taking" 240). Women have had difficulty seeing themselves within a broader context because "[f]or the most part, educational institutions do not know how to reward students for learning about themselves, or about others unless the others are (1) male, (2) white, and (3) dead" (Spelman 243).

Including women's writing, history, and experiences in course content has been one way at attempting to alter the contextual imbalance for women. But many feminists feel that women need to change traditional methodology, as well, in order to create "a theory of feminist pedagogy consistent 
with our needs as women operating at the fringes of patriarchal space" (Friedman 207). They acknowledge the "difficulty of attempting a non-hierarchical relationship in a political context that enforces hierarchical norms" (Davis "Teaching" 252) but insist on making the effort to change existing practices because women have had to write "in a context that does not value what women have to say and often insists that we neutralize what we say in the way we say it" (Annas, "Style" 362).

Many feminists have been influenced by recent work in psychology. Work by clinchy and zimmerman, and by Belenky, Clinchy, Goldberger, and Tarule, suggests the need for women to develop contextual reasoning and understanding and emphasizes that such contextualization is most effectively accomplished when embedded in the interpersonal. These psychologists emphasize that connected knowing is more effective for women than is separate knowing. In addition, in their studies, they found that, while women saw abstract concepts as helpful in organizing their sense of reality, they felt a need for the concrete to precede the abstract. Yet most of the institutions the women in the latter study attended emphasized "abstract, out-of-context learning" (Ways of Knowing 200-201). Women need to understand themselves in relation to others; they often make choices "embedded in and always influenced by a world of relationship and responsibilities," contextualized rather than relativized (Maher "Pedagogies" 55). Present institutional structure compounds the problem of 
exclusionary content. Not only does it enforce the dominant ideology, which excludes women, it has often negated the importance of contextual learning.

Methodology among feminists calls for discussion rather than lecture, allowing for multiple perspectives and shared meaning--not "imposition of a single right answer" (Maher "Pedagogies" 51). Such emphasis is important because the "right answer" handed down has been one that established the way of white males as the correct one. Such a method assumes an objective, "true" information that is, in reality, partial and reflects the view of the patriarchy. Human experience, rather, is "multiple and must be multiply interpreted" (Maher "Classroom 34).

\section{Assuming a Place from Which To Speak}

Feminists have for decades tried to determine the place for women epistemologically because of their need to distinguish between knowledge and prejudicial partial views. Much recent feminist work has been done in reaction to earlier essentialist positions that asserted an experience and knowledge among women that cut across lines of difference. Feminists have posited notions of women's knowledge along cognitive lines (Belenky et al.), according to standpoints of experience (Hartsock), or have attempted to modify earlier essentialist standpoint theories (Alcoff-positionality, Messer-Davidow-perspectivity), or to strengthen feminist theories of knowledge by drawing from postmodernist theories (Fraser and Nicholson). Feminist 
pedagogical theory has in many ways adapted and combined these theories, emphasizing a contextual cognitive improvement while allowing for difference by recognizing the situatedness of all individuals.

Frances Maher, for example, calls for an inductive construction of meaning that permits a multiplicity of meaning, an effort to avoid dichotomizing views and to integrate different perspectives. Traditional teaching methods have posed topics, presented lectures, and organized debates around predetermined generalizations, limiting topics and positions and excluding those already marginalized. Inductive construction of meaning permits women "to name and describe our world, to differentiate its terms and meanings from those of male experiences if only to see our commonalities as well" ("Classroom" 40). Maher's purpose is to negotiate a shared meaning that avoids forced imposition of one "correct" answer. Students' conclusions become partial and changing. Maher is opposed to lecture and proposes discussions that permit multiple perspectives. This method, she believes, may assist students in composing a more complete picture of reality by exposing the traditional interpretation as partial. Maher does not wish to minimize conflict. Disagreement, she believes, is necessary to clarify and place meaning into a larger context.

Joy Ritchie also calls for dialogue as a means of eliminating problems with essentialism. Ritchie believes 
that by including perspectives of a variety of races, ages, and differently situated people, a class can become "a rich source of multiple definitions . . continually posited, affirmed, examined, challenged, discarded, and rearticulated" (251). Drawing from Gayatri Spivak, Jane Gallop, and Teresa de Lauretis, Ritchie suggests a "both/and" perspective that would recognize the complexity of students' identities. By engaging in examinations of varying perspectives of individuals in social reality and by confronting what is contradictory and alienating in human experience, students can resist definitions that society would impose (269). While kitchie's examples are primarily of women students dealing with feminine identity, James V. Catano has suggested that similar essentialist identities may exist for men. Presumably, a dialogic study of situatedness could serve to minimize essentialist notions that apply to all students.

More closely aligned with cognitivists, Ellen Berry and Elizabeth Black "push [students] to examine their own lives in the context of larger cultural, social, and economic issues" (59). Berry and Black attempt to move students beyond multiplist positions, which recognize the influence of context but still see perspectives as relative, to a contextualist position that removes cultural and psychological impediments to a larger view $(60)$.

In another attempt at helping students to become more realistically positioned, Patricinio schweikert stresses the importance of teaching students to listen. Schweikert 
suggests that the teacher arrange discussions among students who have differing positional perspectives (23). She insists that "the realization that others have valid positions does not necessarily mean that one must abandon one's own; one can understand without being converted" (26). Schweikert emphasizes listening so that students see their positions in light of the positions of others, "something more than bare tolerance for other perspectives," (26) a connection with difference.

In a similar effort to help students to recognize their own situatedness, Dale M. Bauer asks students to recognize their own identity and politics as social constructions. Bauer's attempt to promote a recognition of situatedness that allows for change represents her wish to help students to realize that there is "no natural or essential identification, only one forged from rhetorical situations" (391). She, like bel hooks, emphasizes a need to enforce a representation of marginal views--including her own. She fears that failure to actively address inclusion of, for example, a feminist perspective, reinforces the established ideology.

Susan Jarratt and Nedra Reynolds also seek to find a position that allows for experience as well as difference. Jarratt and Reynolds try to avoid the essentialist position of early standpoint theorists by insisting that they do not argue for "the necessary epistemological priority of women's experience," but seek what Jameson calls a "principled 
relativism." Drawing especially from Linda Alcoff, Jarratt and Reynolds strive for a position that admits to change over time but recognizes the authenticity of historical context and differences for creating a place from which individuals can speak and present alternatives to the dominant model.

Feminist work has recently focused primarily on means of avoiding essentialism and allowing for difference. Because these feminists try to avoid problems of essentialism, they emphasize the need for including numerous perspectives. In order to avoid charges of foundationalism, they stop short of claiming a superior position. still, Schweikert's efforts at including numerous perspectives and her defense of positions that will allow for understanding without conversion might lead to accusations of relativism. Bauer's insistence on inclusion of a specifically feminist. position and Jarratt's call for confrontation, while aimed explicitly at including multiple perspectives, if not claiming a superior position, at least suggest that students who are encouraged to examine numerous perspectives might come to alter their own--accepting a "better" view. Simply openly naming one's position and examining those of others does not in and of itself negotiate a foundationalist perspective. Still, Jarratt and Reynolds, in drawing parallels between the problematic stance of our postmodern society and the sophistic practices of "uncovering contradictions and of 'deception' as a way of convincing an audience to accept the truth of a particular position for 
the exploration of the widest range of positions in a group and for the adoption of counter-hegemonic positions," seem to accept the inclusion of difference as a positive step toward an undefined ethical position yet to emerge from a postmodern confusion.

Jarratt and Reynolds claim to be seeking a subject with the potential to change herself and others. Implicit in the recognition of difference and the emphasis on situatedness is a contradiction that has not been completely worked out. Emphasis on difference has focused on acceptance. Presumably, listening to the views and standpoints of others helps to resolve prejudicial stances that privilege one color over another, one sex over the other, etc. When feminists insist on the value of difference, are they, as Bauer and Jarratt and Reynolds suggest, offering alternatives for identification, or are they trying to determine the direction of change among students? Even if feminists believe that, as Bauer seems to suggest, placing differing views in the forefront of conversation in the classroom will in and of itself promote positive change among students, once again, the implicit message is that students, when offered a variety of views, will recognize that some are superior and, therefore, will alter their own positions. If feminists do not beljeve there is a superior position, if, as Bauer suggests, they simply wish to show that there is more than one authority--that there are different voices--are they relativists? Do feminists really 
believe that all positions have equal validity?

susan Jarratt, in calling for a productive conflict, suggests that if there are no superior positions, there are inferior positions or those that infringe upon the rights of others. And Jarratt and Reynolds's suggestion that a positioned perspective will allow students to promote change in themselves and in others implies something other than

total acceptance. Obviously, we all privilege our own thinking, but feminists cannot accept all positions as equal based on experience because they must deal with the realities of marginalization and of violence perpetuated on women. There must be some agreement, some means of determining acceptable positions. As Frances Maher notes:

- - some people's experiences will challenge others. It is important to note, therefore, that while all people's experiences must be accorded equal value, the conclusions and ideas that come from these experiences may not, upon close examination and comparison, have equal value in helping to explain aspects of our social reality. ("Pedagogies" 58)

Feminists are beginning to mention ethics, a word that has been relegated to relative obscurity with the decidedly postmodern emphasis in the social turn. While Jarratt and Bauer both mention ethics, they are not specific as to how to determine ethical positions. There is an implicit acceptance that any position that is oppressive might be deemed unethical. Oppression, in such a context, would almost certainly be identified as that which might be oppressive or offensive to a historically marginalized group. A traditionally privileged white male student or 
religious fundamentalist might be offended or feel oppressed by viewpoints that insist upon the newly defined rights of women to sexual freedom or to intellectual fulfillment outside the traditional familial role for women. Presumably, because their sensitivity to the legitimate positions of others might infringe upon the rights of a large, historically marginalized group, they would necessarily redefine their position.

While feminists continue to address the problems of essentialism by insisting upon the perspectives of the great variety of members of society, there obviously must be a point from which a decision can be made about what constitutes a valid position. Many feminists who draw from standpoint theories insist upon a place from which women can make a stand and still allow for change. Such a position addresses the need for women and other marginalized people to assume an authentic stance and to work for change. But women must also be able to insist upon certain rights and actions as, if not superior, then at least having agreed upon priority. As Frances Maher and Judith Grant have insisted, experience cannot be the determining factor for acceptable viewpoints. Violence against individuals, alone, would insist upon the invalidity of certain positions. And as both Jarratt and Bauer point out, freedom among students to express any perspective might be offensive to others. The trick is to determine which perspectives are legitimate. Implicit in the work of feminists like Maher, Jarratt and Reynolds, and Bauer, is the notion that we can determine 
what constitutes an ethical position, though the emphasis for all three seems to rest on the need for including differing perspectives. While we all are influenced by our positioned reality, we may achieve a more inclusive consciousness. Maher's inductive pedagogy is structured for this very purpose. Jarratt's emphasis on positionality stresses an inclusive approach that insists upon conflict. and places a restriction on those perspectives that violate others. Such an approach, in order to avoid foundationalist claims to a superior feminist standpoint, might include a cognitive ability to transcend the value of relative positions. An agreement among representative parties might define some positions and actions as simply unacceptable. Such a position would be in agreement with social constructionist views with regards to socially accepted norms.

\section{Joining Forces To Come to a Common Position}

The differing philosophies of Marxists, feminists, and social constructionists present a diversity of problems that groups need to address. Because social constructionists generally accept the importance of learning academic discourse, they avoid many of the more troublesome issues that face Marxists and feminists. Since they believe that their primary purpose is to teach academic discourse and because they accept that task as the one way they can most readily serve students, they are free to focus attention on improved means for achieving that goal. For feminists and 
Marxists, pressing social issues of difference, positionality, and acculturation increase the already difficult goals of instruction. While social constructionists, such as Patricia Bizzell, Mike Rose, and David Bartholomae, have consistently addressed problems of marginalized students, their support for what looks like mainstream educational policy positions them differently from members in other groups.

Bizzell's concern with anti-foundationalism that slides into foundationalism echoes a continuing problem for both Marxists and feminists. Efforts by Marxists to expose the hegemonic nature of mass culture and the insistence by feminists that perspectives of difference--especially feminist perspectives--be included, might hint at a foundational belief that a systematic look at certain perspectives will lead to acceptance of the "correct" choice or to problematic charges of relativism. On the other hand, a version of social constructionists' belief in a cognitive ability for a majority of members to come to an agreement on ethics--if truly representational and based on acknowledged differences that avoid oppression--might find acceptance across all groups. 


\section{CHAPTER I I I}

DEFINING COLLABORATIVE LEARNING

With the increasing interest in the social nature of language and knowledge, scholars have focused greater attention on collaborative learning. Like concerns for personal experience, the continuing dialogue and unraveling of implications behind collaborative learning have begun to establish a meaningful accumulation of information, as well as accompanying questions and concerns. Social constructionists have most obviously been associated with collaborative learning in recent years, but feminists and Marxists have a long history of interest in collaborative concerns.

All three groups embrace the practice of collaborative learning, but each differs in defining the term specifically, highlighting the priorities and values of the group. For many social constructionists, achieving consensus serves to make group work truly collaborative and helps to induct students into the conventions of specific communities that permit knowledge making. But the notion of consensus has raised questions, both inside and outside the social constructionists group, because many see the notion of consensus as dangerous. Because group members might feel 
pressured to accept the values of the dominant group and to ignore different views, reaching consensus might be exclusionary and what is accepted as knowledge only the view of the powerful. Such a specific definition and its implications are worrisome, theoretically as well as pedagogically. Emphasis is aifferent for feminists, who highlight the cooperative nature of collaboration. Their continued emphasis on mutual support avoids the problematic notions of consensus and meaning making. Feminists seek a cooperative, supportive environment that in itself resolves problematic differences by achieving greater understanding. Marxists, too, long interested in the notion of solidarity, value most collaborative group work. Marxists work against the problematic notion of consensus in their choice of topics, which question mass society's hegemonic ideals, and in promoting organized support for a more egalitarian society $\cdot$

Pedagogically, social constructionists strive to help students become familiar with and adept at using the conventions and structures of the "real world"--academic, business, and professional disciplines. Feminists promote cooperative undertakings that encourage students to support and take responsibility for one another and to uphold such feminist ideals as shared leadership. Marxists are more likely to critique the "real world" of social constructionists, encouraging students to distance themselves from the establishnent's dominant culture in 
order to gain a clearer perspective.

Social constructionists try to rearrange and disburse hierarchical control, striving to undermine implicit authority in establjshed knowledge, as well as in classroom structure. Feminists face the double bind of wishing to undermine traditional hierarchical control while fearing the increasingly diminished relative power of women in authority positions. For Marxists, the notion of authority seems not to present a problem.

\section{Social Constructionists}

Because of their belief that knowledge is socially created, social constructionists value collaborative learning highly because they accept that the collaborative is inherently social and vital to knowledge formation. Most social constructionists cite Thomas Kuhn's work on the nature of scientific knowledge, Richard Rorty's claims about "normal discourse," sometimes Clifford Geertz, Stanley Fish, and Lev Vygotsky, as well as occasionally Mikhail Bahktin, Jean Piaget, and others as sources for their convictions about the socially constructed nature of knowledge and writing. They also cite work that seems to support the value of group interaction, what David W. Smit has called their "list of semicanonical texts: Edwin Mason's Collaborative Learning, M. L. J. Abercrombie's The Anatomy of Judgment, John Dewey's Experience and Education, and Thomas Kuhn's The Structure of Scientific Revolution" (45). 
Kenneth Bruffee draws on all these sources to support collaborative learning. Bruffee cites Vygotsky's belief that an individual's thoughts are not original or particular to that person, but instead are the result of internalized social conversation. For Bruffee then, "decisions about what to think and now to act grow out of a consensus of community members" ("Kennetin Bruffee Responds" 77). Therefore, "[t]o think well as individuals we must learn to think well collectively" ("Collaborative Learning" 640). The significance for writing, Bruffee believes, lies in the conviction that thought is internalized social language and that writing of all kinds is the making public and social again of that internalized language. Thus, "writing is related to conversation in both time and function... [as] a technologically displaced form of conversation" (641).

Groups are important, according to Bruffee, because talking through the writing task is essential for writing, not merely a helpful pedagogical tool. ("Writing and Reading" 165). Based on Kuhn's demonstration that knowledge is a social artifact, Bruffee believes "learning is a social and not an individual process" (646); therefore, "collaborative learning models how knowledge is generated, how it changes and grows" (647).

The extent of Bruffee's commitment to collaborative learning is acknowledged in his highlighting, again and again, Kuhn's assumption that knowledge is "intrinsically the common property of a group or else nothing at all" and 
his subsequent insistence that "A writer's language originates with the community to which he or she belongs" ("Social Construction" 784). According to Bruffee, language is our means of joining new communities and of cementing our membership in those communities to which we already belong.

For many social constructionists, "writing and knowing are from beginning to end collaborative," are "impossible-inconceivable--without collaboration" (Reither and Vipond 856) - Invention, the highly valued and intrinsic "creative" aspect of writing, "is appropriately viewed as social in nature even when the primary inventor is an individual" (LeFevre 133).

"Normal discourse" has become a byword for many social constructionists who acknowledge their acceptance of Richard Rorty's argument that knowledge is established and maintained by a comrunity. Accoraingly, "[w]riting can succeed only when it adheres to the conventions of 'normal discourse' for a given community, and writers can learn this discourse through using it in the kinds of conversations that occur in collaborative learning" (Gere, Writing Groups 73)

Once knowledge is accepted as socially constructed, theories based on notions of the individual as source of her own knowledge are defunct or, at least, highly questionable. Anne Ruggles Gere juxtaposes collaborative learning with traāitional individualistic models of learning and writing. For Gere, alienation is a primary culprit in disabling or 
disempowering writers. Since traditional models have portrayed the writer as autonomous, romanticizing the notion of the solitary writer, writers have been alienated from the source of knowledge. If knowledge is socially constituted, "groups provide a society integral to the essence of writing" (Writing Groups 88). Theories of collaborative writing are valuable because they "build upon an opposition to alienation and to the highly individualistic view inherent in traditional concepts of authorship and emphasize the communal aspects of intellectual life" (75). Gere's contribution to collaborative emphasis is extensive because of her thorough and scholarly examination of writing groups; however, unlike many social constructionists, Gere "does not negate the concept of the individual author" (6). While writing in support of the social and collaborative, Gere believes writing incorporates both the individual and the social because "all writers must at some time be solo performers" (6). Still, Gere's efforts focus on changing the image of writing as isolated.

Like Gere, Marilyn Cooper, in presenting an ecological model for writing, rejects notions of the solitary author, seeing collaborative learning as a way to escape that tyrannical model. Cooper accepts language and text as social activities, believing traditional models to be too confining ("The Ecology" 366). Like many other social constructionists, Cooper wishes to discard previous interpretations of audience and of the writer's relationship to audience. She believes that collaborative learning 
permits students to "see each other as real readers, not as stand-ins for a general audience" (372), an important perception because writing is a way of "locating ourselves in the enmeshed systems that make up the social world" (373). Karen Burke LeFevre agrees that the inadequate attention that has been paid to collaborative views in the past "is something that requires correction if we are to have a comprehensive understanding of what happens when writers invent" (51).

Social constructionists also value collaborative learning because it more closely approximates the "real world" than do traditional methods. Both John Trimbur and LeFevre have assented to this valuation. Trimbur cites Lisa Ede and Andrea Lunsford's assertion that collaborative writing "approximates more closely than the traditional classroom the actual conditions of writing in business, government, and those acadenic disciplines where collaboration is the norm rather than the exception" ("Collaborative Learning" 88). LeFevre refers to Richard M. Coe's insistence that "In the real world, collectively produced writing is judged according to how well the writing-as-a-whole accomplishes its purpose" (132). For many social constructionists, then, collaborative learning is good because it more closely resembles what goes on outside the classroom, especially in the business world or in the broader academic community. 
Problematic Terminology

A number of problems surface because social constructionists use ambiguous or loosely defined terms that lead to confusing or contradictory claims for collaborative learning. Much of the confusion and criticism surrounding social constructionist models of collaborative learning revolves around ideas of achieving consensus or entering into "normal aiscourse." Bruffee defines normal discourse as conversation "within a community of knowledgeable peers . . who accept. . . the same code of values and assumptions;" he supports normal discourse because it is "agreed to and accepted by the members of a knowledge community" ("Kenneth Bruffee Responds" 77). However, critics express concern that some members pay a higher price than others in joining this community. Normal discourse, many believe, is established by those with greatest power--affluent, white, male inaividuals; thus normal discourse celebrates ideals of the powerful and marginalizes others. While Bruffee sees collaborative learning as democratic, "based on a principle of negotiation rather than a principle of assertion and acceptance" (78), such negotiation does not assure egalitarian representation, and subsequent experiences of many members often depend on the atmosphere of the class, the methods and attitudes of the teacher, and the make-up of the group.

Bruffee agrees that teachers are hired "to induct people into the mores and values of the state, that is, the 
prevailing culture. . . to create community members in good standing" (77); not all composition teachers or composition students agree with the values of the prevailing culture, however, and many would be concerned about the sacrifice students make to become members in good standing. And while Bruffee claims that we "establish knowledge or justify belief collaboratively by challenging each other's biases and presuppositions," these assertions lose force amidst accompanying remarks. For example, Bruffee suggests that students must move toward new paradigms of thinking, perceiving and feeling by joining "larger, more experienced communities of knowledgeable peers through assenting to those communities' interests, values, language, and paradigms of perception and thought" ("Collaborative Learning" 646, emphasis added). Bruffee also recognizes that "students undergo a sort of cultural change... In which they loosen ties to the knowledge communities they currently belong to and join another. These two communities would be seen as having quite different sets of values, mores, and goals, and above all quite different languages" (651).

Most criticism of collaborative learning has been directed at Kenneth Bruffee, probably because he is the most visible proponent of collaborative learning, but also because the other major writer on groups is Anne Ruggles Gere, whose statements about normal discourse and the real world are embedded within an impeccably researched history that avoids the notion of collaborative learning, focusing 
instead on support for writing groups. Gere's primary focus on writing groups is not prescriptive, acknowledging the variability of situations, groups, and purposes. Bruffee's decision to highlight the value of collaboration because it allows entry into normal discourse, his choice of wording-insisting that groups create knowledge, rather than gain meaning or understanding--and his demand that groups reach consensus have left him open to sharp criticism.

Bruffee's supporters have not helped much to alleviate confusion. In his efforts to outline a means for evaluating collaborative learning, Harvey $S$. Wiener differentiates collaborative learning from "mere work in groups" by the group's effort to reach consensus "by their own authority." Wiener insists that consensus does not stifle differences or force conformity. As support for his contention that the word "consensus" is misunderstood, he draws upon John Trimbur's note that collaborative learning "promotes a kind of social pressure." Although the passage continues in noting the willingness of students to fight for their own ideas or modify them in light of the ideas of others, critics fear that those students most susceptible to peer or social pressure will not fight for their own ideas but will instead go along with the majority. If pressure to conform is present, especially in groups left to their own authority, how free are students to insist upon individual differences?

Wiener's distinction between group work and 
collaborative learning is a fine one. If collaborative learning differs from group work because it requires collective judgment and if we add wiener's other criteria involving social pressure and concern for difference, collaborative learning must fall within a very narrow range of group activity. Such a definition of collaborative learning is collective and demands consensual learning, maybe even with the help of peer pressure, but somehow does not threaten difference or demand agreement--a range that, if not inherently contradictory, at least places great restrictions on what might qualify as collaborative learning.

Along these same lines, John Trimbur, who has insisted that consensus can mean to agree to disagree, praises M. L. J. Abercrombie's work with medical students because "the social pressure of reaching consensual solutions helps students see and modify their limited perceptual scheme" ("Collaborative Learning" 92). Though Trimbur insists that collaboration means not forced consensus but agreement on consensus or agreement to disagree, his continued reference to peer social pressure seems somewhat contradictory and fails to alleviate the concerns of those who worry that group members might feel pressure to conform. Where peer pressure is strong, it is precisely outnumbered or less popular students, those who might differ from the consensual agreement, who are not likely to insist upon inclusion of their own minority views.

Other social constructionists seem to imply consensus 
in the traditional sense. Bruffee, for example, suggests that "we should contrive to ensure that students' conversation about what they read and write is similar in as many ways as possible to the way we would like them eventually to read and write" ("Collaborative Learning" 642). Bruffee also suggests that students "loosen ties to the knowledge communities they currently belong to and join another" (651). In similar fashion, James Reither and Douglas Vipond suggest, as a means of making knowledge, first immersing group members in the literature and conventions of the field, a model that for some would sound suspiciously assimilative.

Although Trimbur calls for a compromise, some of his other statements seem inconsistent with this position. For example, Trimbur also believes one advantage of collaborative learning is "helping students make the transition from one community to another, from one discourse to another, from one identity to another" ("Collaborative Learning" 101). Generally, when students make a transition from one community to another, say from their own ethnic community to the academic community, becoming a part of "another" implies joining in the consensus. Trimbur's later work serves to dispel some of the concern with regard to consensus, if not necessarily the confusion. Trimbur calls for a redefinition of consensus "in terms of difference and not just agreement, - - a redefinition [that] represents consensus as a strategy that structures differences by 
organizing them in relation to each other" ("Consensus" $608)$. He suggests "rehabilitating the notion of consensus by redefining it in relation to a rhetoric of dissensus" (610). Trimbur makes what many of Bruffee's critics would see as an admirable call for a redefinition of consensus that allows for difference and dissensus. However, he continues the problematic use of Bruffee's terminology by choosing "not to abandon the notion of consensus but to revise it" (603). For all his insightful and ameliorative explanations, he is still critical of those who fear "group think" as teacher-centered and authoritative, in spite of an infinite number of historical examples, both national and international, upon which critics base very legitimate concerns. He holds onto the notion of consensus despite its substantial semantic baggage. At the same time he calls for a collaborative classroom "based not so much on collective agreements as on collective explanations of how people differ, where these differences come from, and whether they can live and work together with these differences" (610) learning "how differences in interest produce conflicts that may in fact block communication and prohibit the development of consensus" (611). Trimbur contributes further to the complexity of the consensus debate with his suggestion that we distinguish between "spurious" and "genuine" consensus, with a revised notion of consensus as deferred, and with a suggestion that students "base the conversation not on consensus but on reciprocity and the mutual recognition of the participants and their differences" (614). Trimbur 
calls for a "deferred and utopian form" that "turns the conversation . . into a heterotopia of voices--a heterogeneity without hierarchy" (615).

Definitions of collaborative learning bring complicating terminology in another sense. Karen Burke LeFevre more specifically categorizes what Bruffee and others may incorporate under "collaborative" into three modes: internal dialogue, the collaborative, and the collective. LeFevre points out that "An individual cannot be totally divorced from social collectives any more than a social collective can be totally separated from individuals" (51) and suggests that a closer look may permit a positive reinforcement of desirable aspects of the collective view while allowing some measure of control over "unquestioning acquiescence" to its hegemonic nature (93). LeFevre believes that the importance of social collectives has been ignored in composition. While this may be true within the social constructionist camp, feminists and Marxists have long acknowledged what LeFevre defines as the social collective. The terminology differs, however. Feminists see LeFevre's collective as patriarchal hegemony; Marxists, as mass society, mass culture or the capitalistic system. Both feminists and Marxists fail to see any positive force in what LeFevre recognizes as the social collective. While LeFevre agrees that "collectives exert forces that bias perception and cognition, and cause resistance to styles of thought or types of evidence that differ from those they 
espouse," she believes there are positives to be gleaned as well, because collectives provide "structures for thinking and for creating and evaluating new ideas" (89). LeFevre's positive notion with regards to the collective is enticing. If there is positive potential in this notion or in others used within the social constructionist group, more clearly defined meanings might allow for greater understanding and sharing across groups.

The Question of Authority

The issue of authority presents another problem for social constructionists as well as for some other groups who support collaborative learning. Social constructionists value collaborative learning because it challenges authority on two levels. The first challenge to authority is based on the idea that collaborative learning undermines the authority of knowledge per se. According to both Bruffee and Trimbur, collaborative learning reveals that knowledge is a social artifact, thereby making knowledge comprehensible and paving the way for the acculturation of students into knowledge communities they choose to join. Because teachers' authority derives from "the prevailing conception of the authority of knowledge," collaborative learning naturally challenges the traditional authority of the classroom teacher (Bruffee, "Collaborative Learning" $649)$.

And collaborative learning undermines authority on a practical level as well. Collaborative learning can 
reorganize "relations between students and teachers and among the students themselves in their roles as writers and readers" because the focus of knowledge no longer rests with the teacher. Social interaction among learners restructures the classroom and decenters the teacher as the source of knowledge (Trimbur, "Collaborative Learning" 88-89). The issue of authority is important because the "creation of meaning assumes . . that a writing group is autonomous or at least semi-autonomous." Writing groups must be able to develop the vernacular that allows for an effective selfcritique, an impossibility as long as the teacher maintains sole authority (Gere, writing Groups 93). still, if the understanding that knowledge is socially justified can indeed empower students by undermining the authority of knowledge, students must first accept such a belief. How should teachers, then, convince those students whose culture and belief systems revolve around continued acceptance of the authority of traditional religious, familial, or secular concepts of knowledge? And if classroom organization is a major source of the shift in authority, just how does the teacher, who defines so much of the classroom's structure and finally determines grades, manage to relinquish authority to students? Do students really believe that the authority has shifted when the teacher ultimately has the final and, to many, most important say?

Harvey wiener feels that the most effective collaborative groups are those left "pretty much to the 
students themselves" and suggests that teachers are most effective when busy with other things or leave the room during small group discussions. He also insists, however, that the teacher "pay careful attention to dynamics and composition" (58). Though wiener advises teachers to be unobtrusive during small group discussion, he also directs them to note whether or not there are students who monopolize time or are withdrawn or unprepared, or groups who are not on task. Outside small group discussion, according to wiener, the teacher "helps the class compare results, resolve differences, and understand features of the task that students did not work out on their own" (54). The teacher is the task setter and, in addition, "helps students synthesize each group's results with the results produced by other groups. The teacher should lead the class to consider the similarities and contradictions in the recorded points of view and should unite them all, if possible, into a larger vision" (59). In addition, the teacher "acts as a referee" (Bruffee, "Liberal Education" 52). While these activities may constitute admirable classroom procedure, they unquestionably affect any attempt to relinquish authority to students. Again, the teacher walks a fine line in effecting productive classroom interactions and, at the same time, turning a portion of authority over to students.

\section{The Making of Knowledge}

Much justification for collaborative learning rests on the conviction that knowledge is not a given, but that it is 
in fact socially constructed, maintained, and justified. Yet disparity among proponents continues about how knowledge is constructed and at what point beliefs and information become knowledge. Concerns here are closely associated with the notion of "normal discourse." For Bruffee, collaborative learning is valuable because it models how knowledge is established and maintained, as well as how it is generated and how it grows ("Collaborative Learning" 647). But Bruffee perceives the regular workings of groups as "normal discourse," and according to Bruffee, normal discourse maintains established knowledge. It is "abnormal discourse," which, according to Bruffee, cannot be taught directly, that actually generates new knowledge. By implication, then, most collaborative learning does not create knowledge; it simply assimilates students into the already established knowledge of an organized community whose members agree on what is acceptable knowledge for that community. And unlike LeFevre, who insists on the social nature of invention, Bruffee believes creative thought to be "[t]he least social kind of thought. . . locked up in our individual minds" (A Short 105).

On the other hand, James A Reither and Douglas Vipond divide collaborate writing into three areas: co-authoring, workshopping, and knowledge making. Reither and Vipond differentiate co-authoring and workshopping from knowledge making because knowledge, they believe, cannot be constructed simply through dialogue and discussion. 
Knowledge making is a process that involves becoming knowledgeable about a scholarly field's literature, conventions, and topics of importance, because we make meaning in relation to others. While other social constructionists have implied a broader definition of meaning making, one that would include dialogue among group members not necessarily well-versed in disciplinary conventions and literature, Reither and Vipond have narrowed the definition.

Gere's definition is more focused since her work and claims for knowledge are applied only to writing groups-groups who gather to read and contribute to one another's writing. For Gere, these groups gather for the explicit purpose of gaining greater knowledge about writing: by reading and discussing writing, they are able to accomplish that purpose. If they are creating new knowledge, presumably it is personal knowledge about the writer's own writing or about the nature of writing in general.

The notion of invention, of course, is intrinsically related to the concept of knowledge. Karen Burke LeFevre's impressive monograph on invention offers an alternative view to the traditional idea of invention as retrieval of information. LeFevre describes invention as "the creation of something new--new for the individuals or groups who have not previously thought of it, or new in that it has not previously been conceived by anyone at al1" (7). Her definition encompasses both Gere's acceptance of specific individual knowledge about writing and Bruffee's broader 
inclusion.

For social constructionists, it may be necessary to differentiate between the specific intents of gaining knowledge and creating knowledge. Students may gain knowledge about already established and accepted conventions, knowledge that is new to them. They may also help to create new knowledge. According to Reither and Vipond's interpretation, once students have learned established knowledge, they may contribute to the making of new knowledge. Still, this new knowledge is not clearly defined, and inferences from different members of this community leave the specifics in question.

Playing It out in the Classroom

Do these different notions of reaching consensus, of the meaning of making meaning, and of undermining authority alter classroom practice? Bruffee and wiener negotiate consensus in the classroom by letting groups, once established, reach consensus by their own authority. Once each group has reached consensus, the teacher assists the class as a whole to achieve consensus by helping students to examine differences among groups and to work toward reconciliation.

For Reither and Vipond, the notion of consensus is less problematic. Students must cooperate to get the job done. The nature of the task plays a decisive role here. Attaining consensus is a greater problem when controversial, personal issues become involved. Academic topics are more 
amenable to student agreement. Reither and Vipond's assigned investigation of a genuine scholarly field is likely to create situations in which group members are grateful for the contributions of others and eager to negotiate agreement. Discussions on impersonal research topics are not likely to become volatile. A more serious problem might be that of antagonism toward students not contributing their share in the collaborative effort.

As for the transfer of authority based on classroom pedagogy, social constructionists differ widely. John Trimbur believes that "teachers cannot be simply facilitators because such a role ignores the institutional context and the authority it ascribes to the teacher" ("Collaborative Learning" 105). Gere also suggests that the degree of authority students may take is limited because of the nature of the institution and of the teacher as representative of that institution; nevertheless, she believes groups may become semiautonomous with sufficient preparation. Gere notes factors such as degree of the teacher's commitment to the value of writing groups--a feeling that cannot be taught but which may be "caught" by students. She also lists the importance of giving students a "real" task for writing, one that entails critiquing drafts, not finished pieces, and for making a commitment to "preparing students with the necessary social and intellectual skills (modeling behavior and encouraging students' respect for others and for positive sharing as 
well as classwork that encourages a sense of community and develops listening skills)" (103-07).

Bruffee, like wiener, sets a major task for teachers. Much like Gere, Bruffee attributes success for classroom writing groups primarily to teacher preparation. However, Bruffee, in making organizational suggestions, is much more prescriptive. In fact, Bruffee's prescriptive suggestions, while offered with the purpose of rendering support and guidance to those interested in initiating collaborative learning techniques, have led Margaret Tebo-Messina to name him as most conservative on her scale of collaborative learning proponents because he "would have the teacher retain all power and authority in the classroom" (87). While Gere outlines numerous possibilities and suggests that no one way is correct, Bruffee outlines specific guidelines. He suggests that teachers design tasks, organize groups, help students to resolve and/or understand differences, as well as act as final arbiter.

Additionally, Gere suggests fixed groups so that students become familiar and accustomed to working with one another and may let students organize their own groups, or at least have some say in group membership. Bruffee retains authority for assigning groups and does so at the last minute; he prefers that groups not be fixed, but vary for different class meetings. Such last-minute assignments eliminate problems caused by absent students and by personal involvement when students become too familiar with one another (A Short 111). Bruffee's last-minute group 
assignments would never work for Reither and Vipond, who suggest long-term collaborative projects with stable group membership, nor for Marilyn Cooper, who specifically uses small stable groups in the classroom as well as in computer instruction in order to have students focus attention toward one another, thus marginalizing teachers. Both Gere and Bruffee draw upon Vygotsky's notion of a zone of proximal development in assigning another very important and difficult task for the teacher. For a group to work best, the task designated by the teacher should be too difficult for individual group members to accomplish successfully, but within reach of the group as a whole.

Given emphasis on transferring authority, a surprising diversity emerges in suggestions for evaluation. Gere does not address the issue of evaluation; Reither and vipond, however, are very specific as to how they evaluate. They do not grade written work but evaluate according to two criteria, each given approximately equal weight: 1) quantitative criteria, which take effort into account, are based largely upon attendance and number of times each student participates directly in the group project; 2) qualitative criteria are based upon students' confidential assessment of the contributions of their peers. As Bruffee outlines evaluation for collaborative learning, the teacher makes the ultimate determination but takes into account student evaluations in making the final decision. Lefevre, likewise, would have the teacher make the grade 
determination but suggests grade distribution according to group, not by individual effort, thus "fostering a classroom climate in which it is in a student's interest to cooperate rather than compete" (132). Yet another variation is that of Marilyn Cooper. Cooper, who weights exploratory journal writing equally with formal essays, retains responsibility for grading. She evaluates exploratory writing based on the sincere effort of students to engage the questions raised in the materials of the course. When grading formal essays, she adds to the previous standard an ability to use explanations of theory, accounts of observation, analysis, and citations to back up claims. Cooper, as teacher, does not evaluate final drafts of essays, however, but asks another instructor to grade so that she can respond to student writing more as reader than evaluator ("Unhappy" 31). Bruffee makes allowances for those students who are uncomfortable with collaborative learning, allowing them to choose alternative ways of learning, i.e. individual tasks rather than collaborative ones, if they find that collaborative learning is emotionally or academically too demanding or uncomfortable for them--or if they find collaborative learning not demanding enough. However, LeFevre protests against including an "escape clause" because it "runs counter to the entire philosophy of collaboration," suggesting that individuals need not be responsible for anyone but themselves and allowing them to refuse responsibility for other members. Such a policy also "deprives [individual students] of the opportunity to learn 
how to negotiate their desires and needs while solving a mutual problem" (131-32). Given the homogeneous nature of warrants social constructionists use to support

collaborative learning, the great diversity in methodology is surprising. The variety may reflect the exploratory nature of a newly defined group or may result from failure to define terminology closely.

\section{Defining the Problematic}

As Anne Ruggles Gere has shown, collaborative learning is certainly not new. The renewed focus on the importance of collaborative learning differs, however, by connecting collaborative learning's importance with knowledge making, in some ways a troubling aspect with numerous questions still to be answered, especially in a profession where such epistemological issues are at the heart of professed purposes.

Does collaborative learning encourage meaning making or merely make established meaning more accessible? If the process makes meaning more accessible, what or who should determine the nature of that meaning? If collaborative learning permits meaning making, by whose standards are the results determined to be knowledge? How do we assure that the "knowledge" created is accurate for all and not just a misconception that is acknowledged because it is advantageous to certain groups or because it justifies the existing order?

Once claims for the worth of collaborative practices go 
beyond their value as a pedagogical tool that allows for more effective assimilation of meaning, demands change. Terms immediately must be defined more specifically. currently, theorists are trying to come to terms with the use of such terms as consensus, reality, and normal discourse. But if social constructionists promote collaborative learning on the basis of its connection with knowledge making, after all the primary claim for its value among some social constructionists, that term will have to be examined at least as closely as other problematic terms.

\section{Feminist Cooperation}

In the late 1960 s women began meeting in small groups to share experiences and to examine more closely the prevailing social order, as well as to raise awareness about the workings of societal structures and their implications for women. These consciousness-raising groups established an appreciation for collaborative learning that has continued for feminists into the 1990s.

One of the primary concerns within consciousnessraising groups was the establishment of an egalitarian approach, an effort to avoid the patriarchal, hierarchical, authoritative structure of society. There were no group leaders. Theoretically, all women received equal time for talking, and all experiences were deemed equally valid. Consciousness-raising groups thus established women's quest for egalitarianism by means of the small cooperative discussion group. 
More recently, a series of prominent feminist writings has further promoted the idea of cooperative collaboration as a specifically feminist concern. Nancy Chodorow, Carol Gilligan, and Mary Belenky, Blythe clinchy, Nancy Goldberger and Jill Tarule have all suggested, in several influential publications, that relationships and cooperative efforts are specifically "feminine," with Belenky more recently emphasizing that "[0]n the whole women work better in collaborative situations" (Ashton-Jones and Thomas 282). Indeed, the "web" metaphor that describes women's valuing of connectedness and relationships is commonplace among feminist writers. And, as Susan Meisenhelder notes, Nancy Hartsock and Elizabeth Janeway have called for replacing the prevalent notion of power and authority as domination with the notion of effective interaction (193). Meisenhelder herself has suggested a theory of composition that will view writing "not as a game of war or act of rape, but as a collaborative effort between reader and writer" (192), a theory that diminishes the notion of talking to and emphasizes the notion of talking with.

When feminists speak of collaboration, they mean a joint, cooperative effort. Andrea Lunsford and Lisa Ede, too, have reinforced this notion of cooperative collaboration as feminine and have dichotomized the cooperative from a more male-oriented notion of collaboration. In their study of collaborative writers within seven major professions, they identify several 
different modes of collaboration. They single out two modes they believe to be of particular interest to women: the hierarchical mode and the dialogic mode. The hierarchical mode, as Lunsford and Ede define it, is "linearally structured, driven by highly specific goals, and carried out by people who play clearly assigned roles" (235). This mode, whose goals are productivity and efficiency as assigned by a hierarchical superior, devalues multiple voices. They define this mode as predominantly masculine. The dialogic mode, to which they ascribe feminine characteristics, "is loosely structured, and the roles enacted within it are fluid; one 'person' may occupy multiple and shifting roles as the project progresses" (235). In the dialogic mode, the cooperative process is as important as the goals: "the group effort is seen as essential to the production--rather than merely the recovery--of knowledge as a means of individual satisfaction within the group" (236). Lunsford and Ede admit that their classification is tentative but point to the "phallogocentric nature of the academy" (234), which tends to value the hierarchical mode so alien to the dialogic mode of collaboration they find primarily in the work of women. Feminists, then, value collaborative learning because of its potential for altering the traditional masculine structure. They see it as a means for promoting cooperation, for diminishing the competitive nature of the classroom, and for undermining traditional hierarchical authority. Theoretically, collaborative learning supports feminist 
goals, but implementation is forcing a re-assessment of practices that may actually work against feminist purposes.

\section{Defining the collaborative}

In Women's Ways of Knowing, Belenky et al. describe the cooperative, connected way many women learn best; they, like Bruffee and wiener, differentiate between group work and collaborative learning. Instead of using consensus as the determinant, however, they point to the web metaphor in differentiating "real talk" from didactic talk. Didactic talk is simply holding forth--taking the stage. "Real talk" requires careful listening and sharing among members who join in creating an environment where ideas and understanding may grow (144-46). The emphasis is on trust and connectedness.

Others in the feminist camp differentiate group work from cooperative work or collaborative learning as well. Nancy Schniedewind, for example, differentiates cooperative learning from regular group work because cooperative learning is structured to make students accountable to one another ("Cooperatively" 76). And Carol Stanger insists that in order for group work to be termed collaborative learning, the group must solve a problem that has more than one answer and must use "high-level critical thinking skills" (37). Thus, feminists, in a manner similar to that of social constructionists, often define cooperative learning or collaborative learning according to expressed 
intentions and purposes. For social constructionists, however, a movement toward consensus determines true collaborative learning; for feminists, it is the cooperative nature of the exercise.

\section{Pedagogical Implications}

Feminists within the classroom see the traditional university structure and classroom setting as masculine-large lecture halls with an "expert" transferring fixed, objective knowledge to passive students. "This mode... can only reflect one version (usually the one dominant in the culture)" (Maher, "Classroom Pedagogy" 30). This means of instruction is especially pernicious for women because it usually transfers wisdom handed down over generations, content that has traditionally ignored and demeaned women (30).

Many feminists, then, prefer collaborative learning with a strong emphasis on cooperation. They value collaborative learning as a cooperative "alternative to dominant codes of social analysis and interaction" (Schniedewind, "Cooperatively" 74). They question the "competitive bias in standard research and writing" (74), often calling instead for collaboration that requires students to take responsibility for the learning of others as well as for their own. These teachers structure classes so that individual competitiveness is unhelpful (75). Collaborative groups, feminists believe, promote tolerance and equality; because students get to know one another more 
intimately, "the barriers between 'us' and 'them' begin to break down." The groups promote acceptance because "[p] eople that students have typed all of a sudden have faces and feelings, individual needs and talents, and weaknesses. The stereotypes no longer fit" (Frey 99-100).

Some feminists purposely arrange collaborative work so that individual group members must take responsibility for others in order to succeed. Nancy Schniedewind, in questioning the "competitive bias" in traditional writing, believes that truly cooperative learning, "a joint undertaking for mutual benefit," has rarely been a part of pedagogical practice. Schniedewind structures small heterogeneous groups to work in cooperative fashion: a "student obtains her goal if, and only if, others with whom she is linked obtain theirs" ("Cooperatively" 75). Schniedewind consciously arranges collaborative work so that students "sink or swim together," suggesting project structures such as the "jigsaw format" in which, in order for a group to meet its goal, each member must provide important information or input. For example, groups may be assigned a project that requires thorough knowledge of an entire book. If each group member is assigned one portion of the book, she must provide the group with essential information about her portion in order that the group may complete its assignment ("Cooperatively" 78; "Teaching" 23) . Presumably, this forced cooperation helps students to "learn that one's achievement does not always depend on another's 
failure" (Frey 100), but results in "shared meaning through collective problem-solving, rather than the imposition of a single right answer" (Maher, "Pedagogies" 51).

The scenario created by Schniedewind, Frey, and other feminists is ideal, of course. Students do not always contribute their share to a task, and assignments intended to create a cooperative situation may instead lead some students to take on the responsibilities of others in order to save their grade. Such situations may distance students and create angry situations instead of promoting caring concern for one another. And Laura Quinn has highlighted another problem: students' vigorous subversion of such collaborative efforts by coercing female group members or the "least masculine" male members into assuming group functions and responsibilities others wish to avoid (quoted in Rouster). This is particularly significant because women have historically been placed in caretaker roles. In addition, as William Rouster argues, students who come to the classroom from our society's highly competitive culture might not readily accept such cooperative methodology because it is "contrary to their primary and secondary socialization."

Feminists use collaborative groups to promote other ideals as well. Because feminists oppose the hierarchical mode of authority on which much leadership is based, they often emphasize development of leadership skills in the manner of democratic decision making (Schniedewind, "Teaching" 20-21). For example, carolyn Shrewsbury 
suggests that students take part in developing course goals and objectives as a means of learning planning and negotiating skills and of gaining an understanding of their own needs and learning to articulate them. Collaborative groups allow students to assume different leadership roles during the course of the semester and to gain an understanding of the workings and different leadership tasks involved in groups (11).

Small "cooperative" learning groups may also be used, especially where classes are very large, to provide students with a means of active interaction with material and permit a closer look at students' cognitive stages and barriers to learning (Dunn 45). Finally, cooperative groups are especially helpful to returning students, who are generally also commuting students, as a means of social interaction that is otherwise impossible (Jerilyn Fisher 91).

\section{The Authority Double Bind}

While feminists have generally accepted cooperative learning groups as consistent with feminist intentions, there are problems connected with their use. Schniedewind outlines concerns related to her notion of intertwined accountability. The approach, she admits, places significant pressure on students. If the teacher is seeking a relaxed classroom atmosphere or if academically deficient students already are having difficulty with the material, the extra burden of responsibility for others may be inappropriate ("Cooperatively" 81). Additionally, 
Schniedewind focuses primarily on feminist pedagogy in women's studies classes and acknowledges that emphasis on cooperation might make women's studies classes open to charges of being "soft." This notion raises concerns similar to those accompanying use of personal experience. Cooperation has historically been associated with the "feminine" and dichotomized opposite the traditional patriarchal norms considered appropriate for rigid, and therefore respectable, academic learning; thus, its use becomes a double-edged sword. Schniedewind dismisses such charges because she believes "to be soft is to be subversive" since such criticisms actually develop out of fear of subjective learning that cannot be contained and therefore controlled by those in power (85-86).

A more serious concern seems to be the problematic place of authority in the classroom. A primary objective for feminists in promoting the use of collaborative group work has been to undermine the traditional hierarchical structure within the classroom. One purpose of Frances Maher's "interactive" pedagogy is to reduce the image of the teacher as authority figure so that the teacher's perspective is only one, "her viewpoint a partial one, and her authority as given by the specific classroom context, which can also be critically examined" ("Pedagogies" 50-51). But Clare Bright has expressed concern about feminists avoiding the topic of power in their preference for shared power structures and situations. Bright believes that "the 
educational system is not an egalitarian one and regardless of the extent to which a teacher tries to minimize her power, it cannot be completely given away." She fears a situation where power--and its abuse--may be obscured, because the denial of the hierarchical situation mystifies the situation and makes it more difficult for students to accurately name their experience (98).

Another concern expressed by feminist Dale Bauer addresses problems implicit in women's relinquishing power within the classroom: "Because my voice in the classroom is one in competition with other voices speaking for the students' allegiance, . . I would do well to be aware of the rhetorical situation of the classroom" (395). Since she believes there is always already a certain authoritative voice present, Bauer insists that not accepting authority in the classroom reinforces a dominant patriarchal culture that students see as neutral.

Susan Stanford Friedman also notes the danger of perpetuating derogatory patriarchal notions by ignoring "the lens of gender as it operates in classroom dynamics and pedagogy" (206). Friedman suggests that we must recognize both our socialization and that of our students in a culture that negates and trivializes women's authority. She fears that in an effort to subvert and reform the patriarchal culture, feminists "have sometimes participated in patriarchal denial of the mind to women" (207). These feminists are beginning to re-assess efforts to relinguish classroom authority. When teachers give up authority in the 
classroom, they are most likely further empowering those students who already hold most power. A "neutral" classroom atmosphere is most often supportive of the dominant, i.e. white male, power structure.

\section{Toward a More Comfortable Fit}

Feminists, then, are looking carefully at theory and pedagogy with regards to collaboration. While most feminists still stress the feminine nature of collaboration, many are trying to reshape and adjust both theory and practice to enforce feminist interests more positively, what Dale Bauer has called "a mastery that is not oppressive" but allows for "an authoritative voice that is not the only authority" (395).

Women's Ways of Knowing has often been cited as support for the notion that cooperation is a feminine mode of learning; Elizabeth Flynn notes that "It would seem that women are in general, more cooperative than men, more connected to each other and hence more capable than men of collaborating successfully" ("Politicizing" 176). However, this position seems a precarious one. Such a stance ignores the many instances in which men have collaborated rather successfully. Indeed, the laws on which our government is founded and the structure of most of our institutions have resulted from a collaborative effort among men. Men cooperate well in team sports and have collaborated throughout history in a more sinister manner to maintain power and authority by denying rights of suffrage and 
participation to women and minorities. Women, for their part, have for many years competed against one another for men, in beauty competitions, and more productively in recent times, for admission into the professions, politics, and other public leadership roles. Rather than dichotomizing collaborative and competitive learning along gender lines, the more productive theoretical approach may be one that concentrates on the positive aspects of each. Marilyn Cooper has suggested that the two sides of this dualism offer a positive check on one another and argues for a productive use of the tension involving dualisms ("Dueling" 183). Certainly, enforcing a dichotomy that appears to be true only under certain circumstances and that serves to continue the negative oppositional positioning of women and men fails to bring to composition the best of feminist theory that goes on in the larger feminist community.

\section{Marxist Solidarity}

While Marxists place great value on group unity and action, they rarely define such emphasis as collaborative learning. Marxists are more likely to promote the notion of cooperation, as do many feminists, or to emphasize collective action and social solidarity. They never differentiate between group work and collaborative learning, valuing instead any group activity with a productive goal. Group unity is vital to Marxist plans for social action, and Marxists often give reasons for valuing group activity similar to those from other theoretical backgrounds: the 
promotion of cooperation among group members, the reduction of hierarchical authority, and the ownership of responsibility. Usually, most important, is the intention of encouraging vital communication and a sense of community that will increase critical consciousness and undermine the hegemonic ideology of mass culture.

Henry Giroux and Anthony N. Penna express concern that classrooms "enshrine the self at the expense of the group," a trait consistent with a system whose hidden curriculum promotes selfishness and privatization at every level (37). Similarly, Ira Shor believes collaboration serves a purpose because class interaction may foster a sense of community and because students need "collective vehicles" to counteract mass society's obstruction of most attempts to organize for common purposes. Students have been isolated from one another and from their own power. Collective work can be a bonding experience for those whom mass culture has effectively isolated, frustrated, and made unsure of their own powers and abilities (Critical Teaching 108-109).

Giroux and Penna try to address the pervasive selfinterest that pervades all societal relationships. They believe that the cooperative aspect of group dialogue can offset the emphasis in the hidden curricular agenda that fosters "competition and excessive individualism" so that students may actually participate in democratic processes $(37-39)$.

Marxists also place great value on collective action 
because it undermines traditional authority. "A cooperative style of work in the liberatory class locates decisionmaking among students who have reacted to orders all their lives. Thus, an exercise in collective work and group deliberation is therapeutically restoring" (Shor, Critical 109). Both Shor and Giroux and Penna believe that group work is effective in demystifying the "traditional, manipulative role of the teacher" (Giroux and Penna 39). At the same time that group work encourages "the withering away of the teacher," it also formulates "the withering away of authority-dependence" by delegating responsibility among a community of learners (Shor, Critical 109), providing students with "social contexts which stress social responsibility" (Giroux and Penna 39). Shor believes that class projects that depend upon student cooperation promote a large degree of mutual responsibility (Critical 109). Students also learn "how better to ask questions and how to listen." (Ohmann, Politics 163). And students are forced to shed their image of disempowerment when involved in group interaction in which peer transactions are essential (Shor, Critical 109).

\section{Pedagogical Support for the Collective}

Several Marxists offer specific examples for implementing collaborative or group work within the classroom. Since these scholars are generally greatly concerned with content and choose to focus on social issues, the examples also serve the purpose of offering specifics 
for directing students toward a critical consciousness. Because of their concern with collective action and the issue of authority, the examples provide information about dealing with such problems. For example, Ira Shor suggests using what he terms the "component method," which breaks down a general topic (Shor chooses the theme "work" as his example) into smaller subtopics assigned to individual groups. Shor intends to lessen teacher-centered authority and to give detailed means for further encouraging that decentralization. According to shor, since a single teacher cannot be present at all times in all groups, students, in order to get work done, will have to rely upon each other as well as supervise themselves. When groups combine for class deliberation, Shor suggests having a rotating chairperson and exchanging self-discipline (deferring to one another with priority going to those who have spoken least) for hand-raising. To prevent regression to authority within the group, Shor insists that each group member take part in providing the oral report to the class. To discourage regression to teacher authority, Shor, as teacher, refuses to make eye contact with any students who continue to address him rather than other class members. When students address questions to the teacher, Shor advises redirecting the question to the class or to other groups or group members (Critical 109-110).

Another method shor suggests is what he terms the "dictation sequence." Although the primary intent is to connect spoken and written language while students validate 
their own language and knowledge, the task requires mutual cooperation from students in order to complete the assignment. Students join together in pairs to interview and record one another's thoughts on the assigned theme. According to Shor, the technique develops self-confidence and awareness, and significantly proceeds without the need of teachers or texts, serving "to decentralize the responsibility for reaction, criticism, discipline, and correctness from the teacher to the peer group" (Critical $132)$.

Richard Ohmann also uses interviewing to encourage interaction. Ohmann feels that this method fosters collaboration and allows students to question and develop insights about traditional authority and the dominant ideology. Students begin interviewing within the classroom, but move outside the classroom with explicit purposes of finding others to interview who appear to be different from those interviewed within the classroom. Class members share outside interviews as well as outside readings. Ohmann's chief purpose in using interviews is to "extend the field of vision" for elite students who make up the largest component of his teaching institution. At the same time, interviewing gives students the opportunity to ask and listen and talk with people who are different from themselves (Politics $253-63)$

In another effort at redistributing traditional authority, Giroux and Penna suggest minimizing extrinsic rewards when 
possible and allowing students to participate in assessment through dialogic grading, "which involves a dialogue between students and teachers over the criteria, function, and consequences of the system of evaluation" (39). Giroux and Penna find dialogic grading essential because they believe that grades "become in many cases the ultimate discipline instruments by which the teacher imposes his desired values, behavior patterns and beliefs upon students" (38). Thus, they are in agreement with many in other groups who see problems with allegedly diminishing teacher authority while teachers retain the final say in assessing grades.

The Difficult Collective Task

There is some dissension in the Marxist camp with regard to the value of collaborative learning. While most Marxists value collective organizations and community, some doubt the ease of implementing collaborative learning as a pedagogical tool that will promote such community. For example, while Greg Myers agrees that "If there is hope for resistance to ideology, it is through collective action" (Response 213), he sees collaborative techniques as not necessarily liberating in themselves, but able to reinforce or oppose social structures. Therefore, Myers would be more concerned with the instructor's ideology and commitment ("Reality") .

And while Myers is skeptical of the effectiveness of collaborative learning because collaborative practices may just as easily reinforce hegemonic ideology as raise 
critical consciousness, Myron Tuman questions the ability of such techniques to change the systematic social reproduction that takes place in school. While such practices of process pedagogy as learning to collaborate with others may, Tuman agrees, better prepare students "to occupy a privileged position in the mode of production. . . there is no reason to believe that [this] tactic would do much to overcome the disadvantage of students from families headed by parents occupying less privileged places within the work place" ("Class" 49). Tuman, like Basil Bernstein, believes that what often looks like reform is "only a new form of control" (50) and suggests that certain traditional forms of authority may actually help to develop the sense of justice that promotes a critical perspective of social structures. Accordingly, Tuman believes, a writing class with teacher as authority figure, while it may not serve the purpose of "socializing future workers," may promote "aspirations of a better world and lingering suspicions of this one" (50).

\section{Collaborative Problems Across Groups}

While theorists from social constructionism, feminism, and Marxism support collaboration because it decenters authority, the pedagogical suggestions differ greatly. Social constructionists appear to have the least faith in the ability of groups to take on a "proper" authoritarian role and therefore rely most heavily on prescriptive formulas. On the other hand, feminists, who have long supported cooperative learning because it diminishes 
hierarchical authority, are reconsidering the degree to which they wish authority reduced and are searching for a newly defined sense of power and authority. Marxists seem to worry least about danger from diminished authority. Their emphasis on student participation and increased leadership ability is probably a factor here. It should be noted, as well, that all scholars from the Marxist tradition cited here are male, and as Marian Sciachitano has pointed out, a white male's choice of assuming or relinquishing power within the classroom is one many women and minorities do not experience ("Theorizing" 57). While these Marxists are certainly sensitive to the concerns of women and minorities, they would not have experienced the same pedagogical problems associated with diminished authority as would women and minorities and might, therefore, be less apt to address this issue when presenting their own pedagogical approaches. Although Marxists, some social constructionists, and especially feminists stress cooperation, and all groups propose to undermine traditional authority and restructure its balance in the classroom, both goals have limited possibilities within institutional classrooms that demand testing and grading. As long as the teacher retains primary responsibility for naming grades, the teacher's authority is primary and irrefutable. Any attempt toward placing authority elsewhere is either partial or is, in reality, simply a smokescreen. And similar problems abound in attempts to restructure the competitive nature of the classroom by emphasizing cooperation. Even if teachers 
follow suggestions like those of social constructionist Karen Burke LeFevre and feminist Nancy Schniedewind in setting projects and exercises that require members to work together to get the task accomplished, every teacher who has used collaborative learning knows this doesn't always work. One or more members may still not produce the assigned portion, leading often to anger and resentment from other members. But, even more assuredly, as long as grades of any kind are given--unless everyone achieves an $A$, and even this doesn't necessarily lessen competition for the teacher's favor--there will be competition among individuals and groups for the higher or highest marks.

A major factor defining social constructionists is their emphasis on knowledge making. Their drawing of warrants from social constructionists such as Thomas Kuhn and Richard Rorty separates them from the other two groups. While it may be noted that feminism and Marxism are social theories and, in a sense, espoused the social nature of language before the social constructionist term and allegiance were defined, they have not emphasized that all knowledge is socially constructed per se. By doing just that, social constructionists have invited questions about specific definitions of reality and knowledge. They must now address the concerns about how and at what point collaborative learning becomes knowledge producing and more real. Social constructionists may need to define these terms more specifically for themselves, as well as for 
critics, in order to more clearly understand the full value of collaborative learning.

While the term social constructionist is used to encompass a large number of people here, it should be noted that the women in this group, specifically Anne Ruggles Gere, Marilyn Cooper, and Karen Burke LeFevre, are less dogmatic in drawing warrants from the social constructionists. Gere and cooper do not engage in the discussion with regards to the production of knowledge, and all three tend to incorporate some feminist principles. This overlap may account for the fact that LeFevre, while strongly in the social constructionist camp with regards to notions of knowledge making, emphasizes cooperation and, like some feminists, would insist that members work collaboratively, giving them no option of withdrawal, even to the point of collective grading.

The overlap among groups has not diminished the need to define terminology more clearly. The social constructionist notions of consensus and normal and abnormal discourse are still problematic. In addition, LeFevre's use of the term collective, while in reality defining an aspect of social learning long of interest to feminists and Marxists, may be confusing since her terminology differs from that used by members of the other groups for the same reality. The word collective is one long employed by Marxists to define community action for resistance to just such a social consciousness for which LeFevre applies the term.

It becomes increasingly clear that the manner in which 
collaborative groups are used determines the extent to which authority is redistributed within the classroom and the nature of knowledge making that takes place. A careful look at collaborative theory and practices points to the importance of the teacher's ideology and her approach in the classroom and at the same time underlines the necessity of her understanding the implications behind the pedagogical methods she chooses. 
CHAPTER V

UNDERSTANDING THE COMPLEXITY OF SOCIAL PRACTICES

The "social turn" in rhetoric and composition has heralded dramatic changes in the teaching of writing. In acknowledging the connection between language and writing and subsequent implications for the social consequences for those who use language and writing, scholars have recognized the political nature of the teaching of writing. As long as writing instruction was accepted as a neutral transferral of information and skills, and as long as students came primarily from a homogeneous upper class with commonly accepted values, problematic differences associated with social situatedness and relative positioning to demands for literacy remained obscure. The inclusion of greater numbers of diverse individuals and awareness about social implications for those individuals made exclusionary practices of institutions and professions apparent. Moreover, as the increasing acceptance of the socially constructed nature of institutions, especially of language, gained visibility, the classroom became an acceptable place for confronting political ideologies. Writing classrooms based primarily on grammar, structure, and "skills" development changed to focus on content and the development 
of more critical, and questioning, thinking abilities.

The new "social" awareness has engendered concern about the political significance of practices rarely seen as political before. Students have been encouraged to use personal experiences in writing for centuries, but, now, scholars promote personal experience writing, not merely to make learning more interesting or meaningful for students, but in order to help students discover and understand their unique individuality and its relationship to an overall social structure. Group work, once initiated primarily by students outside regularly scheduled class time, has become teacher initiated collaborative learning. Teachers now insist that students participate in group work because collaborative learning models the way knowledge is constructed or because group projects better prepare students for the "real world." And supporters highlight context in order to make its political significance more apparent. By the late twentieth century, the strong emphasis on the social has allowed for political entry into the classroom in a more diverse and more obvious manner than ever before. The new direction in the teaching of writing challenges scholars to work out the unexpected and often problematic developments that accompany such a major revaluation of curriculum.

one challenge requires a redefinition of terminology so that scholars may aiscuss and examine appropriate directions for the field. An examination of theory and pedagogy across 
theoretical groups reveals inexplicitly defined terminology. References to personal experience writing may include anything from very intimate, personal details of one's individual life experiences to examination or reflection on those general cultural and social activities and milieu that are part of everyday life. Allusions to collaborative learning may involve small, informal discussion groups in which members share ideas or may insist upon more formal, carefully assembled groups whose members, already conversant in shared knowleage and language conventions, work toward predetermined goals. Likewise, references to writing in context may include attempts to embed writing and learning within historically and socially situated conditions that are personally meaningful for students or to writing that is embedded in the language and conventions of a specific discipline or discourse community.

Further ambiguous terminology exists with regard to applications within various pedagogies as well. For Marxists, the "real world" is a socially stratified and unequal society; for social constructionists, the "real world is the world of the academy, business and the professions. Similarly, when social constructionists refer to contextual isolation, their intended meaning most often highlights language and writing within academe that disregards the "real" corporate world. Social constructionists suggest improving such a situation by stressing the conventions and expectations of the business world. In contrast, just such a remedy creates what 
Marxists identify as contextual isolation because stress on business and academe isolates students from the context of their own situated personal and historical environment. Collective, a Marxist term for group solidarity that allows for praxis, becomes, for Karen Burke LeFevre, a term for the overall social and cultural expectations and attitudes against which Marxists seek to raise consciousness.

Interestingly, just those theories and pedagogies upon which each theoretical group places greatest emphasis seems to create most problems for that group. Personal experience has been most valued by feminists; yet, increasingly, focus on its use within the composition classroom highlights inherent problems for feminists in incorporating personal experience. Attempts to ensconce personal experience writing within composition classrooms with a nurturing, accepting approach have often undermined perceptions of its legitimacy; critics remark upon such a "soft" approach because of its distance from traditionally rigorous academic fare. Efforts to validate expressions of personal experience by all students have led to intrusions on the sensibilities and rights of some students and teachers. Unwitting valorization and naturalization of the personal experience of white middle class students might undermine students' growth in critical consciousness. And encouraging students to write about very personal intimate experiences may facilitate those willing to exploit students either sexually or emotionally. 
Difficult issues accompany efforts of other groups as well. Social constructionists, who so strongly emphasize the importance of collaborative learning, often make problematic claims for the value of collaboration, leaving important questions unanswered: To what extent does collaborative learning create knowledge? Is this knowledge new for the individual students or new knowledge for society at large? How do we determine which? By whose definition does the meaning become knowledge? Is it not possible that collaborative definitions of knowledge are determined by the dominant members of society who use just those definitions to more effectively marginalize and exclude?

And the emphasis on context by Marxists creates a double-bind for them. If academic discourse is the language of the dominant elite, then teaching academic discourse acculturates students into the language and patterns of the oppressors. But failing to teach students academic discourse most likely relegates them to positions of powerlessness within a socioeconomic culture that marginalizes those who fail to learn the language and conventions of the elite and devalues their contributions with inferior monetary awards and status. Effecting change from such positions of powerlessness is unlikely. How, then, do Marxists best serve the language needs of students within academe?

Perhaps theorists might benefit from examining more closely, not only how theory plays out in the classroom, but also the consistency among suggested theoretical and 
pedagogical practices. While feminists have, in the past, supported personal experience writing, they have also encouraged cooperative, or collaborative, writing, as well as inclusion of historical and material context. In supporting personal experience writing, feminists are supporting a very individualistic form of writing unless class members share their personal writing openly to make connections with that of others. But many feminists encourage students to write about personal experience in private journals that only the teacher reads, or in some cases, that no one but the writer reads. This practice is not consistent with other feminist efforts that insist upon collaborative work and inclusion of broader historical and material contextual information. Marxists, who tend to use a more social and collective form of the personal, appear to be more consistent in methodology, since their use of the personal focuses on experiences from mass culture that all class members are likely to have experienced. Perhaps scholars might more productively focus efforts toward determining what constitutes a balanced methodology. Should we try to achieve a consistency that focuses all classroom proceedings in the direction of group involvement and "social" activities? or do we wish to use a variety of methods that might allow for at least some comfortable means of learning for everyone. Marilyn Cooper's concern that her student, Bartleby, dropped out of the collaborative projects she instituted for her students because they were just too 
uncomfortable for him, and Donald Stewart's railing against those collaborative practices that fit the personalities of extroverted students but that can be excruciatingly painful for introverts may suggest a re-examination of "forced" cooperation and collaborative work. If we require methodologies that are consistently social and group oriented, are we favoring one segment of the student population as surely as we did with lecture and individual writing formats? Does the use of a variety of methods send students mixed messages or simply promote a balanced agenda that develops both the individualistic and social aspects of students?

Important consistencies appear across theoretical groups. Suggestions among many women who support social constructionist theories overlap with ideas proposed by feminists. Patricia Bizzell has consistently been concerned with recognizing differences among students. Karen Burke LeFevre and Marilyn Cooper place a cooperative emphasis on collaborative learning that is much like that of feminists as well. Shirley Brice Heath's inclusion of the social and cultural background of students places her very close in methodology to Ira Shor, who also places most work in the context of the everyday lived experiences of students. And Myron Tuman's insistence on the importance of students' learning symbolic manipulation closely parallels emphasis placed on academic writing among social constructionists. How much difference is really involved? And where is that difference? Do classroom practices really differ 
greatly in methodology or is the distinction primarily in the questions we ask? Does the disparity come from the way we structure our classroom or in where we place emphasis? Interestingly, when we look closely at classroom practices, their connections with supporting theoretical underpinnings are often very subtle. Content provides one relatively tangible ingredient. We give students direct messages by our choice of topics. We also give messages by how individualistic or collaborative we make the learning process, from lecture or class discussion to final written product. With our methodology, we give implicit messages to students about where we see their place in the world. Are we preparing them to work well with others on cooperative projects or are we helping them to better understand their own situatedness and therefore to determine what place, as far as possible, they accept in the overall scheme of things. Can we effectively combine the two?

Many questions about recent social practices have gone unanswered because, in spite of the overwhelming move toward social classroom practices, very few empirical studies have addressed either the effectiveness of the new social practices or the correlation between theoretical claims for the methods and actual results within the classroom. Heavy emphasis on theory in recent years may be partially responsible for inadequate information about many of the methodologies. The infatuation with theory has also resulted in a loss of status for the practitioner, taking 
attention away from the classroom teacher.

A focus that excludes the practitioner is unfortunate. The eventual effectiveness of theory's influence upon classroom practice and upon students relies upon the teacher in the classroom. The teacher determines the direction of classroom activity despite any theoretical efforts to turn over responsibility to students. Theoretical understanding behind practices is vital because teachers who have a consistent understanding of their purposes and directions are more likely to give consistent, effective messages to students. The manner in which composition is structured does present unique problems. A large percentage of classroom teachers of composition are not tenured faculty and are given minimal say in such matters as what texts they will choose and often in what syllabi they will use. These teachers must have some understanding of the theoretical implications behind the materials and practices they use in the classroom. Any hodge-podge use of practices because they are the "in" methods or because they are assigned from above might lead to inconsistent and contradictory practices. In a period of time when we emphasize the importance of critical thinking on the part of students, it is imperative that we help students to see some consistent overall meaningfulness in what we do. If teachers have examined and understand their own motivations behind the theories and practices they implement, they will be prepared to show students the overall purpose and coherence of those practices. 


\section{Bibliography}

Abel, Elizabeth, ed. Writing and Sexual Difference. Chicago: University of Chicago Press, 1982.

Abercrombie, M. L. J. The Anatomy of Judgment. London: Hutchinson, 1960.

Alcoff, Linda. "Cultural Feminism Versus PostStructuralism: The Identity Crisis in Feminist Theory." Signs: Journal of Women in Culture and Society 13 (Spring 1988): $\overline{40} \overline{-36 \text {. }}$

Allen, Henry and Lynn Fauth. "Academic Journals and the Sociological Imagination." The Journal Book Ed. Toby Fulwiler. Portsmouth, NH: Boynton/Cook, 1987. 367-74.

Annas, Pamela. "Silences: Feminist Language Research and the Teaching of Writing." Teaching Writing: Pedagogy, Gender, and Equity. Eds. Cynthia I. Caywood and Gillian R. Overing. Albany: SuNy Press, 1987. 3-17.

--. "Style as Politics: A Feminist Approach to the Teaching of Writing." College English 47 (7 April 1985): 360-71.

Ashton-Jones, Evelyn and Dene Kay Thomas. "Composition, Collaboration, and Women's Ways of Knowing: A

Conversation with Mary Belenky." Journal of Advanced

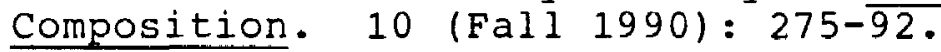

Bakhtin, Mikhail. The Dialogic Imagination. Trans. C. Emerson and M. Holquist. Austin: U. of Texas Press, 1981.

Bartholomae, David. "Inventing the University." When

Writers Can't Write. Ed. Mike Rose. New York: Guilford Press, $1 \overline{985 .} 1 \overline{34-65}$.

--. "Writing Assignments: Where Writing Begins." Forum: Essays on Theory and Practice in the Teaching of Writing. Ed. Patricia I. Stock. Upper Montclair, N. J.: Boynton/Cook Publishers, Inc. 1983. 300-16.

Bauer, Dale M. "The other "F" Word: The Feminist in the Classroom." College English 52 (April 1990): 385-96. 
Beade, Pedro. Comment. College English 49 (October 1987): 707-708.

Belenky, Mary Field, Blythe McVicker Clinchy, Nancy Rule Goldberger, and Jill Mattuck Tarule. Women's Ways of Knowing: The Development of Self, Voice, and Mind. New York: Basic Books, $198 \overline{6}$.

Berlin, James. "Contemporary Composition: The Major Pedagogical Theories." College English 44 (December 1982) : 765-77.

---. "Rhetoric and Ideology in the Writing Class." College English 50 (September 1988): 477-94.

--- Rhetoric and Reality: Writing Instruction in American Colleges, 1900-1985. Carbondale: Southern Illinois University Press, 1987.

Bernstein, Basil. Class, Codes and Control: Towards a Theory of Educational Transmission. Vol. 3. 2nd ed. Boston: Routledge \& Kegan Paul, 1977.

Berry, Ellen and Elizabeth Black. "The Integrative Learning Journal (or, Getting beyond 'True Confessions': and

'Cold Knowledge')." Women's Studies Quarterly XV (Fall/Winter 1987): 59-64.

Bialostosky, Don H. "Liberal Education, Writing, and the Dialogic Self." Contending with Words: Composition and Rhetoric for a postmodern Age. Eds. Patricia Harkin and John Schilb. New York: MLA, 1991. 11-22.

Bizzell, Patricia. "Academic Discourse: Taxonomy of Conventions or Collaborative Practice?" Paper presented at CCCC (March 1986) New Orleans.

---. "Arguing about Literacy." College English 50 (February 1988): 141-53.

---. "Cognition, Convention, and Certainty; what we Need to know about Writing." Pre/Text 3 (1982): 213-44.

---. "College Composition: Initiation into the Academic Discourse Community." Curriculum Inquiry 12 (1982): 191-207.

---. "Cultural Criticism: A Social Approach to Studying writing." Rhetoric Review (Spring 1989): 224-30.

-.-. Rev. of What Makes Writing Good: A Multiperspective. College composition and Communication 37 (May 1986): 244-47. 
---. "Thomas Kuhn, Scientism, and English Studies." College English 40 (March 1979): 761-72.

Bizzell, Patricia and Bruce Herzberg. Review. College Composition and Communication. 57 (May 1986): 244-47.

Brandt, Deborah. Literacy as Involvement: The Acts of Writers Readers, and Texts. Carbondale: Southern Illinois University press, 1990.

---. "The Message is the Massage: Orality and Literacy Once More." Written Communication 6 (January 1989): 31-44.

--- "Toward an Understanding of Context in Communication." Written Communication 3 (April 1986): 139-57.

Bright, Clare. "Teaching Feminist Pedagogy: An Undergraduate Course." Women's Studies Quarterly XV (Fall/Winter 1987): 96-101.

Brodkey, Linda. Academic Writing as Social Practice. Philadelphia: Temple University Press, 1987 .

---. "The Context of Cooperation in Academic Discourse." Paper presented at CCCC (March 1984) New York City.

---. "On the Subjects of Class and Gender in 'The Literacy Letters." College English 51 (February $1989)$ : $125-41$.

---. "Topics of Literacy." Journal of Education. 16 $(1986): 47-54$.

---. "Transvaluing Difference." College English 51 (October 1989): 597-601.

Bruffee, Kenneth A. "Collaborative Learning and 'The Conversation of Mankind.'" College English 46 (1984): $635-52$.

--- "Collaborative Learning: Some Practical Models." College English 34 (February 1973): 47-57.

---. "Kenneth A. Bruffee Responds," College English 48 (January 1986): 77-78.

---. "Kenneth Bruffee Responds." College English 49 (October 1987): 711-16.

--- "Liberal Education, Scholarly Community, and the Authority of Knowledge." Liberal Education 71 (1985): 231-39. 
A Short Course in Writing: Practical Rhetoric for Composition courses, Writing Workshops, and Tutor Training Programs. 2nd ed. Boston: Little Brown, 1982 .

---. A Short Course in Writing: Practical Rhetoric for Composition courses, Writing Workshops, and Tutor Training Programs. 3ra. ed. Boston: Little Brown, 1985.

"Social Construction, Language, and the Authority of Knowledge: A Bibliographical Essay." College English 48 (December 1986): 773-90.

---. "Writing and Reading as Collaborative or Social Acts: The Argument from Kuhn and Vygotsky." The Writer's Mind: Writing as a Mode of Thinking. Ed. Janice $N$. Hays, et al. urbana: NCTE, 1983. 159-69.

Bunch, Charlotte and Sandra Pollack. Learning Our Way: Essays in Feminist Education. Trumansburg, N.Y.: The Crossing press, 1983 .

Card, Claudia, ed. Feminist Ethics. Lawrence, Kansas: University Press of Kansas, 1991.

Carey, Stephen T. and James Cummins. "Communication Skills in Immersion Programs." Alberta Journal of Educational Research 30 (December 1984): 270-83.

Carter, Michael. "The Idea of expertise: An Exploration of Cognitive and Social Dimensions of Writing." College Composition and Communication 41 (October 1990): 26586 .

---. "Problem Solving Reconsidered: A Pluralistic Theory of Problems." College English (September 1988): 551-65.

---. "A Rhetorical (and Teachable) Approach to Style." Teaching English in the Two Year College 14 (October 1987): $187-94$.

Catano, James V. "The Rhetoric of Masculinity: Origins, Institutions, and the Myth of the Self-Made Man." College English 52 (April 1990): 421-36.

Chodorow, Nancy. The Reproduction of Mothering: Psychoanalysis and the Sociology of Gender. Berkeley: University of california Press, 1978 .

Clifford, John. "Ideology into Discourse: A Historical Perspective." Journal of Advanced Composition 7 (1987) : $121-130$. 
---. "The Subject in Discourse." Contending with Words: Composition and Rhetoric in a Postmodern Age. Eds. Patricia Harkin \& John Schilb. New York: MLA, 1991. $38-51$.

Clinchy, Blythe and C. Zimmerman. "Epistemology and Agency in the Development of Undergraduate Women." The Undergraduate Woman: Issues in Educational Equity. Ed. P. Perun. Lexington, MA: D. C. Heath, 1982 .

Code, Lorraine. What Can She Know? Feminist Theory and the Construction of Knowledge. Ithaca, NY: Cornell UP, 1991 .

Coles, William E., Jr. and James Vopat. What Makes Writing Good. Lexington, MA: Heath, 1985.

Connors, Robert J. "Personal Writing Assignments." College Composition and Communication 38 (May 1987): 166-83.

Cooper, Marilyn M. "Dueling with Dualism: A Response to Interviews with Mary Field Belenky and Gayatri

Chakravorty Spivak." Journal of Advanced Composition 11 (Winter 1991) : 179-85.

---. "The Ecology of Writing." College English 48 (April $1986): 364-75$.

---. "Unhappy Consciousness in First-Year English." Writing as Social Action. Marilyn M. Cooper and Michael Holzman. Portsmouth, NH: Boynton/Cook, 1989. 28-60.

--- "Why Are We Talking about Discourse Communities? Or, Foundationalism Rears Its Ugly Head Once More." Writing as Social Action. Marilyn M. Cooper and Michael Holzman. Portsmouth, NH: Boynton/Cook, 1989. 202-20.

Cooper, Marilyn M. and Michael Holzman. Writing as Social Action. Portsmouth, NH: Boynton/Cook, 1989.

Culley, Margo and Catherine Portuges, eds. Gendered Subjects: The Dynamics of Feminist Teaching. New York: Routledge \& Kegan Paul, 1985 .

Davis, Angela. Women, Race and Class. New York: Random House, 1981 .

Davis, Barbara Hillyer, ed. Feminist Education: A Special Topic Issue of the Journal of Thought. Norman: College of Education, university of Ok lahoma, 1985. 
---. "Teaching the Feminist Minority." Gendered Subjects: The Dynamics of Feminist Teaching. Eds. Margo Culley and Catherine Portuges. Boston: Routledge \& Kegan Paul, 1985. 245-52.

---. "Finding New Forms: Students Autonomy in a Patriarchal University." Women's Studies Newsletter 7 (1979): 22-24.

De Lauretis, Teresa. Alice Doesn't: Feminism, Semiotics, Cinema. Bloomington: Indiana UP, 1984 .

---, ed. Feminist Studies/Critical Studies. Basingstoke: Macmilian, 1988 .

---. Technologies of Gender: Essays on Theory, Film, and Fiction. Bloomington: Indiana UP, 1987 .

Dewey, John. Experience and Education. New York: The Macmillan Company, $1 \overline{938}$.

Dunn, Kathleen. "Feminist Teaching: Who are Your Students?" Women's Studies Quarterly XV (Fall/Winter 1987): 40-45.

Eagleton, Terry. The Function of Criticism. London: Verso, 1984 .

--- Iiterary Theory: An Introduction. Minneapolis: U. of Minneapolis Press, $19 \overline{83}$.

Ebert, Teresa L. "The 'Difference' of Postmodern Feminism." College English 53 (December 1991): 886-901.

Emig, Janet. "Writing as a Mode of Learning." The Web of Meaning. Upper Montclair, NJ: Boynton/Cook Publishers, Inc., 1983. 122-31.

Faigley, Lester. "Competing Theories of Process: A Critique and a Proposal." College English 48 (October 1986):

$527-42$.

--- "Judging Writing, Judging Selves." College Composition and Communication 40 (December 1989) : 395412 .

Faigley, Lester and Kristine Hansen. "Learning to Write in the Social Services." College composition and Communication 36 (May 1985): 140-49.

Ferguson, A. "Feminist Teaching: A Practice Developed in Under-graduate Courses." Radical Teacher 20 (1982): 26-29. 
Fish, Stanley Eugene. Is There a Text in This class?: The Authority of Interpretive communities. Cambridge, $\overline{\mathrm{MA}}$ : Harvard University Press, 1980 .

Fisher, Berenice. "What is Feminist Pedagogy?" Radical Teacher $18(1981)$ : 20-24.

---. "The Heart Has Its Reasons: Feelings, Thinking, and Community-Building in Feminist Education." Women's Studies Quarterly 15 (Fall/Winter 1987): $47-\overline{58}$.

Fisher, Jerilyn. "Returning Women in the Feminist Classroom." Women's Studies Quarterly XV (Fall/Winter 1987) : 90-95.

Flynn, Elizabeth. "Composing as a Woman." College Composition and Communication 39 (December 1988): 42335 .

--- "Politicizing the Composing Process and Women's Ways of Interacting: A Response to 'A Conversation with Mary Belenky. "n Journal of Advanced Composition 11 (Winter 1991): $173-78$.

Freire, Paulo. Education for Critical Consciousness. New York: Seabury Press, 1973 .

---. The Pedagogy of the Oppressed. New York: Continuum, $1 \overline{970}$.

Frey, Olivia. "Equity and Peace in the New Writing Class." Teaching Writing: Pedagogy, Gender, and Equity. Eds. Cynthia L. Caywood and Gillian R. Overing. Albany, NY: SUNY, 1987. 93-105.

Frye, Marilyn. The Politics of Reality: Essays in Feminist Theory. Trumansburg, NY: The Crossing Press, 1983.

Friedan, Betty. The Feminine Mystique. New York: Norton, 1963.

Friedman, Susan Stanford. "Authority in the Feminist Classroom: A Contradiction in Terms." Gendered Subjects: The Dynamics of Feminist Teaching. Eds. Margo Culley and Catherine portuges. Boston: Routledge \& Kegan Paul, 1985. 203-208.

Gallop, Jane. The Daughter's Seduction: Feminism and Psychoanalysis. Ithaca, New York: Cornell University Press, 1989 .

--- Thinking Through the Body. New York: Columbia University Press, 1988 . 
Gambill, Sue Dove with Rachel De Vries and Rita speicher. "The Women's Writer's center: An Interview with the Directors." Learning Our Way: Essays in Feminist Education. Eds. Charlotte Bunch and Sandra Pollack. Trumansburg, NY: The Crossing Press, 1983. 200-209.

Gearhart, Sally Miller. "The Womanization of Rhetoric." Women's Studies International Quarterly 2 (1979): 195201 .

Geertz, Clifford. Local Knowledge. New York: Basic, 1983.

Gere, Anne Ruggles. Writing Groups: History, Theory, and Implications. Carbondale: Southern Illinois University Press, 1987.

Gilligan, Carol. In a Different Voice: Psychological Theory and women's Development. Cambridge: Harvard University, 1982 .

Giroux, Henry A. "Border Pedagogy in the Age of Postmodernism." Journal of Education 170 (November 3, 1988): 162-81.

---. "Liberal Arts Education and the struggle for Public Life: Dreaming about Democracy." The South Atlantic Quarterly. 89 (Winter 1990): 113-38.

--- "The Politics of Educational Theory." Social Text 5 (Spring 1982): 87-104.

--- Teachers as Intellectuals: Toward a Critical Pedagogy of Learning. Granby, MA: Bergin \& Gärvey Publishers, Inc., 1988 .

---. Theory and Resistance in Education. South Hadley, MA: Bergin and Garvey, 1983 .

Giroux, Henry and Anthony N Penna. "Social Education in the Classroom: The Dynamics of the Hidden Curriculum." Teachers as Intellectuals: Toward a Critical Pedagogy of Learning. Granby, MA: Bergin \& Garvey Publishers, Inc., 1988.

Gramsci, Antonio. Slections from the Prison Notebooks. Eds. Quintin Hoare and Geoffrey Newel 1 Smith. New York: International Publishers, 1971.

Grumet, Madeleine R. Bitter Milk. Amherst: The University of Massachusetts $\overline{\text { Press, }} \overline{1988}$.

--- "Pedagogy for Patriarchy: The Feminization of Teaching." Interchange 12 (1981): 165-84. 
Grant, Judith. "I Feel Therefore I Am: A Critique of Female Experience as the Basis for a Feminist Epistemology." Women and Politics 7 (Fall 1987): 99-114.

Hairston, Maxine. "Diversity, Ideology, and Teaching writing." College Composition and Communication 43 (May 1992): $179-93$.

---. "The winds of Change: Thomas Kuhn and the Revolution in the Teaching of Writing." College Composition and Communication 33 (February 1982) : 7688 .

Harding, Sandra and Merrill B. Hintikka, eds. Discovering Reality: Feminist Perspectives on Epistemology, Metaphysics, Methodology and Philosophy of Science. Boston: Reidel, 1983 .

Harkin, Patricia and John Schilb. Contending with Words. New York: MLA, 1991.

Hartsock, Nancy C. M. "The Feminist Standpoint: Developing the Ground for a Specifically Feminist Historical Materialism." Discovering Reality: Feminist Perspectives on Epistemology. Metaphysics, Methodology and Philosophy of Science. Eds. Sandra Harding and Merrill B. Hintikka. Boston: Reidel, 1983. 283-310.

---. Money, Sex, and Power: Toward a Feminist Historical Materialism. New York: Longman, 1983.

Hawkesworth, Mary E. "Knowers, Knowing, known: Feminist Theory and Claims of Truth." Signs: Journal of Women in Culture and Society 14 (Spring 1989): 533-57.

Haywoode, Terry L. and Laura Polla scanlon. "World of our Mothers: College for Neighborhood Women." Women's Studies Quarterly XV (Fall/Winter 1987): 101-09.

Heath, Shirley Brice. "A Child Resource Policy: Moving Beyond Dependence on School and Family." Phi Delta Kappan 68 (April 1987): 576-80.

--- "The Cross-Cultural study of Language Acquisition." Papers and Reports on Child Language Development." 24 (August $\overline{19} 8 \overline{5 \text { ): } 1-21}$.

--. "Research Currents: A Lot of Talk About Nothing." Language Arts 60 (November-December 1983) : 999-1007.

---. Ways with Words. New York: Cambridge UP, 1983.

Herrington, Anne J. "Writing to Learn: Writing Across the Disciplines." College Englisı 43 (April 1981): 379-87. 
hooks, bell. Talking Back: Thinking Feminist, Thinking Black. Boston: South End Press, 1989 .

Howe, Florence. "New Teaching Strategies for a New Generation of Students." Women's Studies Quarterly 11 (1983): 7-11.

Janeway, Elizabeth. Between Myth and Morning: Women Awakening. New York: Morrow,$\overline{19} 7 \overline{4}$.

Jarratt, Susan. "Feminism and Composition: The Case for Conflict." Contending with Words: Composition in the Post-Modern Era. Eds. Patricia Harkin and John Schilb. New York: MLA, 1991. 105-123.

Jarratt, Susan and Nedra Reynolds. "The Splitting Image: Contemporary Feminisms and the Ethics of ethos." Ethos: New Essays in Rhetorical and Critical Theory. Eds. James and Tita Baumlin. Dallas: Southern Methodist University Press, Forthcoming.

Jolliffe, David. The Content of Composition: Subjects and Genres in college Writing Instruction. Forthcoming, 1993.

Joseph, Gloria and Jill Lewis. Common Differences: Conflicts in Black and White Feminist Perspectives. New York: Anchor Press/Doublday, 1981 .

Journet, Debra. "Forms of Discourse and the Sciences of the Mind: Luria, Sacks, and the Role of the Narrative in Neurological Case Histories." Written Communication 7 (April 1990) : 171-99.

Kent, O. T. "Student Journals in the Teaching of English." The Journal Book. Ed. Toby Fulwiler. Portsmouth, NH: Boynton/Cook, 1987. 269-275.

Knoblauch, C. H. and Lil Brannon. Rhetorical Traditions and the Teaching of Writing. Upper Montclair, NJ:

Boynton/Cook Publishers, Inc., 1984.

--. "Writing as Learning Through the Curriculum." College English 45 (September 1983): 465-474.

Kuhn, Thomas S. The Structure of Scientific Revolutions. 2nd ed. Chicago: University of Chicago Press, 1970 .

Lavine, Ann. "The Subject Matter and Gender." Teaching Writing: Pedagogy, Gender, and Equity. Eds. Cynthia L. Caywood and Gillian R. Overing. Albany: SUNY Press, 1987 . 135-43.

LeFevre, Karen Burke. Invention as a Social Act. Carbondale: Southern Illinois U,$\frac{1987 .}{198}$ 
LeFevre, Karen Burke and Mary Jane Dickerson. Until I See What I Say: Teaching Writing in All Disciplines.

Burlington: Vermont: IDC Publications, 1981.

Lentricchia, Frank. Criticism and Social Change. Chicago: U. of Chicago Press, 1983.

Levitas, Maurice. Marxist Perspectives in the Sociology of Education. Boston: Routledge and Kegan Paul, 1974 .

Lincoln, Sara Ann. A Feminist Process in Teaching: $A$ Personal Account. Ph.D. dissertation, University of Michigan, 1975 .

Lunsford, Andrea A. and Lisa Ede. "Rhetoric in a New Key: Women and Collaboration." Rhetoric Review. 8 (Spring 1990): 234-41.

Mackinnon, Catherine. "Feminism, Marxism, Method and the State: An Agenda for Theory." Signs: Journal of Women in culture and society. 7 (Spring 198 8 ): 515- $\overline{45}$.

Maher, Frances. "Classroom Pedagogy and the New Scholarship on Women." Gendered Subjects: The Dynamics of Feminist Teaching. Eds. Margo Culley and Catherine portuges. Boston: Routledge \& Kegan Paul, 1985. 29-47.

-- . "Pedagogies for the Gender-Balanced Curriculum." Journal of Thought 20 (Fall 1985): 48-64.

Mahoney, Deirdre. "A Woman's Solitude, Silence, Interruptions and Work: Negotiating a Self." Paper Presented at the Wyoming conference on Rhetoric (June 1991) Laramie, Wyoming.

Maimon, Elaine P. "Maps and Genres: Exploring Connections in the Arts and Sciences." Composition and Literature: Bridging the Gap. Ed. Winifred Bryan Horner. Chicago: University of Chicago Press, 1983. 110-25.

Maimon, Elaine P., Gerald Belcher, Fail W. Hearn, Barbara F. Nodine, and Finbarr W. O'Connor. Writing in the Arts and Sciences. Boston: Little, Brown, 1981 .

Marshall, J. D. "Process and Product: Case Studies of Writing in Two Content Areas." Contexts for Learning to Write: Studies of Secondary Instruction. Ed. A. N. $\overline{A p p} \overline{l e b e e .}$ Norwood, $\bar{N} J:$ Ablex Publishing Corp. 149-168.

Martin, Jane Roland. "Bringing women Into Educational Thought." Educational Theory 34 (Fall 1984): 341-53.

Mason, Edwin. Collaborative Learning. New York: Agathon, 1972 . 
Meisenhelder, Susan. "Redefining 'Powerful' Writing: Toward a Feminist Theory of Composition." Journal of Thought 20 (Fall 1985): 184-95.

Messer-Davidow, Ellen. "Knowers, Knowing, Knowledge:

Feminist Theory and Education." Journal of Thought 20

(Fall 1985): 74-87.

Mett, Coreen L. "Writing in Mathematics: Evidence of Learning Through Writing." Clearing House 62 (March 1989): 293-96.

Mishler, Elliot. "Meaning in context: Is There Any Other Kind? Harvard Educational Review 49 (February 1979): 1-19.

Mitrano, Barbara. "Feminism and Curricular Theory:

Implications for Teacher Education." Journal of Curricular Theorizing (1981): 5-85.

Myers, Greg. "Reality, Consensus, and Reform in the Rhetoric of Composition Teaching." College English 48 (February 1986): $154-74$.

--- Response. College English 49 (February 1987): 211-14.

--- "The Social Construction of Two Biologists' Proposals." Written Communication 2 (July 1985): 219-45.

Newe1l, G. E. "Learning from Writing in Two Content Areas: A Case Study/Protocol Analysis." Research in the Teaching of English 18 (October 19 $\overline{84 \text { ): } 265-\overline{28}} \overline{\text {. }}$

Newel1, G. E., Suszynski, K., \& Weingart, K. "The Effects of Writing in a Reader-Based and Text-Based Mode on Students' Understanding of Two Short Stories." Paper presented at the annual meeting of the American Educational Research Association, San Francisco.

Newkirk, Thomas. "Anatomy of a Breakthrough: Case study of a College Freshman Writer." New Directions in the Composing Process. Eds. Richard $\overline{\text { Beach and Lillian }}$ Bridwell. New York: Guilford, 1983. 131-48.

Nicholson, Linda J., ed. Feminism/Postmodernism. New York: Routledge, 1990.

Noddings, Nel and Paul J. Shore. Awakening the Inner Eye: Intuition in Education. New York: Teachers College Press, 1984 . 
North, Stephen. "Composition Now: Standing on One's Head." College Composition and Communication 29 (May 1978): $177-80$.

---. The Making of Knowledge in Composition: Portrait of an Emerging Field. Upper Montclair, NJ: Boynton/Cook Publishers, 1987 .

Ohmann, Richard. "Literacy, Technology, and Monopoly Capital." College English 47 (November 1985): 675-89.

-- Politics of Letters. Middletown, Connecticut: Wesleyan university press, 1987.

---. "Reflections on Class and Language." College English 44 (January 1982) : 1-17.

---. "Use Definite, Specific, Concrete Language." College English 41 (December 1979): 390-97.

Olson, Gary A. "Social Construction and Composition Theory: A Conversation with Richard Rorty." Journal of Advanced Composition 9 (1989): 1-9.

Penelope (Stanley) Julia and Susan J. Wolfe. "Consciousness as Style; Style as Aesthetic." Language, Gender, and Society. Eds. Barrie Thorne, Chris Kramarae, and Nancy Henley. Cambridge: Newbury house Publishers, 1983. $125-39$.

Perry, Donna M. "Making Journal Writing Matter." In Teaching Writing: Pedagogy, Gender, and Equity. Eds. Cynthia L. Caywood and Gillian R. Overing. Albany: SUNY Press, 1987. 151-57.

Peterson, Linda H. "Gender and the Autobiographical Essay: Research Perspectives, Pedagogical Practices." College Composition and Communication 42 (May 1991): 170-83.

Porter, Nancy. "Liberating Teaching." Liberal Education. 68 (Summer 1982): 115-26.

Powell, Alfred. "A Chemist's View of Writing, Reading, and Thinking Across the Curriculum." College Composition and Communication 36 (December 1985): 414 $-\overline{18}$.

Reimer, James D. "Becoming Gender Conscious: Writing about Sex Roles in a Composition Class." In Teaching Writing: Pedagogy, Gender, and Equity. Eds. Cynthia L. Caywood and Gillian R. Overing. Albany: SuNY Press, 1987. 15764 .

Reither, James A. and Douglas Vipond. "Writing as Collaboration." College English 51 (December 1989): $855-67$. 
Rich, Adrienne. "Taking Women Students Seriously." On $\frac{\text { Lies, }}{\text { New York: W. W. }}, \frac{\text { Secrets, }}{\text { Norton, 1979. }} \frac{\text { Silences: }}{237-45 .}$ Prose $1966-1978$.

---. "When we Dead Awaken: Writing as Revision." On Lies, Secrets, and Silences: Selected Prose 1966-1978. New York: W. W. Norton, 1979.33-49.

Riley, Denise. "Am I That Name?" Feminism and the Category of "Women" in history. Minneapolis: University of Minnesota press, 1988.

Ritchie, Joy S. "Confronting the 'Essential' Problem: Reconnecting Feminist Theory and Pedagogy." Journal of Advanced Composition 10 (Fall 1990): 249-73.

Rorty, Richard. Philosophy and the Mirror of Nature. Princeton: Princeton university Press, 1979 .

Rose, Mike. "Remedial Writing Courses: A Critique and a Proposal." College English 45 (February 1983): 109121.

---. "When Faculty Talk About Writing." College English 41 (November 1979): 272-279.

Rosen, Harold. "Language and Class: A Critical Look at the Theories of Basil Bernstein." The Urban Review 7 (1974): 97-114.

Rouster, William J. "Why Collaborative Learning Often Does Not Work As Expected in the English Classroom: A Theoretical Perspective." Paper presented at The Wyoming Conference on Rhetoric (June 1991) Laramie, Wyoming.

Ruddick, Sara. "Maternal Thinking." Feminist Studies 6 (Summer 1980): 342-367.

Russell, Michele. "Black-eyed Blue Connections: Teaching Black Women." Gendered Subjects: The Dynamics of Feminist Education. Eds. Margo Cul ley and Catherine Portuges. Boston: Routledge \& Kegan Paul, 1985. 15568 .

Sarris, Greg. "Storytelling in the Classroom: Crossing Vexed Chasms." College English 52 (February 1990): 169-85.

Schniedewind, Nancy. "Cooperatively-Structured Learning: Implications for Feminist Pedagogy." Journal of Thought 20 (Fall 1985): 74-87. 
---. "Teaching Feminist Process." Women's Studies Quarterly XV (Fall/winter 1987): 15-31.

Schulman, Alix Kates. "Overcoming Silences: Teaching Writing for Women." Harvard Educational Review 49 (November 1979): 527-33.

Schweickart, Patrocinio. "The Challenge of Diversity." ADE Bulletin 88 (Winter 1988): 21-26.

Sciachitano, Marian. Paper presented at The Penn State Conference on Rhetoric (July 1990) State College, Pennsylvania.

---. Letter to the author. 14 sept. 1990.

---. "Theorizing about Ideology, Culture, and Gender Conflict in the Classroom: Can an Asian American Woman 'talk back'?" Works and Days. 8 (1990): 49-60.

Selfe, Cynthia L, Bruce T. Petersen, and Cynthia L. Nahrgang. "Journal Writing in Mathematics." Writing Across the Disciplines: Research into Practice. Eds. Art Young and Toby Fulwiler. Upper Montclair, NJ: Boynton/Cook Publishers, Inc., 1986. 192-207.

Shor, Ira. Critical Teaching and Everyday Life. Boston: South End Press, 1980.

---. "Equality is Excellence: Transforming Teacher Education and the Learning Process." Harvard Educational Review 56 (November 1986): $\frac{\text { 406-26. }}{406}$

---, ed. Freire for the Classroom. Portsmouth: Boynton, 1988 .

Shor, Ira, and Paulo Freire. "What is the 'Dialogic Method' of Teaching?" Journal of Education 169 (Fall 1987): $11-31$.

Shrewsbury, Carolyn M. "What is Feminist Pedagogy?" Women's Studies Quarterly XV (Fall/Winter 1987): 6-13.

Slevin, James F. "Genre Theory, Academic Discourse, and Writing Within the Disciplines." Audits of Meaning: A Festschrift in Honor of Ann E. Berthoff. Ed. Louise $\bar{z}$. Smith. Portsmouth, $\overline{\mathrm{NH}}$ : Boynton/Cook, 1988. 3-16.

Smit, David w. "Some Difficulties with Collaborative Learning." Journal of Advanced Composition 9 (1989): 45-58.

Sommers, Nancy S. "The Need for Theory in Composition." College Composition and Communication 30 (February 1979) : $46-9$. 
Spelman, Elizabeth V. "Combating the Marginalization of Black Women in the Classroom." Gendered Subjects: The Dynamics of Feminist Teaching. New York: Routledge \& Kegan Paul, 1985.240-244.

--- Inessential Woman: Problems of Exclusion in Feminist Thought. Boston: Beacon Press, 1988 .

Spender, Dale. "Learning to Create our Own Knowledge." Convergence: An International Journal of Adult Education 13 (1980): 14-23.

---. The Writing or the Sex? Or Why You Don't Have to Read Women's Writing to know It's No Good. New York: Pergamon, $198 \overline{9}$.

---. Men's Studies Modified: The Impact of Feminism on the Academic Disciplines. Oxford: Pergamon Press, $19 \overline{81}$.

Spivak, Gayatri Chakravorty. In Other Worlds: Essays in Cultural Politics. New York: Methuen, 1987.

Stanger, Carol A. "The Sexual politics of the one-To-one Tutorial Approach and Collaborative Learning."

Teaching Writing: Pedagogy, Gender, and Equity. Eds.

Cynthia L. Caywood and Gillian R. Overing. Albany: SunY Press, 1987. 31-44.

Stanley, Liz and Sue Wise. Breaking Out: Feminist Consciousness and Feminist Research. Boston: Routledge \& Kegan Paul, 1983 .

Steffens, Henry. "Journals in the Teaching of History." The Journal Book. Ed. Toby Fulwiler. Portsmouth, NH:

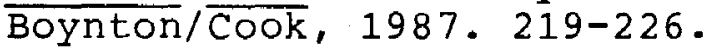

Steinem, Gloria. "The Politics of Talking in Groups." Ms. May 1981: 43, 45, 84, 86-9.

Tebo-Messina, Margaret. "Authority and Models of the Writing Workshop: All Collaborative Learning is Not Equal." The Writing Instructor. 9 (Winter 1989): 8692 .

Thompson, Martha E. "Diversity in the Classroom: Creating Opportunities for Learning Feminist Theory." Women's Studies Quarterly XV (Fall/winter 1987): 81-87.

Tierney, R. "Using Expressive writing to Teach Biology." Two studies of Writing in High School Science. Eds. A. Wotring \& R. Tierney. San Francisco: Bay Area Writing Project. Rpt. in Miles Myers, The Teacher-Researcher: How to study Writing in the classroom. Urbana IL: $\overline{\text { NCT }} \overline{\text {, }} 1 \overline{985.1} 1 \overline{49-166 .}$ 
Trimbur, John. "Collaborative Learning and Teaching Writing." Perspectives on Research and Scholarship in Composition. New York: $\overline{\mathrm{ML}}$. 1985. 87-109.

---. "Consensus and Difference in Collaborative Learning." College English 52 (October 1989): 602-16.

Tuman, Myron C. "Class, Codes, and Composition: Basil Bernstein and the Critique of Pedagogy." College Composition and Communication 39 (February 1988): 4251 .

--. A Preface to Literacy: An Inquiry into Pedagogy, practice, and Progress. Tuscaloosa: The University of Alabama Press, 1987.

Vygotsky, Lev Semenovich. Mind in Society. Eds. Michael Cole, Vera John Steiner, Sylvia Scribner, and Ellen Souberman. Harvard: Harvard University Press, 1978.

--- Thought and Language. Trans. Eugenia Hanfmann and Gertrude Vakar. Cambridge, MA: MIT Press, 1962.

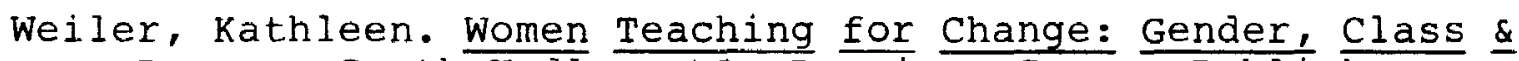
Power. South Hadley, MA: Bergin \& Garvey Publishers, Inc., 1988 .

Wiener, Harvey S. "Collaborative Learning in the Classroom: A Guide to Evaluation." College English 48 (January 1986): 52-61.

Weiss, R. H. "Research on Writing and Learning: Some Effects of Learning centered Writing in Five subject Areas." Paper presented at the annual meeting of the NCTE (1981) San Francisco: ERIC ED 191073.

Williams, Raymond. Keywords: A Vocabulary of culture and Society. New York: Oxfor $\bar{d}, \frac{\text { Och }}{1976 .}$

---. Marxism and Literature. New York: Oxford University Press, $19 \overline{77 .}$

Young, Richard E. "Paradigms and Problems: Needed Research in Rhetorical Invention." Reserach on Composing: Points of Departure. Eds. Charles R. Cooper and Lee

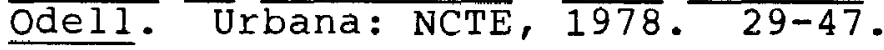


VITA

The author, Carol Mattingly, was born on July 31, 1945, the daughter of Josephine Fleig and Joseph Hubert Mattingly, in Loretto, Ky. She attended public schools in Loretto, graduating from St. Francis High School in 1963.

Carol earned a Bachelor of Arts degree from Brescia College, Owensboro, Ky, in 1967, and a Master of Arts degree from the University of Louisville in 1977. She has served in both teacing and administrative capacities with a number of educational institutions, including the Jefferson county Kentucky Public Schools, the Archdiocese of Louisville Schools, Indiana University Southeast, and the University of Louisville. 